
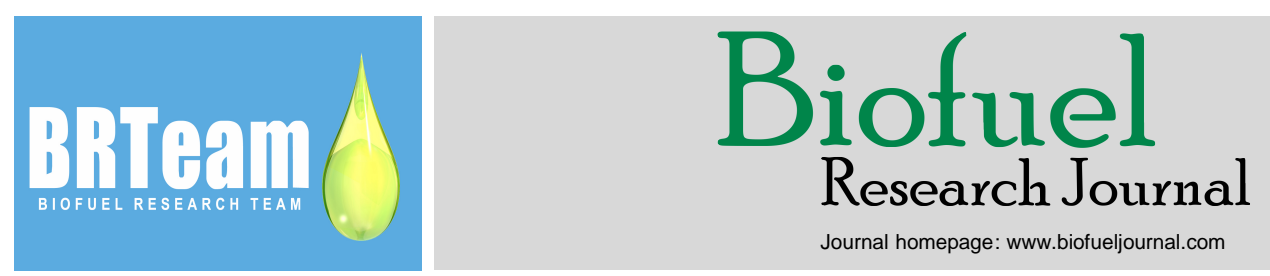

Journal homepage: www.biofueljournal.com

Original Research Paper

\title{
A comparative evaluation of design factors on bubble column operation in photosynthetic biogas upgrading
}

\author{
Archishman Bose ${ }^{1,2}$, Richard O’Shea ${ }^{1,2, *}$, Richen Lin ${ }^{1,2}$, Jerry D. Murphy ${ }^{1,2}$ \\ ${ }^{I}$ Environmental Research Institute, MaREI Centre, University College Cork, Cork, Ireland. \\ ${ }^{2}$ School of Engineering, University College Cork, Cork, Ireland.
}

\section{HIGHLIGHTS}

$>$ Multiple factors and their interaction influence photosynthetic biogas upgrading.

$>\mathrm{pH}$ and liquid to gas flow $(\mathrm{L} / \mathrm{G})$ ratio affect $\mathrm{CO}_{2}$ removal the most.

$>$ Interaction between $\mathrm{pH}$ and $\mathrm{L} / \mathrm{G}$ ratio has the highest influence on $\mathrm{CO}_{2}$ removal.

$>\mathrm{L} / \mathrm{G}$ ratio, followed by algal concentration has the highest influence on $\mathrm{O}_{2}$ stripping.

$>$ Bubble column operation predicted to produce grid quality biomethane.

\section{GRAPHICAL ABSTRACT}

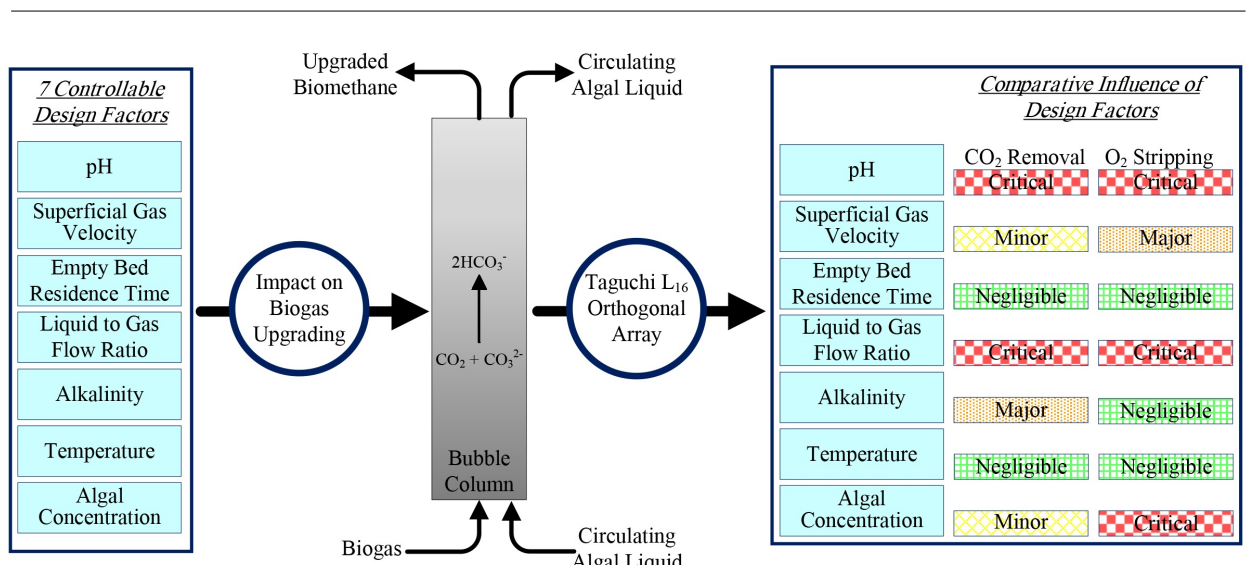

\section{ARTICLE INFO}

\section{Article history:}

Received 15 January 2021

Received in revised form 22 March 2021

Accepted 23 April 2021

Available online 1 June 2021

\section{Keywords:}

Biomethane

$\mathrm{CO}_{2}$ removal

Bubble column

Taguchi method

Microalgae

\begin{abstract}
Studies attempting to optimise photosynthetic biogas upgrading by simultaneous investigation of the bubble columnphotobioreactor setup have experienced considerable variability in results and conclusions. To identify the sources of such variation, this work quantitatively compared seven design factors (superficial gas velocity; liquid to gas flow rate (L/G) ratio; empty bed residence time; liquid inlet $\mathrm{pH}$; liquid inlet alkalinity; temperature; and algal concentration) using the $\mathrm{L}_{16}$ Taguchi orthogonal array as a screening design of experiment. Assessments were performed using the signal to noise $(\mathrm{S} / \mathrm{N})$ ratio on the performance of $\mathrm{CO}_{2}$ removal $\left(\mathrm{CO}_{2}\right.$ removal efficiency, $\mathrm{CO}_{2}$ absorption rate, and overall $\mathrm{CO}_{2}$ mass transfer coefficient) and $\mathrm{O}_{2}$ stripping $\left(\mathrm{O}_{2}\right.$ concentration in biomethane and $\mathrm{O}_{2}$ flow rate in biomethane). Results showed that $\mathrm{pH}$ and $\mathrm{L} / \mathrm{G}$ ratio were the most critical design factors. Temperature and gas residence times had minimal impact on the biomethane composition. The interactive effect between $\mathrm{pH}$ and $\mathrm{L} / \mathrm{G}$ ratio was the most impactful, followed by the interactive effects between superficial gas velocity and $\mathrm{L} / \mathrm{G}$ ratio and $\mathrm{pH}$ on $\mathrm{CO}_{2}$ removal efficiency. The impact of $\mathrm{L} / \mathrm{G}$ ratio, algal concentration, and $\mathrm{pH}$ (in that order of impact) caused up to a $90 \%$ variation in oxygen content in biomethane. However, algal concentration had a diminishing role as the $\mathrm{L} / \mathrm{G}$ ratio increased. Using only the statistically significant main effects and interactions, the biomethane composition $\left(\mathrm{CO}_{2} \%\right.$ and $\mathrm{O}_{2} \%$ ) was predicted with over $95 \%$ confidence through regression equations for superficial gas velocity up to $0.2 \mathrm{~cm} / \mathrm{s}$.
\end{abstract}




\section{Contents}

1. Introduction......

1.1. Microalgal (photosynthetic) biogas upgrading

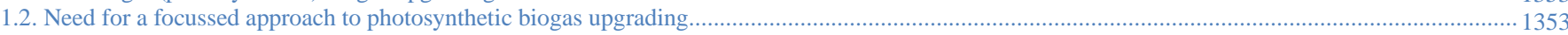

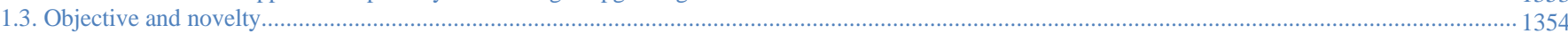

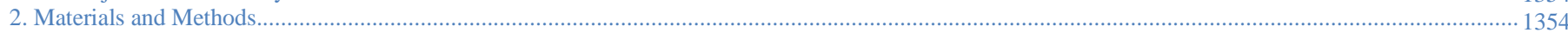

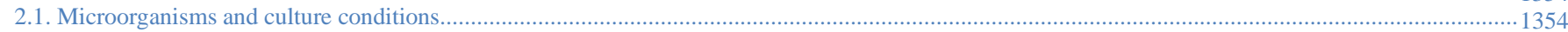

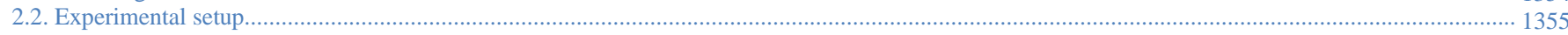

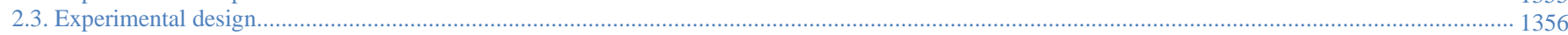

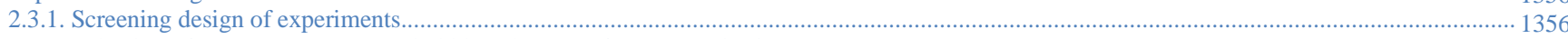

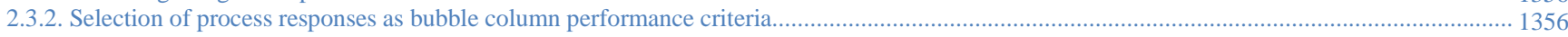

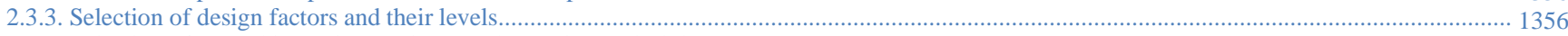

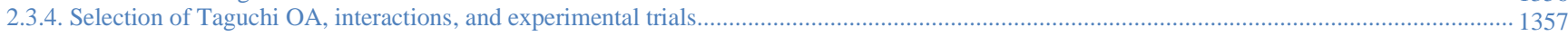

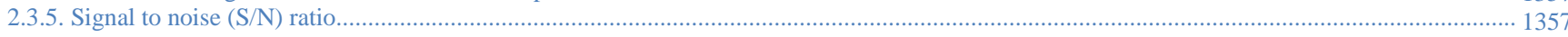

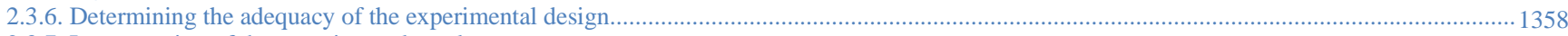

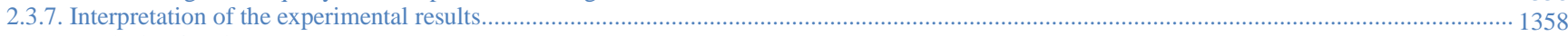

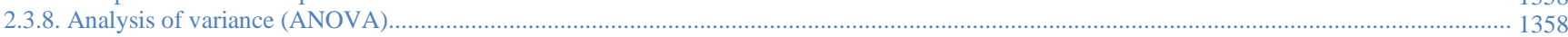

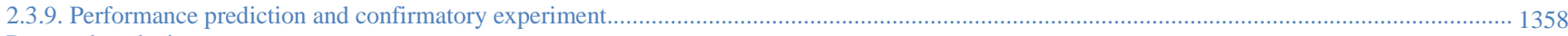

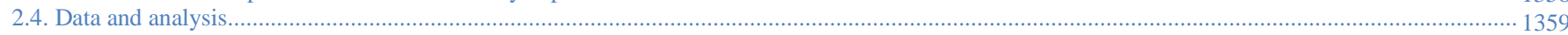

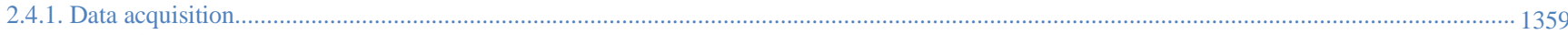

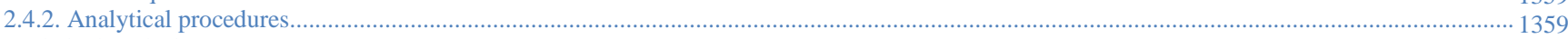

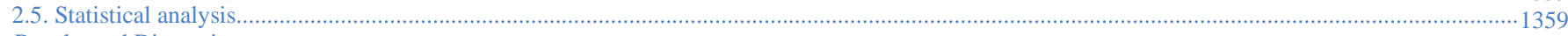

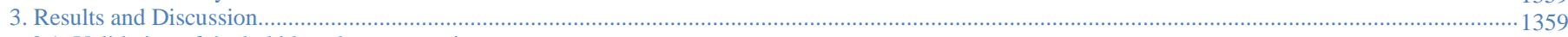

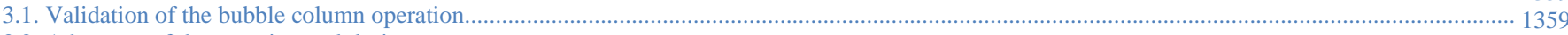

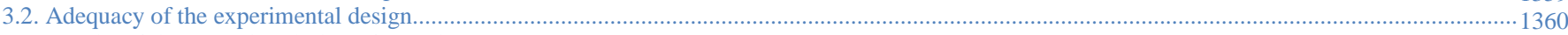

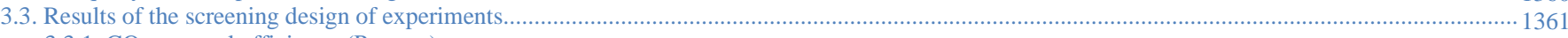

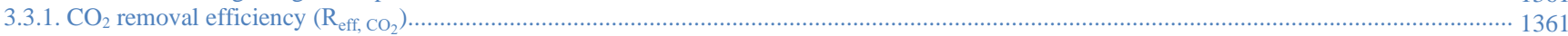

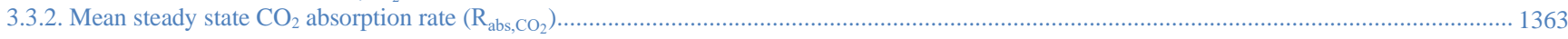

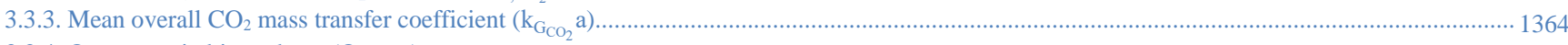

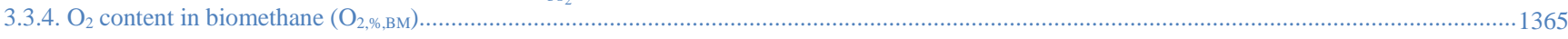

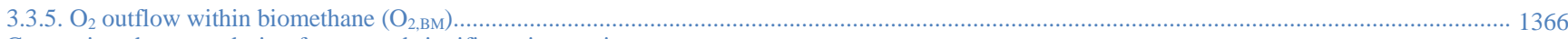

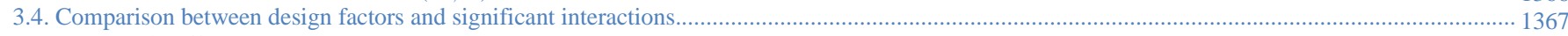

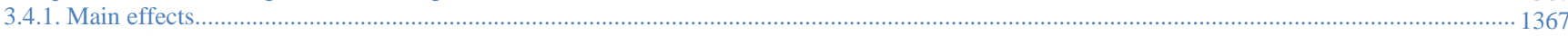

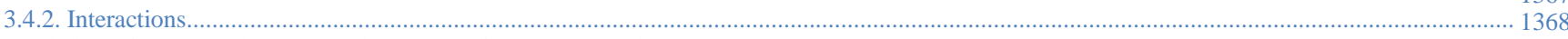

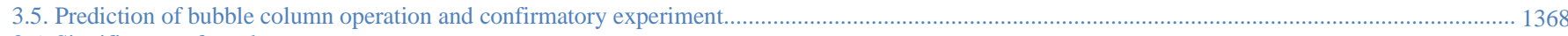

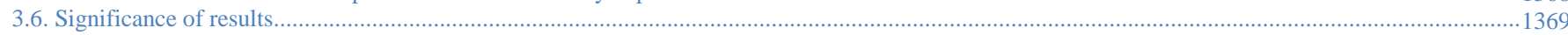

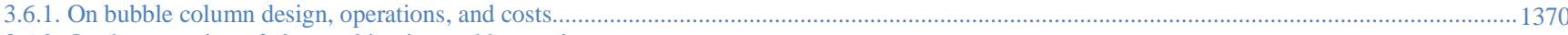

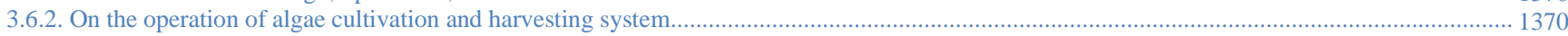

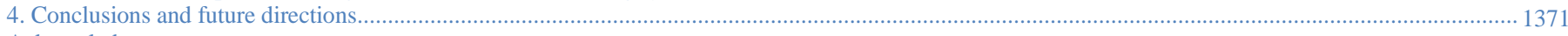

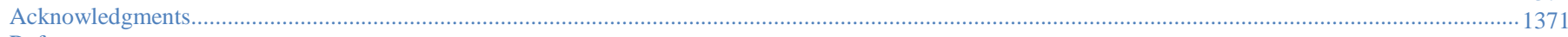

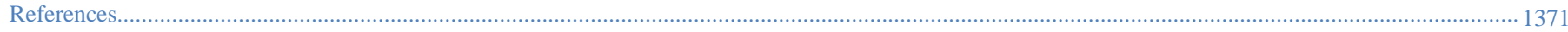

\begin{tabular}{|llll}
\hline \multicolumn{2}{|l}{ Abbreviations and Nomenclatures } & & \\
& & & \\
$\mathrm{Adj}$ & Adjusted & $\mathrm{n}_{\mathrm{ex}}$ & Number of experiments \\
$\mathrm{Alk}$ & Alkalinity $(\mathrm{g}-\mathrm{IC} / \mathrm{L})$ & $\mathrm{OA}$ & Orthogonal array \\
$\mathrm{ANOVA}$ & Analysis of variance & $\mathrm{PI}$ & Prediction interval \\
$\mathrm{C}_{\mathrm{alg}}$ & Algae concentration $(\mathrm{g}-\mathrm{DW} / \mathrm{L})$ & $\mathrm{R}_{\mathrm{abs}, \mathrm{CO}_{2}}$ & Mean steady state $\mathrm{CO}_{2}$ absorption rate $(\mathrm{mol} / \mathrm{L} / \mathrm{s})$ \\
$\mathrm{CI}$ & Confidence interval & $\mathrm{R}_{\mathrm{eff}, \mathrm{CO}_{2}}$ & Efficiency of $\mathrm{CO}_{2}$ removal from biogas $(\%)$ \\
$\mathrm{DoF}$ & Degree of freedom & $\mathrm{SB}$ & Smaller-the-better \\
$\mathrm{DW}$ & Dry weight & $\mathrm{S} / \mathrm{N}$ & Signal to noise \\
$\mathrm{EBRT}$ & Empty bed residence time $(\mathrm{min})$ & $\mathrm{SS}$ & Sum of squares \\
$\mathrm{G}$ & Biogas flow rate $(\mathrm{mLn} / \mathrm{s})$ & $\mathrm{SSE}$ & Sum of square errors \\
$\mathrm{IC}$ & Inorganic carbon & $\mathrm{T}_{\mathrm{col}}$ & Temperature of bubble column $\left({ }^{\circ} \mathrm{C}\right)$ \\
$\mathrm{k}$ & kilo & $\mathrm{TRL}$ & Technology readiness level \\
$\mathrm{k}_{\mathrm{G}_{\mathrm{CO}}} \mathrm{a}$ & Mean overall CO ${ }_{2} \mathrm{mass}$ transfer coefficient $\left(\mathrm{h}^{-1}\right)$ & $\mathrm{u}_{\mathrm{G}}$ & Superficial gas velocity $(\mathrm{cm} / \mathrm{s})$ \\
$\mathrm{LB}$ & Lower-the-better & & \\
$\mathrm{L} / \mathrm{G}$ & Liquid to gas flow rate $(\mathrm{L} / \mathrm{G})$ ratio & $\mathrm{Subscripts}$ & \\
$\mathrm{mL}$ & Milli-litres normal & $\mathrm{BC}$ & Bubble column \\
$\mathrm{MS}$ & Mean squares & $\mathrm{BG}$ & Biogas \\
$\mathrm{N}$ & Molar flow rate $(\mathrm{mol} / \mathrm{s})$ & $\mathrm{BM}$ & Biomethane \\
\end{tabular}




\section{Introduction}

\subsection{Microalgal (photosynthetic) biogas upgrading}

Biomethane from anaerobic digestion (AD) is a renewable and versatile biofuel (Rajendran et al., 2019; Wall et al., 2017). Compared to conventional biogas upgrading technologies such as water scrubbing and pressure swing absorption, novel biogas upgrading technologies aim to increase the sustainability of biomethane derived from biogas by reducing costs and energy demands (Angelidaki et al., 2018). The two-step photosynthetic biogas upgrading process, employing $\mathrm{CO}_{2}$ removal and subsequent utilisation of $\mathrm{CO}_{2}$ by microalgae, is considered a novel biogas upgrading technology (Meier et al., 2015; Bose et al., 2019). In the first step, as shown in Figure 1, $\mathbf{C O}_{2}$, as well as $\mathrm{H}_{2} \mathrm{~S}$ are absorbed in a bubble column by a carbonate-rich sodium carbonatebicarbonate buffer solution ( $\mathrm{pH} 9$ and above) via the principle governing Equation 1 (Bose et al., 2019), decreasing the $\mathrm{pH}$. In the subsequent step, the bicarbonate uptake by the algae in a photobioreactor regenerates carbonate in the solution with a corresponding rise in $\mathrm{pH}$ (Equation 2). The re-circulation of the regenerated carbonate-rich solution into the bubble column then continues the carbonate-bicarbonate cycle. In addition to the biomethane, the cultivated microalgae is a high-value product critical to improving both the economic benefits and sustainability of the biomethane produced (Bose et al., 2020).

Bubble Column: $\mathrm{CO}_{2}+\mathrm{H}_{2} \mathrm{O}+\mathrm{CO}_{3}{ }^{2-} \rightarrow 2 \mathrm{HCO}_{3}{ }^{-}$

Photobioreactor: $\left\{\begin{array}{l}\mathrm{HCO}_{3}{ }^{-} \stackrel{\text { Algae }}{\longrightarrow} \mathrm{CO}_{2}+\mathrm{OH}^{-} \\ \mathrm{HCO}_{3}{ }^{-}+\mathrm{OH}^{-} \stackrel{\text { Medium }}{\longrightarrow} \mathrm{CO}_{3}{ }^{2-}+\mathrm{H}_{2} \mathrm{O}\end{array}\right\}$

\subsection{Need for a focussed approach to photosynthetic biogas upgrading}

Ensuring continuous grid-quality biomethane $\left(\mathrm{CO}_{2}\right.$ and $\mathrm{O}_{2}$ less than $2.5 \%$ and $1 \%$ by volume, respectively) (Meier et al., 2017; Gas Networks Ireland, 2018) and adequate carbon uptake by microalgae is essential to maximise the economic and environmental benefits from the photosynthetic biogas upgrading system. To achieve this, the influence of multiple operational factors (compiled in Table 1) such as pH (Bahr et al., 2014; Bose et al., 2019), gas and liquid flow velocities (Bose et al., 2019; Meier et al., 2019) and flow rates (Toledo-Cervantes et al., 2017), temperature (del Rosario Rodero et al., 2018), alkalinity (del Rosario Rodero et al., 2018 and 2020b), biogas composition (Bose et al., 2019), the concentration of the algae (Bose et al., 2019; del Rosario Rodero et al., 2020b), as well as the microalgae species and its cultivation conditions (Bose et al., 2019) must be simultaneously taken into account. Accordingly, the operations of the individual components in photosynthetic biogas upgrading such as the bubble column and the microalgae cultivation and harvesting systems could significantly deviate from those of optimised stand-alone setups. For example, when Spirulina platensis is chosen as the microalgae, the bubble column in the photosynthetic biogas upgrading system should operate below a $\mathrm{pH}$ of 11 and a temperature of $40{ }^{\circ} \mathrm{C}$ to prevent severe damage to the microalgae (De Oliveira et al., 1999). This is in contrast to operating conditions of $\mathrm{pH}$ above 11 and a temperature above $40{ }^{\circ} \mathrm{C}$, commonly employed for $\mathrm{CO}_{2}$ removal in an alkaline medium without the presence of microalgae (Knuutila et al., 2010). In another example of differentiation between individual components and the integrated system, researchers aimed to achieve a carbon balance in the bubble column-photobioreactor system by fixing algal productivity (Marín et al., 2021). The controlled values varying between $7.5-15 \mathrm{~g} / \mathrm{m}^{2} / \mathrm{d}$ were much lower than the achievable productivity of $20-25 \mathrm{~g} / \mathrm{m}^{2} / \mathrm{d}$ in open pond systems (Sun et al., 2016).

The simultaneous influence of multiple design factors and their corresponding levels of operation on photosynthetic biogas upgrading (compiled in Table 1) could be seen to generate variability in conclusions on the system performance. For instance, Toledo-Cervantes et al. (2017) suggested the use of co-current bubble column configuration and a liquid to gas flow rate $(\mathrm{L} / \mathrm{G})$ ratio of less than 1 to achieve grid-quality biomethane. However, del Rosario Rodero et al. (2020a), employing a counter-current bubble column, reported $14.1 \% \mathrm{CO}_{2}$ concentration in upgraded biomethane at an L/G ratio of 0.8 in a pilot-scale facility. In a more recent study, the $\mathrm{CO}_{2}$ content in the biogas varied between $1.5 \%$ and $4.4 \%$ at an alkalinity of $1200 \mathrm{mg} / \mathrm{L}$ inorganic carbon (IC) and inlet $\mathrm{pH}$ between 9.7 and 9.8 (del Rosario Rodero et al., 2020b). In contrast, Marín et al. (2021), in a similar experimental range and using a similar setup, reported a much lower $\mathrm{CO}_{2}$ content in biogas of $0.5 \%$. Seasonal variations,

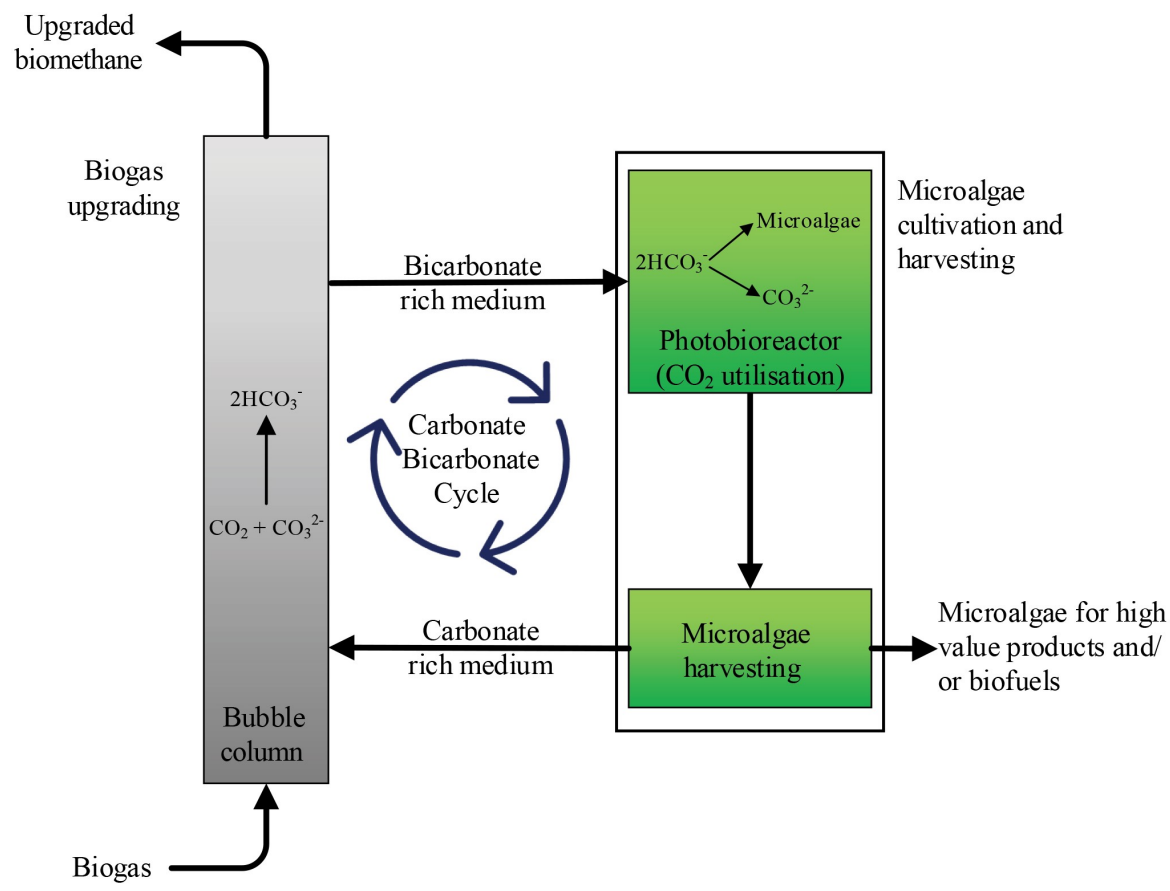

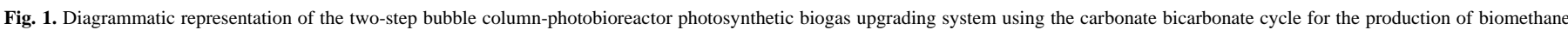
and microalgae for high-value products and/or biofuels. 
Table 1.

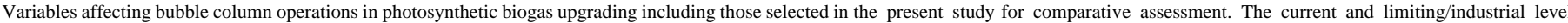
have been compiled from multiple literature sources*.

\begin{tabular}{|c|c|c|c|c|c|}
\hline \multirow{2}{*}{ Variables } & \multirow{2}{*}{ Description } & \multicolumn{3}{|c|}{ Levels } & \multirow{2}{*}{$\begin{array}{l}\text { Factor selection in current } \\
\text { study }\end{array}$} \\
\hline & & Current & Limits/Levels & Research need & \\
\hline Superficial gas velocity $(\mathrm{cm} / \mathrm{s})$ & Inlet velocity of biogas to the bubble column & $0.05-0.5$ & 4 & To be increased & Selected \\
\hline Empty bed residence time (min) & $\begin{array}{l}\text { Time of biogas in an empty bubble column, } \\
\text { indicating the height of the column }\end{array}$ & $10-90$ & $3-6$ & To be reduced & Selected \\
\hline Aspect ratio & Ratio of column height to diameter & $10-110$ & $\begin{array}{c}3-10 \\
\text { (Jakobsen, 2009) }\end{array}$ & To be reduced & $\begin{array}{l}\text { Not selected as confounded } \\
\text { with the both the previous } \\
\text { factors }\end{array}$ \\
\hline L/G ratio & Ratio of liquid to gas flow rate & $0.5-10$ & NA & To be optimised & Selected \\
\hline Flow configuration & $\begin{array}{l}\text { Co-current or counter current gas-liquid flow } \\
\text { configurations }\end{array}$ & $\mathrm{Co} /$ Counter current & NA & N/A & $\begin{array}{l}\text { Co-current chosen after } \\
\text { Toledo-Cervantes et al. (2017) }\end{array}$ \\
\hline $\mathrm{pH}$ & $\mathrm{pH}$ of the algal solution at the bubble column inlet & $7-10.5$ & $8.5-11$ & To be optimised & Selected \\
\hline Alkalinity (g-IC/L) & $\begin{array}{l}\text { Strength of a buffer solution, indicating the } \\
\text { amount of dissolved inorganic carbon content in } \\
\text { solution }\end{array}$ & $0.1-4.1$ & N/A & To be optimised & Selected \\
\hline Temperature $\left({ }^{\circ} \mathrm{C}\right)$ & Operating temperature of bubble column & $10-28$ & $20-40$ & To be optimised & Selected \\
\hline Algae concentration (g-DW/L) & $\begin{array}{l}\text { Concentration of microalgae in cultivation } \\
\text { medium }\end{array}$ & $\begin{array}{l}\text { Algae circulated } \\
\text { after harvesting }\end{array}$ & $\begin{array}{c}\text { Up to } 10 \\
\text { (Huang et al., 2017) }\end{array}$ & To be optimised & Selected \\
\hline Light (klux) & $\begin{array}{l}\text { Cool white light affecting appreciable Spirulina } \\
\text { platensis growth }\end{array}$ & On/Off & $\begin{array}{l}\text { As per those } \\
\text { required by chosen } \\
\text { algal species }\end{array}$ & $\begin{array}{l}\text { Effect to be } \\
\text { understood }\end{array}$ & $\begin{array}{l}\text { Kept on at all times in the } \\
\text { bubble column setup }\end{array}$ \\
\hline Algae productivity (g-DW/L/d) & Average daily growth rate of microalgae & $0.06-0.1$ & $\begin{array}{l}0.175 \\
\text { (De Oliveira et al., } \\
\text { 1999) }\end{array}$ & $\begin{array}{l}\text { To be } \\
\text { maximised }\end{array}$ & $\begin{array}{l}\text { Not considered as not directly } \\
\text { linked to bubble column } \\
\text { optimisation }\end{array}$ \\
\hline $\mathrm{CO}_{2}$ in biogas $(\%)$ & $\mathrm{CO}_{2}$ concentration in the influent biogas & NA & $20-55$ & External factor & Kept constant as an external \\
\hline $\mathrm{H}_{2} \mathrm{~S}$ in biogas (ppm) & $\mathrm{H}_{2} \mathrm{~S}$ concentration in the influent biogas & NA & $0-10,000$ & External factor & factor \\
\hline $\begin{array}{l}\text { Dissolved oxygen (DO) } \\
\text { concentration }(\mathrm{mg} / \mathrm{L})\end{array}$ & $\begin{array}{l}\text { The content of the dissolved oxygen in the inlet } \\
\text { algal liquid }\end{array}$ & $2-15$ & $\begin{array}{c}<100 \% \text { air } \\
\text { saturation level } \\
\text { (Molina et al., } \\
\text { 2001) }\end{array}$ & External factor & $\begin{array}{l}\text { Kept constant as an external } \\
\text { factor }\end{array}$ \\
\hline
\end{tabular}

NA: Not applicable; IC: Inorganic carbon; DW: Dry weight

* Sources: Bahr et al. (2014), Posadas et al. (2015a and b), Franco-Morgado et al. (2017), Meier et al. (2017), Toledo-Cervantes et al. (2017), Marín et al. (2018 and 2021), Bose et al. (2019), del Rosario Rodero et al. (2018, 2019a and b, 2020a and b)

especially with open pond microalgae cultivation caused $\mathrm{CO}_{2}$ percentages in biomethane to vary from $0.7 \%$ during summer to $11.9 \%$ during winter; the corresponding $\mathrm{O}_{2}$ concentration varied between $0 \%$ and 3.5\% (Marín et al., 2018). Diurnal variations between $2 \%$ and $4.5 \%$ in $\mathrm{CO}_{2}$ content in the upgraded biomethane were reported by Meier et al. (2017).

These variabilities and uncertainties arise not only from the different experimental conditions that exist in each study but also from the probable interactive effects among operating factors that are seldom assessed in studies. Present Technology Readiness Levels (TRLs) would suggest viable knowledge for scale-up and industrial-scale implementation of photosynthetic biogas upgrading but would still suffer from significant uncertainty. Therefore, rather than trying to optimise the overall photosynthetic biogas upgrading system, a focused look into individual sub-systems could be beneficial. It would allow optimisation of biogas upgrading and hence the selection of appropriate microalgae cultivation and harvesting techniques to maximise the overall system effectiveness and robustness.

\subsection{Objective and novelty}

Research on bubble columns for $\mathrm{CO}_{2}$ absorption in sodium/potassium carbonate-bicarbonate solutions has primarily focused on performance improvement in either pure or catalysed solutions in the absence of microalgae (Knuutila et al., 2010; Hu et al., 2016). On the contrary, microalgae cultivation (Vasumathi et al., 2012; Huang et al., 2017) and harvesting (Barros et al., 2015; Singh and Patidar, 2018) have been extensively studied and discussed in the literature under similar conditions suitable for photosynthetic biogas upgrading.
Thus, in a novel approach, rather than optimisation by varying a few factors, the present work aims to compare the main effects of, and interactions between, different design factors on the bubble column performance for biogas upgrading. The Taguchi orthogonal array (OA) as screening design of experiment was selected as the statistical tool. Using this comparative assessment, the authors believe a significant knowledge gap in the operation of the bubble column and hence the overal photosynthetic biogas upgrading system could be overcome. Accordingly, experiments were conducted on a lab-scale bubble column to:

i. determine and rank the factors according to their influence on the performance of the bubble column for photosynthetic biogas upgrading

ii. determine the most impactful interactive effects between the design factors in affecting the bubble column operations

iii. identify the suitable operating setpoints of the design factors to ensure robust operation of the bubble column

iv. predict and analyse the operation of the bubble column with respect to product biomethane composition and its significance to photosynthetic biogas upgrading.

\section{Materials and Methods}

\subsection{Microorganisms and culture conditions}

All experiments were performed with microalgae Arthrospira (Spirulina) platensis SAG 85.79, from Sammlung von Algenkulturen Goettingen (SAG), Germany. The microalgae were grown in 3-L batches 
within 5-L Erlenmeyer Flasks with continuous bubbling of air. Temperature and light were maintained at $20 \pm 1{ }^{\circ} \mathrm{C}$ and $4000 \pm 500$ lux with a $16: 8$ light/dark cycle. Modified Zarrouk's medium was used as the nutrient medium, the detailed composition of which can be found elsewhere (Madkour et al., 2012). The cultures were transferred to a new medium every three to four weeks to continue cultivation. Strains were maintained in $100 \mathrm{~mL}$ Erlenmeyer flasks, maintaining a $\mathrm{pH}$ between 9 and 10 .

\subsection{Experimental setup}

Experiments were conducted in a 2-m high, 24-mm diameter absorption (bubble) column made from a clear acrylic tube of the same dimensions. Multiple liquid outlets at desired heights were fitted to allow the study of variable gas flow rates and empty bed residence time (EBRT). A 24-mm diameter, 300-mm high gas liquid separator was used to remove all trapped gas bubbles at the liquid outlet. The entire setup was housed in a cabinet capable of maintaining temperature and light intensities between 20 to $40{ }^{\circ} \mathrm{C}$ and 2000 to 6000 lux, respectively. A schematic overview of the experimental setup is provided in Figure 2.

The microalgae solution was pumped through the bottom of the column by a VWR® AU-UPC-EZ programmable peristaltic pump in a co-current configuration to the biogas. Synthetic biogas, at an absolute pressure of $1.2 \mathrm{bar}$ was bubbled through a $25-\mathrm{mm}$ long and $18-\mathrm{mm}$ diameter air-stone diffuser placed at the bottom of the bubble column. Synthetic biogas comprising $40 \% \mathrm{CO}_{2}$ and the remainder $\mathrm{N}_{2}$ (in lieu of $\mathrm{CH}_{4}$ ) without any $\mathrm{H}_{2} \mathrm{~S}$ was chosen from safety considerations. $\mathrm{N}_{2}$ in lieu of $\mathrm{CH}_{4}$ has been previously used in literature (Posadas et al., 2015a) due to its inertness and similar solubility $\left(0.0019 \mathrm{~g} / 100 \mathrm{~g} \mathrm{H}_{2} \mathrm{O}\right)$ to that of $\mathrm{CH}_{4}\left(0.0023 \mathrm{~g} / 100 \mathrm{~g} \mathrm{H}_{2} \mathrm{O}\right)$ (Kaye and Laby, 1986) under atmospheric conditions. The individual $\mathrm{N}_{2}$ and $\mathrm{CO}_{2}$ flows were controlled by separate flow controllers (Red-y smart controller GSC, Vögtlin Instruments ${ }^{\circledR} \mathrm{GmbH}$ ). Differential pressure between the top of the bubble column and the atmosphere fluctuated between $0.01 \pm 0.01 \mathrm{bar}(\mathrm{g})$ measured by a manometer fitted to the outlet of the column.

The liquid outlet from the gas/liquid separator was routed to a tee with one end open to the atmosphere via a U-shaped connection, as shown in Figure 2. This prevented the syphoning out of the liquid from the gas-liquid separator while allowing the outlet flow to match the inlet flow controlled by the peristaltic pump. The combined outlet gas from the bubble column and the gas liquid separator were sequentially routed through a foam trap and an ice bath to remove foam and moisture. Inside the ice bath, a larger pipe diameter pipe was used as a condensate trap and was regularly drained after a few experiments to ensure its adequacy of operation. Flow and composition measurements were hence performed on a dry gas basis as described in Section 2.4.

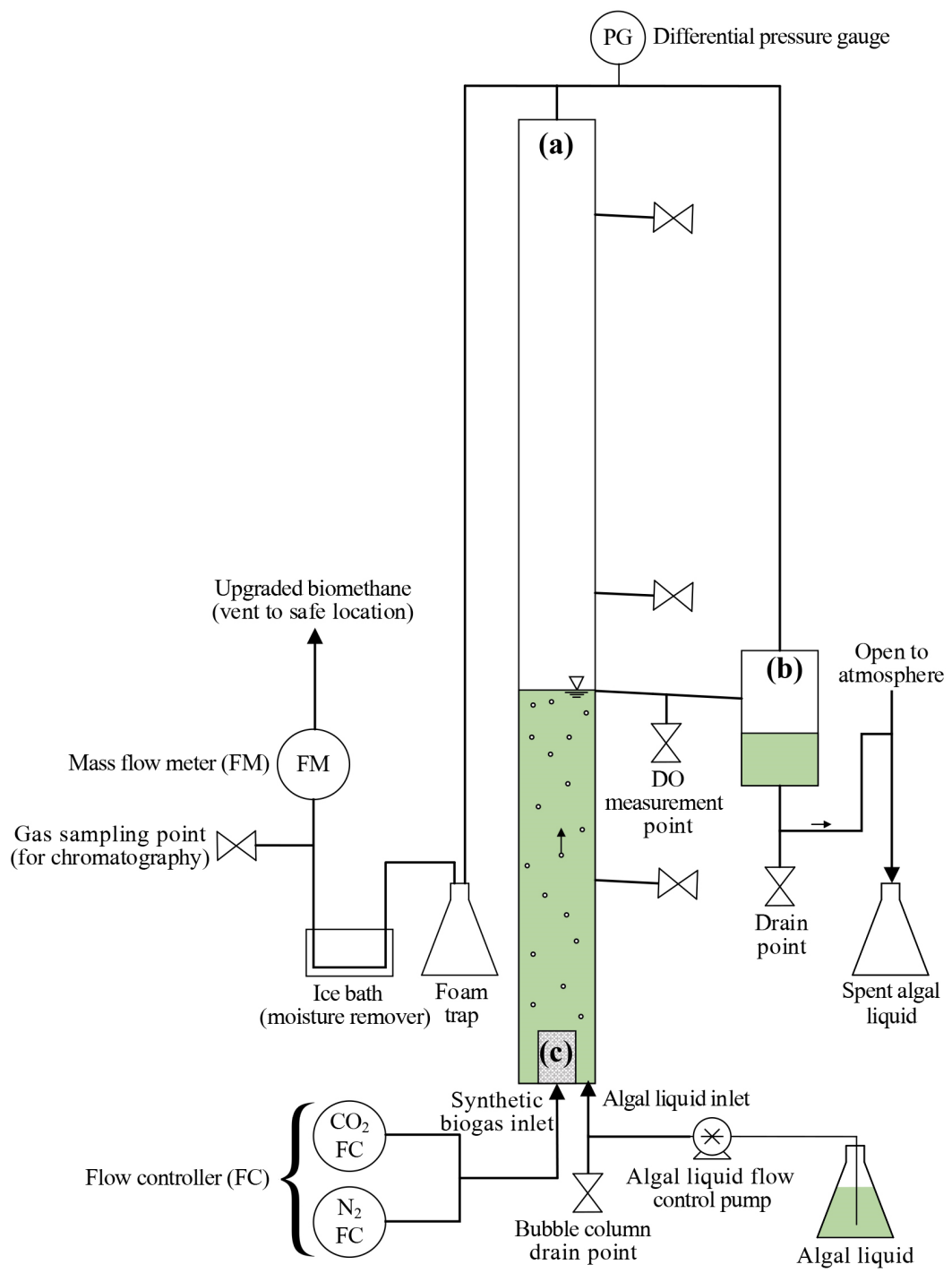

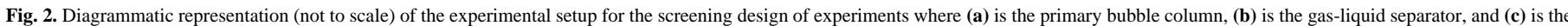
gas diffuser. 


\subsection{Experimental design}

\subsubsection{Screening design of experiments}

The Taguchi OA as a screening design of experiments was used to quantitatively determine the most critical design factors and their corresponding settings at which both the desired output is achieved, and the system resilience is maximised (Krishnaiah and Shahabudeen, 2012; Montgomery, 2012). This method was selected as it provides a robust, balanced, and unbiased technique to compare the main effects of the design factors independently of each other with a minimum number of experiments (Krishnaiah and Shahabudeen, 2012; Chiranjeevi and Mohan, 2016; Awtycarroll et al., 2020). Additionally, a few interactions among the design factors can also be studied (Rao et al., 2008; Krishnaiah and Shahabudeen, 2012). In this concept, each design factor is studied at two levels ("high" or "low" for quantitative factors or "on" or "off" for qualitative ones) to systematically record and rank their influences on the desired outcome (Smith et al., 2016). Figure 3 outlines the step-by-step methodology of the Taguchi experimental design used in the present study. A brief description of each step has been provided in the following sections, further details of which can be found in multiple pieces of literature and textbooks (Roy, 2010; Krishnaiah and Shahabudeen, 2012)

\subsubsection{Selection of process responses as bubble column performance criteria}

To prevent confounding and to develop a perspective on the bubble column design, cost, and operations, system performance was assessed in terms of $\mathrm{CO}_{2}$ removal and oxygen stripping from the microalgal medium into the biomethane. $\mathrm{CO}_{2}$ removal efficiency $\left(\mathrm{R}_{\text {eff, }} \mathrm{CO}_{2}\right)(\%)$; the mean steady-state absorption rate of $\mathrm{CO}_{2}\left(\mathrm{R}_{\mathrm{abs}, \mathrm{CO}_{2}}\right)(\mathrm{mol} / \mathrm{L} / \mathrm{s})$; and the mean overall $\mathrm{CO}_{2}$ mass transfer coefficient $\mathrm{k}_{\mathrm{G}_{\mathrm{CO}_{2}}}$ a $\left(\mathrm{h}^{-1}\right)$ were used to assess $\mathrm{CO}_{2}$ removal (Chen et al, 2015). To measure oxygen stripping, the oxygen concentration in the upgraded biomethane $\left(\mathrm{O}_{2, \%, \mathrm{BM}}\right)(\%)$, together with the flow rate of oxygen in the outlet biomethane $\left(\mathrm{O}_{2, \mathrm{BM}}\right)\left(\mathrm{mL}_{\mathrm{n}} / \mathrm{min}\right)$ were studied.

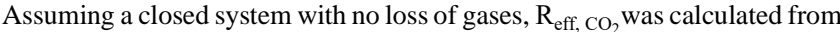
the inlet molar flow rate of $\mathrm{CO}_{2}$ in the biogas $\left(\mathrm{N}_{\mathrm{CO}_{2}, \mathrm{BG}}\right)$ and the outlet molar flowrate of $\mathrm{CO}_{2}$ in the biomethane $\left(\mathrm{N}_{\mathrm{CO}_{2}, \mathrm{BM}}\right)(\mathrm{mol} / \mathrm{min})$ according to Equation 3. The corresponding mean steady-state absorption rate of $\mathrm{CO}_{2}\left(\mathrm{R}_{\mathrm{abs}, \mathrm{CO}_{2}}\right)$ $(\mathrm{mol} / \mathrm{L} / \mathrm{s})$ is described in Equation 4 in which $\mathrm{V}_{\mathrm{BC}}$ denotes the liquid volume in the bubble column (L) (Chen et al., 2015). The following assumptions were made: i) a two-phase system with minimal influence of the solid phase (Clark, 1990; Deckwer et al., 1980); ii) a thoroughly mixed homogeneous system that can be considered as a plug flow and can be well represented by the two-film theory (Fernández et al., 2017; Chen and Lin, 2018); iii) isothermal conditions conforming to the ideal gas laws; and iv) fast chemical reactions occurring above pH 8 (Borhani et al., 2015). Finally, the mean overall mass transfer coefficient for $\mathrm{CO}_{2}$ absorption $\mathrm{k}_{\mathrm{G}_{\mathrm{CO}}}$ a $\left(\mathrm{h}^{-1}\right)$ was estimated after Chen and Lin (2018) via Equation 5, where G represents the total gas flow rate in the influent biogas in $\mathrm{mL}_{\mathrm{n}} / \mathrm{s}$.

$\mathrm{R}_{\text {eff, } \mathrm{CO}_{2}}=\frac{N_{\mathrm{CO}_{2}, B G}-N_{\mathrm{CO}_{2}, B M}}{N_{\mathrm{CO}_{2}, B G}} \times 100$

$\mathrm{R}_{\mathrm{abs}, \mathrm{CO}_{2}}=\frac{N_{\mathrm{CO}_{2}, \mathrm{BG}}-\mathrm{N}_{\mathrm{CO}_{2}, \mathrm{BM}}}{V_{\mathrm{BC}}}$

$\mathrm{k}_{\mathrm{G}_{\mathrm{CO}_{2}}} \mathrm{a}=\frac{G}{V_{B C}} \cdot \ln \frac{N_{\mathrm{CO}_{2}, B G}}{N_{\mathrm{CO}_{2}, B M}}$

\subsubsection{Selection of design factors and their levels}

Seven controllable variables or design factors affecting the operation of the bubble column in photosynthetic biogas upgrading were selected for comparative assessment, namely: superficial gas velocity $\left(\mathrm{u}_{\mathrm{c}}\right)$; the liquid to gas flow rate $(\mathrm{L} / \mathrm{G})$ ratio; EBRT; liquid inlet $\mathrm{pH}$; liquid inlet alkalinity (Alk); temperature $\left(\mathrm{T}_{\mathrm{col}}\right)$; and algal concentration in the liquid circulating in the bubble column $\left(\mathrm{C}_{\text {alg }}\right)$. As discussed in Section 1.2, and compiled in Table 1, all factors except algal concentration and EBRT have been

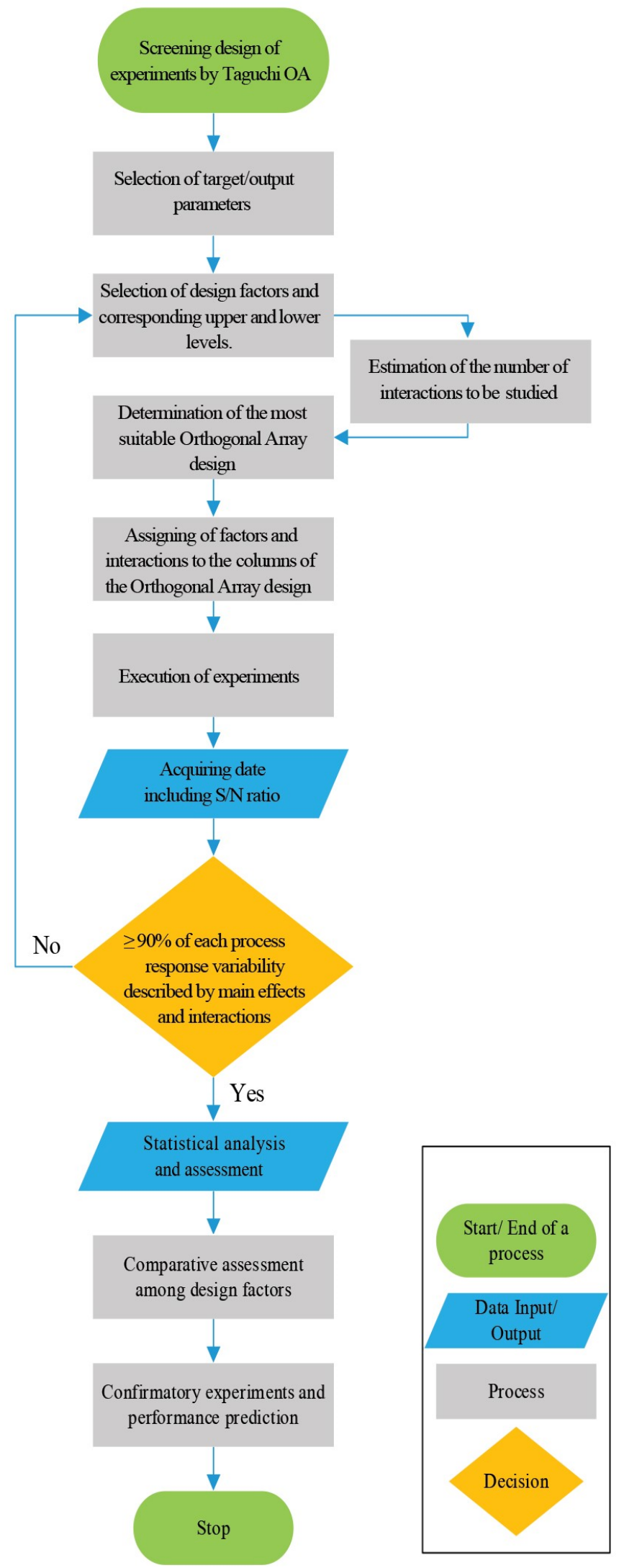

Fig. 3. Outline of the Taguchi screening design of experiments using orthogonal arrays 
separately investigated for their importance to the operations of the overall photosynthetic biogas upgrading system. While factors such as the $\mathrm{pH}$ and alkalinity would need to be optimised, understanding the relative importance of superficial gas velocity is important in order to increase the throughput of the bubble column. On the contrary, the influence of EBRT and algal concentration have only been evaluated explicitly by Bahr et al. (2014) and del Rosario Rodero et al. (2020b), respectively. However, in a previous work by the authors (Bose et al., 2019), these factors were discussed to be of potentially considerable importance and hence are selected for assessment herein. Indeed, decreasing the EBRT to current industrial levels is critical towards ensuring the use of state-of-the-art bubble columns for photosynthetic biogas upgrading, as this would reduce construction and operation costs. Other variables, such as the $\mathrm{CO}_{2}$ and $\mathrm{H}_{2} \mathrm{~S}$ content in biogas and the dissolved oxygen (DO) in the circulating algal liquid, which affect the bubble column operation, are exogenous to the bubble column design and hence not included in the design factors.

The upper and lower bound value of each design factor was selected by assessing current trends and future targets from literature as indicated in Table 2. However, for $\mathrm{u}_{\mathrm{i}}$ and EBRT, the upper values were selected based on the limitation of the experimental setup described in Section 2.2. Thus, the maximum $\mathrm{u}_{\mathrm{G}}$ and EBRT were limited to $0.2 \mathrm{~cm} / \mathrm{s}$ and $15 \mathrm{~min}$, respectively, although their maximum limits lie at $4 \mathrm{~cm} / \mathrm{s}$ and $90 \mathrm{~min}$, respectively. Additionally, the maximum algal density was fixed at $0.75 \mathrm{~g}-\mathrm{DW} / \mathrm{L}$, limited by foaming of the algae medium observed during pre-experiments (Bose et al., 2021). However, it is still representative of the algal concentrations obtained in closed and open photobioreactors (Hu et al., 1996; Costa et al., 2003). Similarly, the lower and upper temperature values correspond to the tolerable and ideal values for S. platensis (De Oliveira et al., 1999).

\subsubsection{Selection of Taguchi OA, interactions, and experimental trials}

The Taguchi OA comprising 16 experimental trials $\left(\mathrm{L}_{16}\right)$ was selected to quantitatively compare (screen) seven factors (tested at two levels, referred to as " 2 "”). Each design factor was assigned one column in the fifteen column $L_{16}$ $\mathrm{OA}$. The remaining eight columns were used to study two-factor interactions, namely: i) $\mathrm{L} / \mathrm{G} v s \mathrm{pH}$; ii) $\mathrm{L} / \mathrm{G} v s . \mathrm{u}_{\mathrm{G}}$; iii) $\mathrm{u}_{\mathrm{G}} v s$. EBRT; iv) $\mathrm{u}_{\mathrm{G}} v s . \mathrm{pH}$; v) $\mathrm{u}_{\mathrm{G}} v s$. Alk; vi) $\mathrm{u}_{\mathrm{G}}$ vs. $\mathrm{T}_{\text {col }}$; vii) $\mathrm{pH}$ vs. Alk; and viii) $\mathrm{T}_{\text {col }}$ vs. $\mathrm{C}_{\text {alg. }}$.
Table 2.

Design factors and corresponding levels.

\begin{tabular}{llccc}
\hline \multirow{2}{*}{ Factor } & \multirow{2}{*}{ Design factors } & \multirow{2}{*}{ Notation } & \multicolumn{2}{c}{ Level } \\
\cline { 3 - 5 } & & & Low (1) & High (2) \\
\hline $\mathrm{A}$ & L/G Ratio & $\mathrm{L} / \mathrm{G}$ & 0.2 & 1 \\
$\mathrm{~B}$ & Superficial gas velocity $(\mathrm{cm} / \mathrm{s})$ & $\mathrm{u}_{\mathrm{G}}$ & 0.06 & 0.2 \\
$\mathrm{C}$ & Empty bed residence time $(\mathrm{min})$ & $\mathrm{EBRT}$ & 6 & 15 \\
$\mathrm{D}$ & Inlet $\mathrm{pH}$ & $\mathrm{pH}$ & 9 & 10.5 \\
$\mathrm{E}$ & Inlet alkalinity $(\mathrm{g}-\mathrm{IC} / \mathrm{L})$ & $\mathrm{Alk}$ & 1 & 2.5 \\
$\mathrm{~F}$ & Temperature $\left({ }^{\circ} \mathrm{C}\right)$ & $\mathrm{T}_{\text {col }}$ & 20 & 35 \\
$\mathrm{G}$ & Algae concentration $(\mathrm{g}-\mathrm{DW} / \mathrm{L})$ & $\mathrm{C}_{\mathrm{alg}}$ & 0.05 & 0.75 \\
\hline
\end{tabular}

Accordingly, the following Taguchi OA structure was generated as shown in Table 3. All higher order interactions were neglected with fair confidence (Montgomery, 2012).

Experiments were conducted using each row in the selected $\mathrm{L}_{16} \mathrm{OA}$ (Table 3) as individual experimental runs. Columns 1, 5, 6, 8, 10, 11, and 12 represent the different settings of the design factors for the 16 experimental runs; the remaining columns accommodated the interactions. Each run was triplicated and randomised to minimise repeatable errors, also referred to as systematic bias (Mehta, 2001), and to enable accurate estimation of the variations in the bubble column performance due to uncontrollable factors or noise.

\subsubsection{Signal to noise $(S / N)$ ratio}

Each process response can be categorised as $i$ ) the signal or the intended response from the influence of the design factors and ii) unintended outcomes resulting from noise (Kishore et al., 2018). In the Taguchi method, to estimate the sensitivity of the main effects and interactions against the noise, the signal to noise $(\mathrm{S} / \mathrm{N})$ ratio is used as a qualitative metric (Roy, 2010). A higher value of the $\mathrm{S} / \mathrm{N}$ ratio is always desired as,

Table 3.

$\mathrm{L}_{16}$ Taguchi Orthogonal array for screening design of 16 experiments $\left(\mathrm{L}_{16}\right)$ with seven factors $(\mathrm{A}-\mathrm{G})$ at two levels $\left(2^{7}\right)$.

\begin{tabular}{|c|c|c|c|c|c|c|c|c|c|c|c|c|c|c|c|}
\hline \multirow{3}{*}{$\begin{array}{l}\dot{\vec{z}} \\
\dot{\Xi} \\
\dot{\Xi}\end{array}$} & \multicolumn{15}{|c|}{ Taguchi $\mathrm{L}_{16}$ columns } \\
\hline & 1 & 2 & 3 & 4 & 5 & 6 & 7 & 8 & 9 & 10 & 11 & 12 & 13 & 14 & 15 \\
\hline & $\begin{array}{l}ذ \\
\vdots \\
\vdots\end{array}$ & \multicolumn{3}{|c|}{ Interaction } & 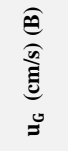 & 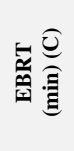 & 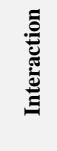 & $\underset{\mathrm{E}}{\widehat{\mathrm{a}}}$ & 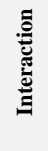 & 娄 & 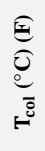 & 产 & \multicolumn{3}{|c|}{ Interaction } \\
\hline 1 & 0.2 & \multirow{16}{*}{ 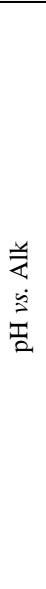 } & \multirow{16}{*}{ 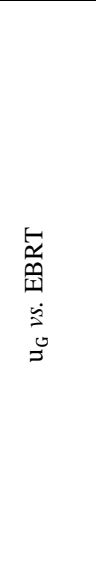 } & \multirow{16}{*}{ 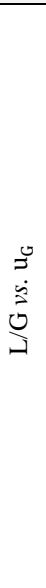 } & 0.06 & 6 & & 9 & & 1 & 20 & 0.05 & \multirow{16}{*}{$\begin{array}{l}\frac{\pi}{2} \\
\dot{d} \\
= \\
=\end{array}$} & \multirow{16}{*}{ 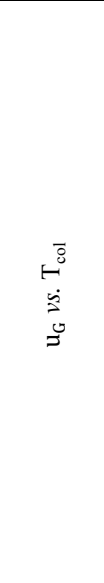 } & \multirow{16}{*}{$\begin{array}{l}\ddot{z} \\
\ddot{z} \\
\dot{z} \\
\tilde{J}\end{array}$} \\
\hline 2 & 0.2 & & & & 0.06 & 6 & & 10.5 & & 2.5 & 35 & 0.75 & & & \\
\hline 3 & 0.2 & & & & 0.2 & 15 & & 9 & & 1 & 20 & 0.75 & & & \\
\hline 4 & 0.2 & & & & 0.2 & 15 & & 10.5 & & 2.5 & 35 & 0.05 & & & \\
\hline 5 & 0.2 & & & & 0.06 & 15 & & 9 & & 2.5 & 35 & 0.05 & & & \\
\hline 6 & 0.2 & & & & 0.06 & 15 & & 10.5 & & 1 & 20 & 0.75 & & & \\
\hline 7 & 0.2 & & & & 0.2 & 6 & $\frac{20}{\sqrt{5}}$ & 9 & $I$ & 2.5 & 35 & 0.75 & & & \\
\hline 8 & 0.2 & & & & 0.2 & 6 & $\dot{u}$ & 10.5 & $\vec{a}$ & 1 & 20 & 0.05 & & & \\
\hline 9 & 1 & & & & 0.2 & 6 & $\frac{y}{5}$ & 9 & ऐُ & 1 & 35 & 0.05 & & & \\
\hline 10 & 1 & & & & 0.2 & 6 & $H^{8}$ & 10.5 & בૅ & 2.5 & 20 & 0.75 & & & \\
\hline 11 & 1 & & & & 0.06 & 15 & & 9 & & 1 & 35 & 0.75 & & & \\
\hline 12 & 1 & & & & 0.06 & 15 & & 10.5 & & 2.5 & 20 & 0.05 & & & \\
\hline 13 & 1 & & & & 0.2 & 15 & & 9 & & 2.5 & 20 & 0.05 & & & \\
\hline 14 & 1 & & & & 0.2 & 15 & & 10.5 & & 1 & 35 & 0.75 & & & \\
\hline 15 & 1 & & & & 0.06 & 6 & & 9 & & 2.5 & 20 & 0.75 & & & \\
\hline 16 & 1 & & & & 0.06 & 6 & & 10.5 & & 1 & 35 & 0.05 & & & \\
\hline
\end{tabular}


the higher the value of $\mathrm{S} / \mathrm{N}$ ratio, the more stable the process response is against the noise (Roy, 2010; Priyadarshi and Paul, 2019). Based on the objective, a process response might require to be minimised or maximised. When a process response needs to be maximised $\left(\mathrm{R}_{\mathrm{eff}, \mathrm{CO}_{2}}, \mathrm{R}_{\mathrm{abs}, \mathrm{CO}_{2}}, \mathrm{k}_{\mathrm{G}_{\mathrm{CO}_{2}}}\right.$ ), the $\mathrm{S} / \mathrm{N}$ ratio is classified as the larger-the-better (LB) criterion, given by Equation 6. On the contrary, when the process response is intended to be minimised $\left(\mathrm{O}_{2, \mathrm{BM}}\right.$, $\mathrm{O}_{2, \%, \mathrm{BM}}$ ), the smaller-the-better ( $\left.\mathrm{SB}\right) \mathrm{S} / \mathrm{N}$ ratio is used, represented by Equation 7 (Davis and John, 2018)

$(\mathrm{S} / \mathrm{N})_{\mathrm{LB}}=-10 \log _{10}\left[\frac{1}{\mathrm{n}} \sum_{\mathrm{i}}^{\mathrm{n}} \frac{1}{y_{i j}^{2}}\right]$

$(\mathrm{S} / \mathrm{N})_{\mathrm{SB}}=-10 \log _{10}\left[\frac{1}{\mathrm{n}} \sum_{\mathrm{i}}^{\mathrm{n}} y_{i j}^{2}\right]$

where $y_{i j}$ refers to the $\mathrm{i}^{\text {th }}$ output signal $(\mathrm{i}=1,2,3)$ of the process response $\mathrm{j}$ (e.g.,

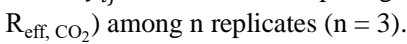

\subsubsection{Determining the adequacy of the experimental design}

Prior to analyses of results, a statistical test was performed to check the adequacy of the chosen experimental design. A general linear model via analysis of variance (ANOVA) (summarised in Section 2.3.8) was fitted, considering each replicate as a separate experiment (Myers et al., 2017). If the experimental design is adequate, the fitted model should be able to describe the majority of the variabilities in the process responses using the fifteen factors (seven main effects and eight interactions) chosen in the experimental design.

\subsubsection{Interpretation of the experimental results}

Based on the results of the Taguchi OA, the influence of the design factors on the performance of $\mathrm{CO}_{2}$ removal and oxygen stripping in the bubble column were compared using the following steps:

Step 1: A main effects plot showing the mean process response at each level (low (1) or high (2)) of the design factors was first plotted to graphically identify the influence of the design factors on the mean process responses. This also allowed the identification of the design factor settings to obtain the desired process responses. The slope of the plot additionally indicates the influence of each design factor on the response (Antony, 2014); a positive slope shows an increase in response on increasing the design factor value and vice-versa.

Step 2: A similar main effects plot with the $\mathrm{S} / \mathrm{N}$ ratio of the process response was then plotted. The design factor that caused the highest variation in the $\mathrm{S} / \mathrm{N}$ ratio of the process response between its low and high setting was concluded to have the largest influence on the studied process response (Antony, 2014). All other design factors were then ranked subsequently.

Step 3: A general linear model via the ANOVA was then fitted to the S/N ratios to obtain the percentage contributions of the design factors and the interactions towards the process response (described in Section 2.3.8).

Step 4: A half normal probability plot was plotted to graphically compare the relative contribution of both the main effects of the design factors and the studied interactions on the process response (Ganapathy et al., 2009).

Step 5: A confirmatory pooled ANOVA was performed using only the design factors and interactions having over $95 \%$ contribution towards the process response to determine the factors (main effects and interactions) that are statistically significant $(\mathrm{P}<0.05)$. All other factors were pooled under the error term. The higher value of $95 \%$ was selected to minimise the possibility of falsely rejecting important design factors, also known as type II error in statistical jargon (Montgomery, 2012; Jones, 2016). Especially for screening experiments, such a false rejection effecting the omission of a major design factor from future detailed designs could severely limit the development of a product or process (Jones, 2016).

\subsubsection{Analysis of variance (ANOVA)}

ANOVA provides a statistical approach to quantify the variations in the process responses resulting from the main effects and interactions (Kishore et al., 2018). Additionally, it also provides an estimation of the unexplained variations or errors resulting from noise, experimental limitations, and assumptions (Kishore et al., 2018). The results of the multivariate ANOVA are typically represented as a table having the following entries (not in order): $i$ ) sources, signifying the design factors, interactions, errors, and the cumulative total of variations $i i$ ) degree of freedom (DoF); iii) adjusted sum of squares (Adj SS); iv) adjusted mean squares (Adj MS); $v$ ) the Fischer's F distribution (F-value); v) P-value; and vii) contribution $\left(\%_{\text {contrib }}\right)$ of each main effect, interaction, and error term towards the process response calculated by Equation 8 .

$\%_{\text {contrib }}=\frac{A d J M S_{\text {source }}}{A d J M S_{\text {total }}} \times 100$

Eq. 8

In the ANOVA table, the degrees of freedom of a source or a model signifies the number of independent inputs required to describe itself (Montgomery, 2012). The F-value signifies the extent to which the variance due to a certain source compares with variance arising from the errors, i.e., how large or small the variations due to a certain source is with respect to the unexplained variations (Mohsin et al., 2020). Irrespective of its value to evaluate if the $\mathrm{F}$ value as obtained is true, the corresponding $\mathrm{P}$-value is calculated as the probability of the $\mathrm{F}$ value being obtained by random chance (Montgomery, 2012; Mohsin et al., 2020). Thus, a higher P-value indicates a greater probability of obtaining the F-value as a random chance and hence, a lower statistical significance of the calculated F-value. Contrarily, a lower $\mathrm{P}$-value indicates a lesser probability of obtaining the $\mathrm{F}$ value as a chance and thus, indicates a greater statistical significance of the calculated F-value. Additionally, for each general linear model, a model-F value is also generated by ANOVA that signifies the predictability of the model in comparison with a model that contains no independent variables. The model F-value must be higher than the value of the F statistic below which there exists a probability of $\alpha$ to mistakenly reject a true null hypothesis (i.e., the two variances are equal) (Kim, 2017), also known as the critical F-value $\left(\mathrm{F}_{\text {crit }}\right) . \mathrm{F}_{\text {crit }}$, given in the form of $\mathrm{F}_{\alpha\left(\mathrm{k}-1, \mathrm{n}_{\mathrm{ex}}-\mathrm{k}\right)}$ can be obtained from standard statistical handbooks, where $\mathrm{k}$ is the number of predictors in the model and $\mathrm{n}_{\mathrm{ex}}$ is the total number of experimental trials. The respective model $\mathrm{P}$ value signifies the probability that the model $\mathrm{F}$ value was derived from the influence of noise, and hence, a lower P-value is always desired (Kishore et al., 2018; Mohsin et al., 2020). The details of each of these statistics can be further explored in multiple pieces of literature and textbooks (Roy, 2010; Montgomery, 2012).

\subsubsection{Performance prediction and confirmatory experiment}

Using the statistically significant $(\mathrm{P}<0.05)$ main effects and interactions, the biomethane composition exiting the bubble column under different conditions was predicted by a general linear equation in the form expressed in Equation 9.

$\hat{Z}=A_{0}+A_{i} X_{i}+A_{i j} X_{i} X_{j}$

where $A_{0}$ represents the constant of the model, $A_{i}$ is the coefficient of each design factor $X_{i}$, and $A_{i j}$ is the coefficient of each interaction between the design factors $X_{i}$ and $X_{j}$. These coefficients are derived from the ANOVA analysis and also signify the relative quantitative influence of main effect and interaction on the process response variable (Smith et al., 2016). $\mathrm{CO}_{2}$ removal efficiency $\left(\mathrm{R}_{\text {eff, } \mathrm{CO}_{2}}\right)(\%)$ and $\mathrm{O}_{2}$ outflow rate $\left(\mathrm{O}_{2, \mathrm{BM}}\right)\left(\mathrm{mL}_{\mathrm{n}} / \mathrm{min}\right)$ were used as estimates for $\mathrm{CO}_{2}$ and $\mathrm{O}_{2}$ flow rates, respectively, from which their respective compositions in biomethane can then be derived. The goodness of fit of the model was assessed with regards to the regression coefficient $\mathrm{R}^{2}$ (a measure of the agreement between predicted and actual values) and standard error of regression (S), signifying the average deviation of the observed data from the predicted model.

As the predictive regression equations were derived from ANOVA that utilises the S/N ratio statistic, Equations 10 and 11 were used to convert the predictors back into actual responses for physical interpretation.

$\hat{R}_{\mathrm{eff}, \mathrm{CO}_{2}} \cong\left[10^{\left(-(S / N)_{\left.R_{\text {eff }, C O_{2}} / 10\right)}\right.}\right]^{-0.5}$

Eq. 10 
$\hat{O}_{2, \mathrm{BM}} \cong\left[10^{\left(-(S / N) O_{2, B M} / 10\right)}\right]^{0.5}$

where $\hat{R}_{\text {eff, } \mathrm{CO}_{2}}$ and $\hat{O}_{2, \mathrm{BM}}$ predicts for $\mathrm{R}_{\text {eff, } \mathrm{CO}_{2}}$ and $\mathrm{O}_{2, \mathrm{BM}}$, respectively. For each prediction, the $95 \%$ confidence interval $\left(\mathrm{CI}_{95 \%}\right)$ was calculated by Equation 12 (Roy, 2010)

$C I_{95 \%}=\hat{Z} \pm \sqrt{\frac{F_{0.05}\left(f_{1}, f_{2}\right) \times V_{\text {error }}}{n_{\text {eq }}}}$

where $\hat{Z}\left(\hat{R}_{\text {eff, } \mathrm{CO}_{2}}\right.$ and $\left.\hat{O}_{2, \mathrm{BM}}\right)$ represents the predicted value and $V_{\text {error }}$ stands for the variance in the error term. $F_{0.05}\left(f_{1}, f_{2}\right)$ is the F-value for DoF $f_{1}$ and $\mathrm{f}_{2}$ at a significance level of 0.05 (confidence interval of $95 \%$ ); where $f_{1}=1$, being the DoF of factors in the regression model and $\mathrm{f}_{2}$ is the DoF of error term. This value of $\mathrm{F}$ is obtained from the F-tables from any standard statistical handbook. $\mathrm{n}_{\mathrm{eq}}=$ Number of trials $/\left(\mathrm{f}_{1}+\mathrm{f}_{\text {factors }}\right)$ is known as the number of equivalent replications in which, $f_{\text {factors }}$ is the DoF of factors in the regression model, also equal to 1 .

On the other hand, the $95 \%$ prediction interval $\left(\mathrm{PI}_{95 \%}\right)$ for each prediction was calculated via Equation 13 (Kitchin, 1994) to estimate the range within which $95 \%$ of the predicted values would lie with a confidence of $95 \%$.

$P I_{95 \%}=\hat{Z} \pm t_{\alpha / 2,(n-2)} \times \sqrt{\frac{S S E}{n-2}\left(1+\frac{1}{n}+\frac{n\left(x^{*}-\bar{x}\right)^{2}}{n \sum_{i=1}^{n} x_{i}-\left(\sum_{i=1}^{n} x_{i}\right)^{2}}\right.}$

In the above equation, $t_{\alpha / 2,(n-2)}=t_{0.05 / 2,(16-2)}$ is the $100(\alpha / 2)$ percentile of the student's t-distribution with 14 degrees of freedom with the significance level $(\alpha)$ as 0.05 and $\mathrm{n}=16$ from the 16 experimental runs. SSE denotes the sum of squared errors given as $\sum_{i=1}^{n}\left(x_{i}-\bar{x}\right)^{2}$ where $x_{i}$ is the value of the $\mathrm{i}^{\text {th }}$ observation and $\bar{x}$ indicates the value of the mean of all observations. $x^{*}$ represents the value of the independent predictor for predicting the corresponding $\hat{Z}$.

A confirmatory experiment was performed at a chosen level of control (different from the sixteen Taguchi trial settings) based on the experimental trials and conclusions from the screening design of experiments. The mean from the triplicated experiment $\left(Z_{\text {actual }}\right)$ was compared with the predicted output $(\hat{Z})$ with the following consideration (Eq. 14):

$\hat{Z}-C I_{95 \%} \leq Z_{\text {actual }} \leq \hat{Z}+C I_{95 \%}$

Finally, using the predictive regression equations, the variation in biomethane composition was studied between the interval of $\mathrm{pH} 9$ (factor level "1") and $\mathrm{pH} 10.5$ (factor level "2") and L/G ratio 0.2 (factor level "1") and 1 (factor level " 2 "). For this, the superficial gas velocity was varied at two levels, namely $0.06 \mathrm{~cm} / \mathrm{s}$ (factor level " 1 ") and $0.2 \mathrm{~cm} / \mathrm{s}$ (factor level "2"). All other design factors were fixed to maximise the $\mathrm{S} / \mathrm{N}$ ratio.

\subsection{Data and analysis}

\subsubsection{Data acquisition}

The steady state criteria to acquire measurements and assess the system performance were defined as follows: $i$ ) a constant gas flow rate (less than 5\% variation on average), and ii) less than $5 \%$ variation in the $\mathrm{pH}$ of the liquid at the outlet of the gas liquid separator over a period of $120 \mathrm{~s}$ each. Gas was sampled for compositional assessment via chromatography from a tap placed between the ice bath and the mass flow meter, as indicated in Figure 2. A 10 $\mathrm{mL}$ plastic syringe was used for this purpose. The DO content of the outlet liquid was measured near the bubble column outlet to prevent distortion of results from the ingression of oxygen.

\subsubsection{Analytical procedures}

The algal density was measured as optical density at a wavelength of 530 $\mathrm{nm}$ in a VWR ${ }^{\circledR}$ V-3000 PC manual spectrophotometer calibrated to the microalgae dry weight. All $\mathrm{pH}$ and DO measurements were performed using a handheld $\mathrm{pH}$ meter (VWR ${ }^{\circledR} \mathrm{MD} 8000 \mathrm{H}$ Multi Parameter Meter) fitted with respective interchangeable probes (pHenomenal VWR ${ }^{\circledR} \mathrm{pH} / \mathrm{ORP}$ sensor/ pHenomenal VWR ${ }^{\circledR}$ OPOX 11-3 sensor). Alkalinity was measured using Titronic $^{\circledR}$ Universal Titrator as per Method No. 2320 B of APHA (American Public Health Association-APHA, 1992) by titrating up to $\mathrm{pH}$ 4.5. Algal solution for photosynthetic biogas upgrading was prepared by diluting 2-3 g-DW/L microalgae culture with distilled water to the algal concentration. In an actual photosynthetic biogas upgrading cycle, algae will be circulated after cultivation to ensure $\mathrm{CO}_{2}$ uptake. As such, nutrient adjustment was not performed in order to resemble the nutrient replete medium after cultivation. The DO content in the inlet liquid varied between 6 to $10 \mathrm{mg} / \mathrm{LO}_{2}$ as per those obtained during S. platensis cultivation and are representative of those typically obtained in photobioreactors (Yang et al. 2017).

Volumetric gas flow rate was measured in terms of equivalent $\mathrm{N}_{2}$ flow using a thermal mass flow meter (Bronkhorst ${ }^{\circledR}$ F101D Low- $\Delta$ P-Flow Thermal Mass Meter). $\mathrm{CO}_{2}, \mathrm{~N}_{2}$, and $\mathrm{O}_{2}$ content in the gas were analysed by a gas chromatograph (GC; Agilent ${ }^{\circledR} 7890 \mathrm{~B}$, USA) equipped with a therma conductivity detector and a $5 \mathrm{~A}$ column. The online gas Converter tool by Fluidat ${ }^{\circledR}$ (Bronkhorst ${ }^{\circledR}$ ) was used to convert the recorded gas flow to the volumetric flow in terms of its constituents based on the composition obtained from the gas chromatograph. The actual gas flow rate and composition were obtained after a further correction step to the individual oxygen and nitrogen flow rates. This was done because noticeable air $\left(\mathrm{N}_{2}\right.$ and $\mathrm{O}_{2}$ ) ingress by diffusion into the gas tubing used in the experiment was recorded during pre-experiments (Bose et al., 2021). To obtain the correction terms needed to remove this interference from the recorded flowrates, $\mathrm{N}_{2}$ was blown into the system at the same rate as that used in the subsequent experiments, and the gas composition and flow rates were measured. The additional $\mathrm{O}_{2}$ and $\mathrm{N}_{2}$ flow rates that were obtained as correction factors were subtracted from the respective biomethane component flow rates to calculate the final biomethane composition and flow rate.

\subsection{Statistical analysis}

All statistical analyses, including the design and assessment of the Taguchi $\mathrm{L}_{16}$ OA, were performed using Minitab ${ }^{\circledR}$ software version 19 (Minitab LLC., Pennsylvania, USA). For all assessments, a confidence level of $95 \%(P<0.05)$ was selected for asserting statistical significance.

\section{Results and Discussion}

\subsection{Validation of the bubble column operation}

The biomethane composition generated during each trial, together with the $\mathrm{pH}$ of the liquid at the bubble column outlet and the process responses (e.g., $\mathrm{R}_{\text {eff, } \mathrm{CO}_{2}}$ and $\mathrm{R}_{\mathrm{abs}, \mathrm{CO}_{2}}$ ) are compiled in Table 4. Out of all the trials, grid quality biomethane was obtained only in Run 4 (L/G ratio of $0.2, \mathrm{pH} 10.5$ and values for other 5 variables); the respective $\mathrm{CO}_{2}$ and $\mathrm{O}_{2}$ in the outlet biomethane was $0 \% \pm 0.00 \%$ and $0.23 \% \pm 0.1 \%$.

A mass balance approach was used to validate the outcomes of $\mathrm{O}_{2}$ and $\mathrm{N}_{2}$ in the upgraded biomethane. Investigative assessments were performed on four experimental runs (Runs 5, 8, 9, and 12 of the Taguchi OA) that use low algal concentration. This was to ensure that the $\mathrm{O}_{2}$ in the biomethane is derived primarily from stripping of the DO of the circulating algal liquid with minimal influence of the $\mathrm{O}_{2}$ released by the active photosynthesising microalgae. Considering no $\mathrm{O}_{2}$ in the inlet biogas, a good agreement was found between the theoretical and the experimental values for oxygen in the outlet biomethane (Fig.4a). On the other hand, as shown in Figure 4b, the $\mathrm{N}_{2}$ flow in the biogas generally matched closely with that in the biomethane, confirming the assumption of minimal $\mathrm{N}_{2}$ stripping.

$\mathrm{CO}_{2}$ removal performance was validated by comparing the values of the evaluation metrics with data from the literature. As can be seen from Table 4 , the $\mathrm{CO}_{2}$ removal efficiencies varied between $19.29 \%$ and $100 \%$; the corresponding absorption rates $\left(\mathrm{R}_{\mathrm{abs}, \mathrm{CO}_{2}}\right)$ ranged from $0.036 \times 10^{-4} \mathrm{~mol} / \mathrm{L} / \mathrm{s}$ to $0.459 \times 10^{-4} \mathrm{~mol} / \mathrm{L} / \mathrm{s}$. The volumetric mass transfer coefficient $\left(\mathrm{k}_{\mathrm{G}_{\mathrm{CO}}}\right.$ a) varied from $0.87 \mathrm{~h}^{-1}\left(0.0002 \mathrm{~s}^{-1}\right)$ to $97.64 \mathrm{~h}^{-1}\left(0.027 \mathrm{~s}^{-1}\right)$. The results are in a close agreement with those reported by Chen et al. (2015), who studied the behaviour of $\mathrm{CO}_{2}$ removal with $\mathrm{NaOH}$. 


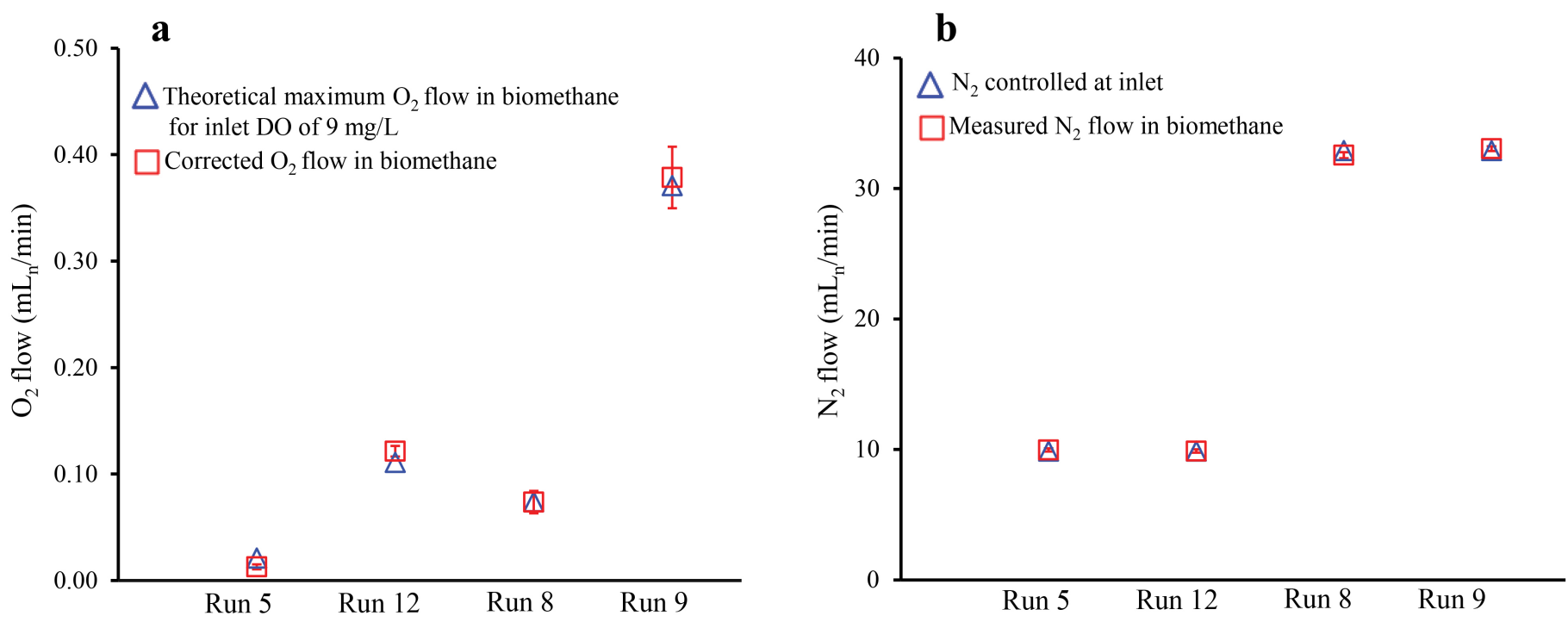

Fig. 4. Comparison between expected and measured values of (a) $\mathrm{O}_{2}$ and (b) $\mathrm{N}_{2}$ to validate the bubble column operations and measurement techniques utilised.

Table 4.

Results from the 16 experimental runs in triplicates performed on the $\mathrm{L}_{16}$ Taguchi Orthogonal Array along with the S/N ratios of the responses selected for factors screening studies.

\begin{tabular}{|c|c|c|c|c|c|c|c|c|c|c|c|}
\hline \multicolumn{2}{|c|}{ Biomethane composition } & \multirow{2}{*}{$\begin{array}{c}\text { Liquid outlet } \\
\text { pH }\end{array}$} & \multirow{2}{*}{$\begin{array}{l}\mathrm{R}_{\text {eff, } \mathrm{CO}_{2}} \\
(\%)\end{array}$} & \multirow{2}{*}{$\begin{array}{r}\mathrm{R}_{\mathrm{abs}, \mathrm{CO}_{2}} \\
(\mathrm{~mol} / \mathrm{L} / \mathrm{s})\end{array}$} & \multirow{2}{*}{$\begin{array}{l}\mathbf{k}_{\mathrm{G}_{\mathrm{CO}_{2}}} \mathbf{a} \\
\left(\mathbf{h}^{-1}\right)\end{array}$} & \multirow{2}{*}{$\begin{array}{c}\mathrm{O}_{2, \mathrm{BM}} \\
\left(\mathrm{mL}_{\mathrm{n}} / \mathrm{min}\right)\end{array}$} & \multicolumn{5}{|c|}{$\mathrm{S} / \mathrm{N}$ ratios } \\
\hline $\mathrm{CO}_{2}(\%)$ & $\mathrm{O}_{2}(\%)$ & & & & & & $\mathrm{R}_{\text {eff, } \mathrm{CO}_{2}}{ }^{\zeta}$ & $\mathrm{R}_{\mathrm{abs}, \mathrm{CO}_{2}}{ }^{\zeta}$ & $\mathbf{k}_{\mathbf{G}_{\mathrm{CO}_{2}}} \mathbf{a}^{\zeta}$ & $\mathbf{O}_{2, \%, \mathrm{BM}}{ }^{\S}$ & $\mathbf{O}_{2, \mathrm{BM}}{ }^{\S}$ \\
\hline $27.76 \pm 0.07$ & $0.16 \pm 0.06$ & $7.74 \pm 0.04$ & $40.44 \pm 0.46$ & $0.189 \pm 0.002$ & $5.23 \pm 0.08$ & $0.023 \pm 0.008$ & -7.87 & 14.37 & -14.48 & 55.32 & 32.33 \\
\hline $6.47 \pm 1.09$ & $0.28 \pm 0.13$ & $9.68 \pm 0.02$ & $89.48 \pm 1.87$ & $0.418 \pm 0.009$ & $22.91 \pm 1.83$ & $0.030 \pm 0.014$ & -0.97 & 27.12 & -7.59 & 50.07 & 29.55 \\
\hline $34.23 \pm 1.71$ & $0.51 \pm 0.12$ & $8.26 \pm 0.01$ & $19.29 \pm 3.61$ & $0.036 \pm 0.007$ & $0.87 \pm 0.18$ & $0.263 \pm 0.062$ & -14.79 & -1.83 & -29.38 & 45.66 & 11.36 \\
\hline $0.00 \pm 0.00^{*}$ & $0.23 \pm 0.01^{*}$ & $9.49 \pm 0.07$ & $100.00 \pm 0.00$ & $0.187 \pm 0.000$ & $40.38 \pm 0.00$ & $0.078 \pm 0.004$ & 0.00 & 32.12 & -14.58 & 52.56 & 22.16 \\
\hline $23.99 \pm 0.47$ & $0.09 \pm 0.02$ & $8.19 \pm 0.07$ & $52.11 \pm 0.85$ & $0.097 \pm 0.002$ & $9.92 \pm 0.24$ & $0.013 \pm 0.002$ & -5.66 & 19.92 & -20.24 & 60.01 & 37.63 \\
\hline $7.69 \pm 0.42$ & $1.28 \pm 0.24$ & $9.18 \pm 0.06$ & $87.35 \pm 0.74$ & $0.163 \pm 0.001$ & $27.87 \pm 0.78$ & $0.139 \pm 0.027$ & -1.18 & 28.89 & -15.75 & 37.71 & 17.011 \\
\hline $32.06 \pm 0.09$ & $0.39 \pm 0.02$ & $\begin{array}{c}7.82 \pm \\
0.07\end{array}$ & $29.57 \pm 0.68$ & $0.138 \pm 0.003$ & $1.06 \pm 0.03$ & $0.187 \pm 0.013$ & -10.59 & 0.51 & -17.21 & 48.21 & 14.55 \\
\hline $13.21 \pm 0.89$ & $0.19 \pm 0.03$ & $7.94 \pm 0.04$ & $77.01 \pm 1.66$ & $0.359 \pm 0.008$ & $4.46 \pm 0.22$ & $0.074 \pm 0.011$ & -2.28 & 12.96 & -8.89 & 54.18 & 22.56 \\
\hline $18.34 \pm 0.93$ & $0.94 \pm 0.06$ & $7.97 \pm 0.04$ & $66.25 \pm 1.69$ & $0.309 \pm 0.008$ & $3.29 \pm 0.15$ & $0.379 \pm .0 .029$ & -3.58 & 10.33 & -10.20 & 40.54 & 8.41 \\
\hline $1.06 \pm 0.52$ & $1.39 \pm 0.04$ & $10.15 \pm 0.02$ & $98.35 \pm 0.84$ & $0.459 \pm 0.004$ & $12.79 \pm 1.42$ & $0.471 \pm 0.019$ & -0.14 & 21.96 & -6.76 & 37.12 & 6.53 \\
\hline $14.23 \pm 0.55$ & $0.82 \pm 0.10$ & $8.15 \pm 0.02$ & $75.07 \pm 0.5$ & $0.140 \pm 0.001$ & $18.71 \pm 0.27$ & $0.094 \pm 0.011$ & -2.49 & 25.44 & -17.07 & 41.70 & 20.48 \\
\hline $0.33 \pm 0.47$ & $1.21 \pm 0.04$ & $10.09 \pm 0.06$ & $99.48 \pm 0.73$ & $0.186 \pm 0.001$ & $97.64 \pm 29.35$ & $0.121 \pm 0.005$ & -0.04 & 38.14 & -14.62 & 38.34 & 18.30 \\
\hline $2.52 \pm 0.18$ & $0.88 \pm 0.18$ & $8.39 \pm 0.04$ & $96.06 \pm 0.27$ & $0.179 \pm 0.001$ & $13.07 \pm 0.29$ & $0.300 \pm 0.066$ & -0.35 & 22.32 & -14.93 & 40.96 & 10.29 \\
\hline $0.00 \pm 0.00$ & $1.35 \pm 0.2$ & $9.84 \pm 0.04$ & $100.00 \pm 0.00$ & $0.187 \pm 0.000$ & $40.38 \pm 0.00$ & $0.450 \pm 0.065$ & 0.00 & 32.12 & -14.58 & 37.28 & 6.85 \\
\hline $10.13 \pm 0.67$ & $0.73 \pm 0.25$ & $8.54 \pm 0.07$ & $82.60 \pm 1.42$ & $0.386 \pm 0.007$ & $17.69 \pm 0.85$ & $0.082 \pm 0.026$ & -1.66 & 24.93 & -8.28 & 42.24 & 21.28 \\
\hline $3.13 \pm 1.04$ & $0.89 \pm 0.14$ & $10.06 \pm 0.05$ & $95.10 \pm 1.46$ & $0.444 \pm 0.007$ & $31.01 \pm 3.51$ & $0.094 \pm 0.019$ & -0.44 & 29.68 & -7.06 & 40.94 & 20.39 \\
\hline
\end{tabular}

*: Denotes grid quality biomethane was achieved; $\zeta$ : Denotes process responses using larger-the-better (LB) criteria; $\S$ : Denotes process responses using smaller-the-better (SB) criteria.

Operating between $\mathrm{pH}$ of 10 and 11 , temperatures of $25^{\circ} \mathrm{C}$ and $35^{\circ} \mathrm{C}$ and $\mathrm{L} / \mathrm{G}$ ratios of 0.05 and $0.16, \mathrm{k}_{\mathrm{G}_{\mathrm{CO}_{2}}}$ a extended from $54 \mathrm{~h}^{-1}$ to $154.8 \mathrm{~h}^{-1}$, while the lowest and the highest absorption rates were $1.03 \times 10^{-4} \mathrm{~mol} / \mathrm{L} / \mathrm{s}$ and $2.13 \times 10^{-4}$ $\mathrm{mol} / \mathrm{L} / \mathrm{s}$, respectively; the higher values recorded at higher $\mathrm{pH}$ and temperature. It must be mentioned here that as the $\mathrm{CO}_{2}$ absorption reaction is primarily driven by carbonate-derived $[\mathrm{OH}]^{-}$ions (Hikita et al., 1976; Knuutila et al., 2010), the comparison with $\mathrm{NaOH}$ is reasonable. These comparisons were concluded as sufficient to validate the bubble column operations and measurement techniques for acceptable prediction of the experimental outcomes.

\subsection{Adequacy of the experimental design}

The result of the design adequacy test as explained in Section 2.3.6 is summarised in Table 5. For each process response, the chosen 15 factors (seven main effects and eight interactions) were able to account for at least over $90 \%$ of the variations in each process response. $\mathrm{CO}_{2}$ removal efficiency and absorption rates were almost sufficiently described, with an unknown variation of less than $0.5 \%$ in the outcome. However, to describe the hydrodynamic aspect of $\mathrm{CO}_{2}$ absorption, a few other variables might be 
Table 5 .

Results of ANOVA for each process response considering each replicate as a separate experimental trial as an adequacy test of the designed screening experiment.

\begin{tabular}{|c|c|c|c|c|c|}
\hline Regression parameters & $\mathrm{R}_{\mathrm{eff}, \mathrm{CO}_{2}}(\%)$ & $\mathrm{R}_{\mathrm{abs}, \mathrm{CO}_{2}}\left(\times 10^{-4} \mathrm{~mol} / \mathrm{L} / \mathrm{s}\right)$ & $\mathbf{k}_{\mathrm{G}_{\mathrm{CO}_{2}}} \mathbf{a}\left(\mathbf{h}^{-1}\right)$ & $\mathbf{O}_{2, \mathrm{BM}}(\%)$ & $\mathbf{O}_{2, \mathrm{BM}}\left(\mathrm{mL}_{\mathrm{n}} / \mathrm{min}\right)$ \\
\hline Total DoF & 47 & 47 & 47 & 47 & 47 \\
\hline Model DoF & 15 & 15 & 15 & 15 & 15 \\
\hline Error DoF & 32 & 32 & 32 & 32 & 32 \\
\hline Explained variations (Model contribution) $(\%)$ & 99.72 & 99.86 & 90.78 & 92.09 & 95.76 \\
\hline Unexplained variations (\%) & 0.28 & 0.14 & 9.22 & 7.91 & 4.24 \\
\hline Model F value & $762.26(\mathrm{P}<0.001)$ & $1520.37(\mathrm{P}<0.001)$ & $21.01(\mathrm{P}<0.001)$ & $25.02(\mathrm{P}<0.001)$ & $48.22(\mathrm{P}<0.001)$ \\
\hline
\end{tabular}

$\mathbf{a}$

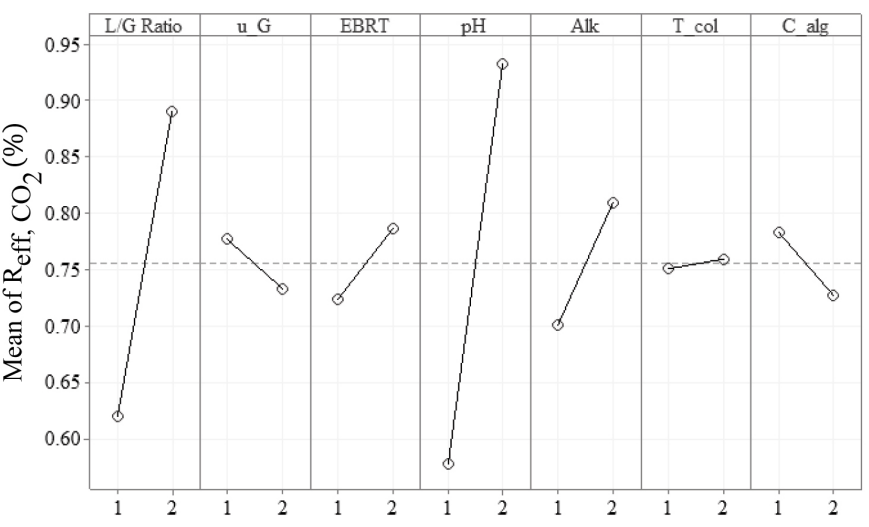

c

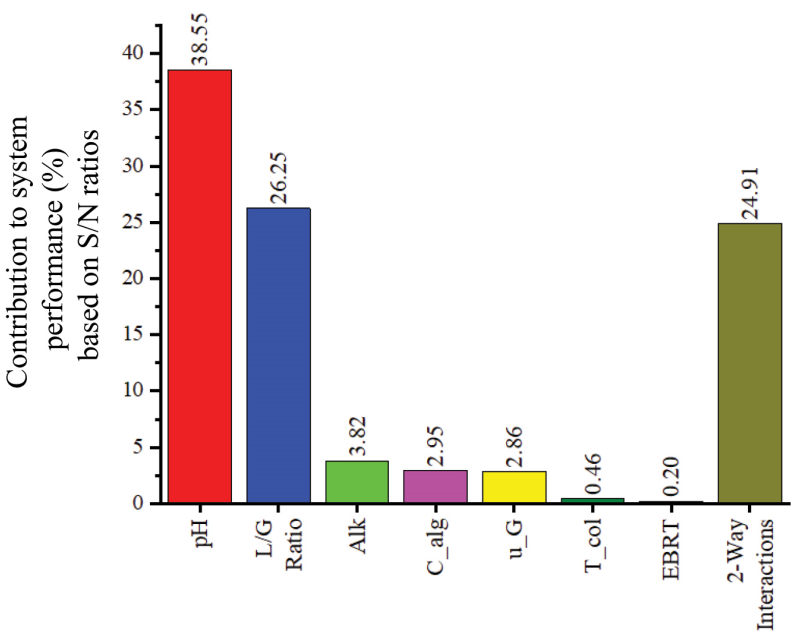

b

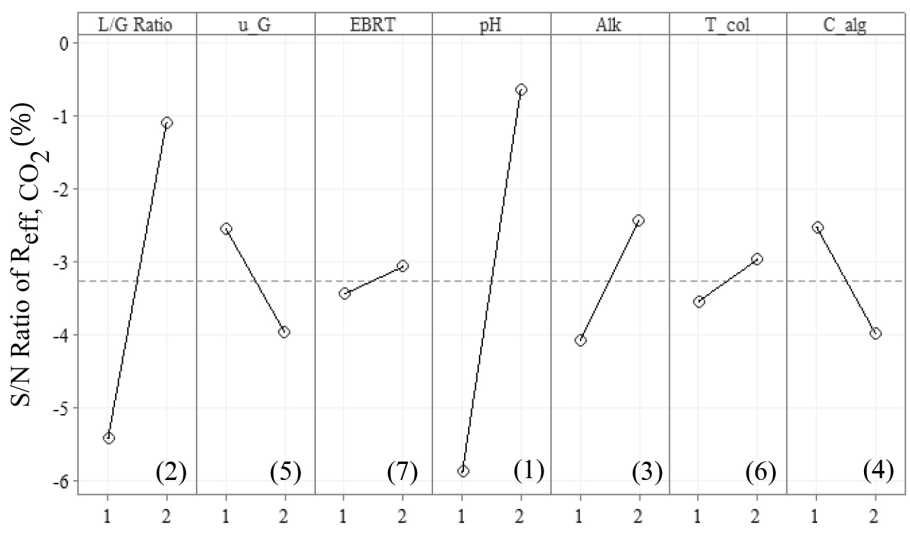

d

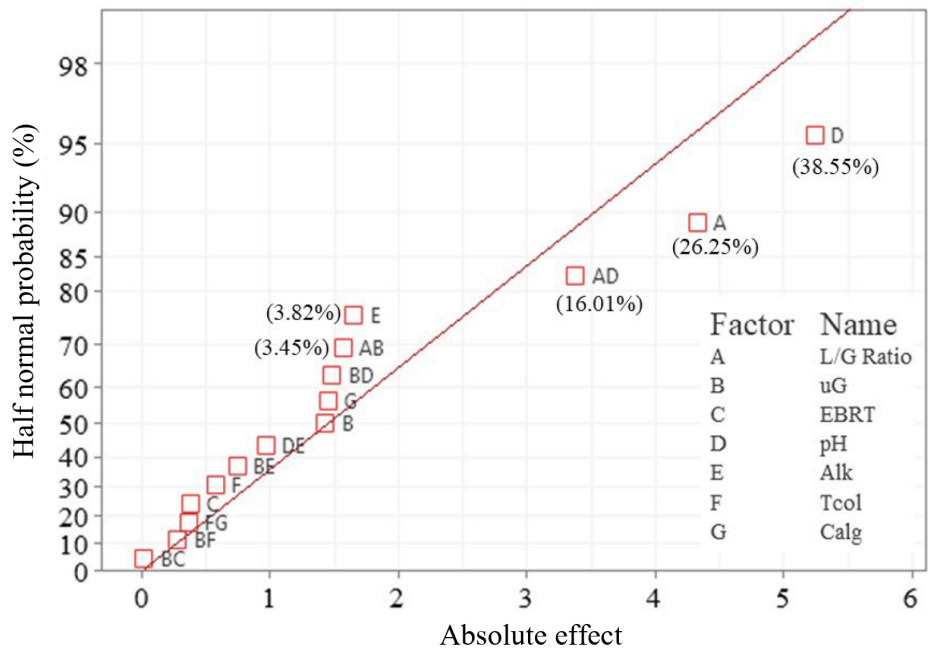

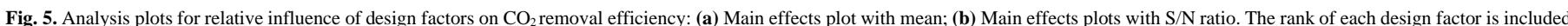

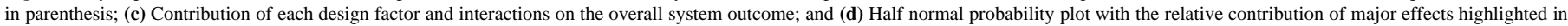
brackets.

required to explain the remaining $9.22 \%$ of the system fluctuations. The chosen screening design was able to explain over $92 \%$ of the variations for $\mathrm{O}_{2}$ stripping during biogas upgrading.

From a statistical perspective, the $\mathrm{F}$ values of the fit models were also much higher than the critical F-value $\left(\mathrm{F}_{0.05(15,32)}\right)(\mathrm{k}=16$ including the constant and $\mathrm{N}=48$ from 16 triplicated experiments) of 1.99 at a $95 \%$ confidence level with a corresponding $\mathrm{P}$ value less than 0.001 . This indicates the statistical significance of the selected main effects and interactions to describe the bubble column performance in photosynthetic biogas upgrading (Shah et al., 2013).

\subsection{Results of the screening design of experiments}

The following section summarises the results from the Taguchi OA for each process response describing $\mathrm{CO}_{2}$ removal and $\mathrm{O}_{2}$ stripping in the bubble column.

\subsection{1. $\mathrm{CO}_{2}$ removal efficiency $\left(\mathrm{R}_{\text {eff, } \mathrm{CO}_{2}}\right)$}

Figure 5a shows the main effects plot with mean $\mathrm{CO}_{2}$ removal efficiency $\left(R_{\text {eff. } \mathrm{CO}_{2}}\right)$. The highest variation in the mean response was 
obtained from the variation of $\mathrm{pH}$, closely followed by that due to the $\mathrm{L} / \mathrm{G}$ ratio. For both these factors, a higher setting increases the mean response, i.e., improves the $\mathrm{CO}_{2}$ removal efficiency. Higher alkalinity and empty bed residence time were also found to increase the $\mathrm{CO}_{2}$ removal efficiency signifying a lower average $\mathrm{CO}_{2}$ content in the upgraded biomethane. Between $20{ }^{\circ} \mathrm{C}$ (factor level "1") and $35^{\circ} \mathrm{C}$ (factor level "2"), temperature caused a negligible increase in $R_{\text {eff, } \mathrm{CO}_{2}}$, closely resembling the results presented by Chen et al. (2015). On the other hand, an increase in superficial gas velocity and algal concentration decreased the $\mathrm{CO}_{2}$ removal efficiency.

A study of the main effects plot of the $\mathrm{S} / \mathrm{N}$ ratio in Figure $5 \mathrm{~b}$ also reveals a similar trend for the design factors. Operations at a higher $\mathrm{pH}, \mathrm{L} / \mathrm{G}$ ratio, alkalinity, and temperature setting would result in more robust operations (higher S/N ratios). The effect of EBRT on the system fluctuations was minimal (minimal variation in the $\mathrm{S} / \mathrm{N}$ ratio). An increased superficial gas velocity and algal concentration would cause larger system variabilities (lower $\mathrm{S} / \mathrm{N}$ ratios and negative slope of the main effects plot). Comparing variation of the $\mathrm{S} / \mathrm{N}$ ratio corresponding to each main effect (Fig. 5b), $\mathrm{pH}$ was found to be the most influential factor towards the efficiency of $\mathrm{CO}_{2}$ removal from biogas followed by $\mathrm{L} / \mathrm{G}$ ratio and alkalinity. These are followed by microalgae concentration and superficial gas velocity, however, as explained before, in a negative way. Temperature and EBRT were obtained as the two of the least affecting factors in the selected experimental regime to affect the removal efficiency of $\mathrm{CO}_{2}$

The quantification of the rankings and influences provided in Figure $5 c$ shows the contribution of the different main effects and the two-way interactions (pooled together) towards the process response $\left(\mathrm{CO}_{2}\right.$ removal efficiency). Matching the observations from the main effects plots, $\mathrm{pH}$ was found to account for $38.55 \%$ of the variations in the $\mathrm{CO}_{2}$ removal efficiencies followed by $\mathrm{L} / \mathrm{G}$ ratio $(26.25 \%)$ and alkalinity $(3.82 \%)$. Interactions were found to play a major role, whereby they were responsible for almost $25 \%$ of the system variations. To obtain a further detailing of the results, a half normal probability plot (Fig. 5d) was used to demonstrate the influence of the fifteen factors (seven main effects and eight interactions). In it, the factors that have the highest influence on the process response and are also statistically significant $(\mathrm{P}<0.05)$ usually lie further away from linearity, indicated by the straight line with a $45^{\circ}$ slope (Ganapathy et al., 2009; Myers et al., 2017). As expected, $\mathrm{pH}$ and $\mathrm{L} / \mathrm{G}$ ratio can be seen to be located furthest away from the $45^{\circ}$ linearity. Moreover, it can be clearly interpreted that of all the interactions, the interaction between $\mathrm{pH}$ and $\mathrm{L} / \mathrm{G}$ ratio had the highest influence (above 16\%) on the efficiency of $\mathrm{CO}_{2}$ removal. Alkalinity and the interactions of superficial gas velocity with $\mathrm{pH}$ and $\mathrm{L} / \mathrm{G}$ ratio could also be seen to deviate somewhat from linearity, indicating their possible influence on the process response. All other factors being nearer to the $45^{\circ}$ line could be concluded to have a minimal influence on the efficiency of $\mathrm{CO}_{2}$ removal from biogas.

Table 6.

Results of ANOVA assessment for $\mathrm{CO}_{2}$ removal efficiency with main effects and interaction contributing over $95 \%$ towards the output response.

\begin{tabular}{lcccccc}
\hline Source & DoF & Adj SS & Adj MS & F-Value & P-Value & $\begin{array}{c}\text { Contribution } \\
(\%)\end{array}$ \\
\hline $\mathrm{pH}^{*}$ & 1 & 110.024 & 110.024 & 88.92 & $<0.001$ & 38.55 \\
$\mathrm{~L} / \mathrm{G}^{*}$ & 1 & 74.911 & 74.911 & 60.54 & $<0.001$ & 26.25 \\
$\mathrm{~L} / \mathrm{G} v s . \mathrm{pH}^{*}$ & 1 & 45.692 & 45.692 & 36.93 & 0.001 & 16.01 \\
$\mathrm{Alk}^{*}$ & 1 & 10.893 & 10.893 & 8.8 & 0.021 & 3.82 \\
$\mathrm{~L} / \mathrm{G} v s . \mathrm{u}_{\mathrm{G}}{ }^{*}$ & 1 & 9.842 & 9.842 & 7.95 & 0.026 & 3.45 \\
$\mathrm{u}_{\mathrm{G}}$ vs. $\mathrm{pH}^{*}$ & 1 & 8.773 & 8.773 & 7.09 & 0.032 & 3.07 \\
$\mathrm{C}_{\text {alg }}{ }^{*}$ & 1 & 8.425 & 8.425 & 6.81 & 0.035 & 2.95 \\
$\mathrm{u}_{\mathrm{G}}{ }^{*}$ & 1 & 8.159 & 8.159 & 6.59 & 0.037 & 2.86 \\
Pooled error $^{*}$ & 7 & 8.661 & 1.237 & - & - & 3.03 \\
Cumulative total & 15 & 285.38 & - & - & - & - \\
\hline
\end{tabular}

${ }^{*}$ Denotes the statistically significant $(\mathrm{P}<0.05)$ source (factors).
To confirm the above hypothesis, a pooled ANOVA was performed; the results are indicated in Table 6 . As can be seen, all the main effects of $\mathrm{pH}$, $\mathrm{L} / \mathrm{G}$ ratio, alkalinity, superficial gas velocity, and algal concentration were found to be statistically significant $(\mathrm{P}<0.05)$. The statistically significant interactions to affect $\mathrm{CO}_{2}$ removal efficiency were those between $\mathrm{pH}$ and $\mathrm{L} / \mathrm{G}$ ratio and between superficial gas velocity and $\mathrm{pH}$ and $\mathrm{L} / \mathrm{G}$ ratio.
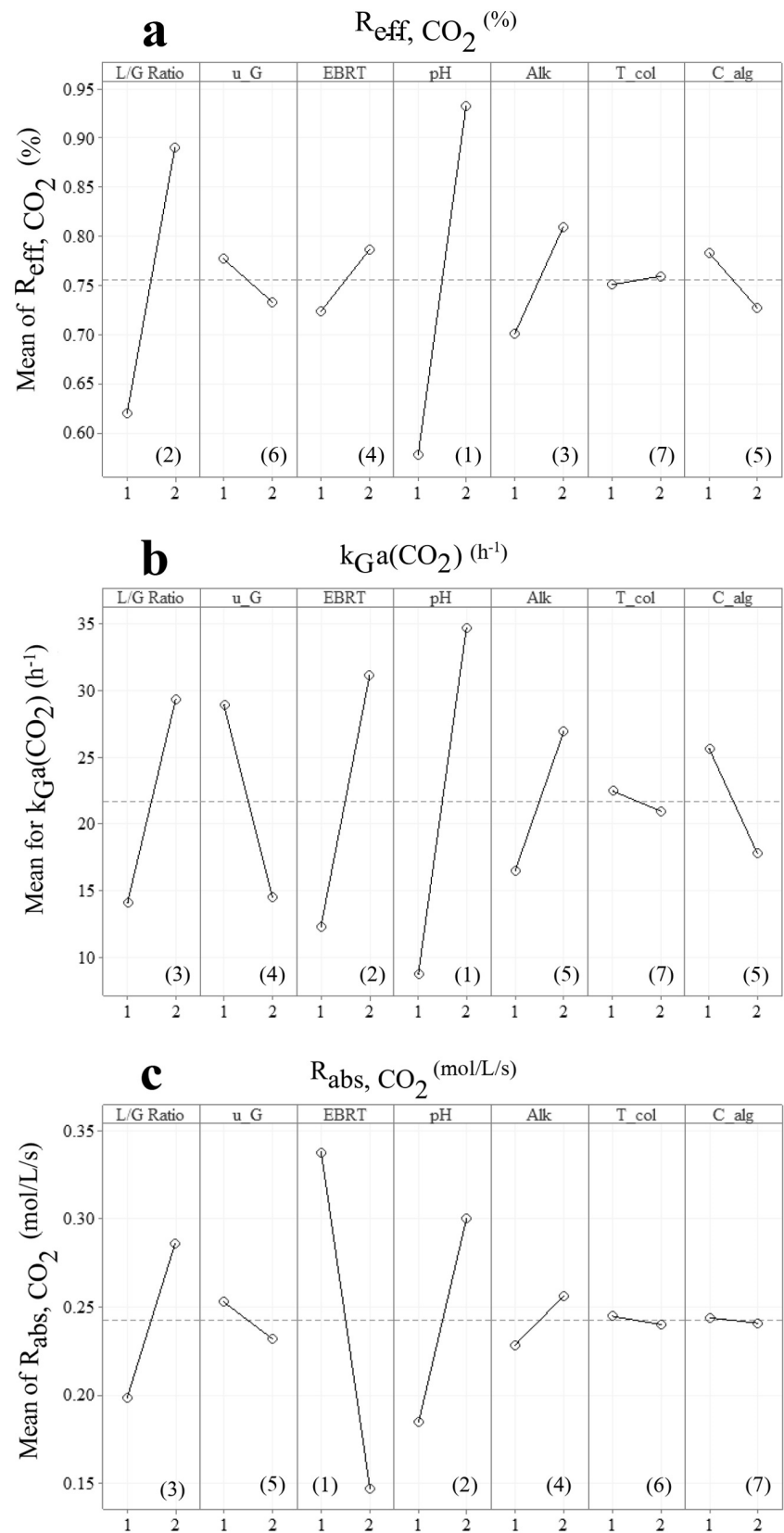

Fig. 6. Interactive effects between (a) $\mathrm{pH}$ and $\mathrm{L} / \mathrm{G}$ ratio; (b) superficial gas velocity $\left(\mathrm{u}_{\mathrm{G}}\right)$ and $\mathrm{pH}$; and $(\mathbf{c})$ superficial gas velocity $\left(\mathrm{u}_{\mathrm{G}}\right)$ and $\mathrm{L} / \mathrm{G}$ ratio on $\mathrm{CO}_{2}$ removal efficiency.

Figure 6 shows the statistically significant $(\mathrm{P}<0.05)$ interactions affecting $\mathrm{CO}_{2}$ removal efficiency. For the interactive effect between $\mathrm{L} / \mathrm{G}$ ratio and $\mathrm{pH}$, depicted in Figure 6a, at lower $\mathrm{pH}$ levels $(\mathrm{pH} 9$, factor level of " 1 "), $\mathrm{L} / \mathrm{G}$ ratio can be seen to have a greater influence on the performance of the $\mathrm{CO}_{2}$ removal efficiency (higher variation in the $\mathrm{S} / \mathrm{N}$ ratio). 
a

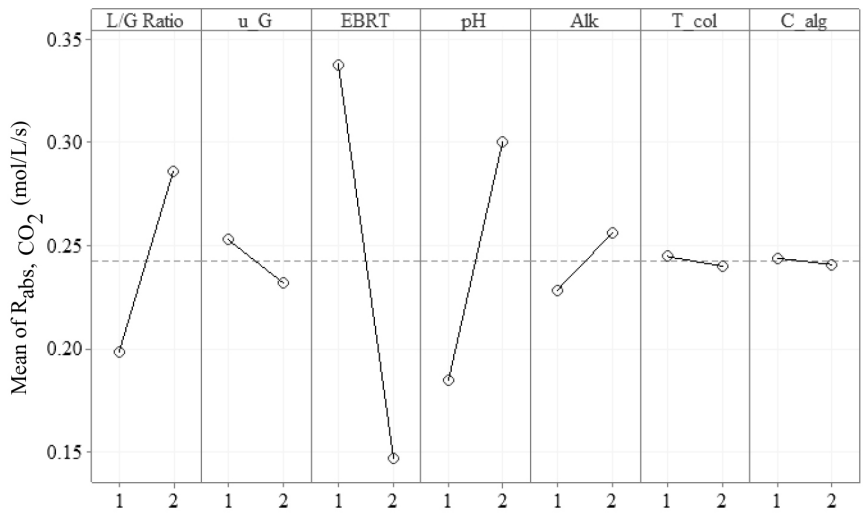

c

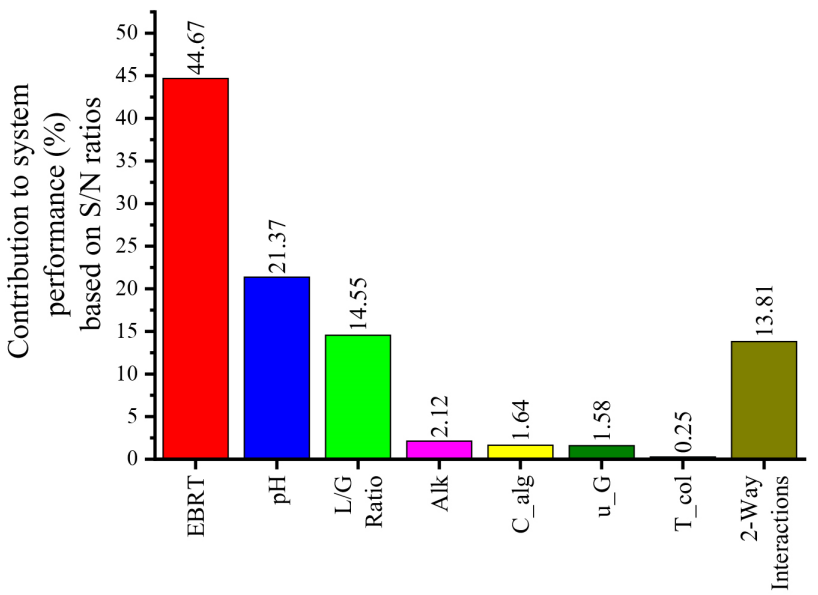

b

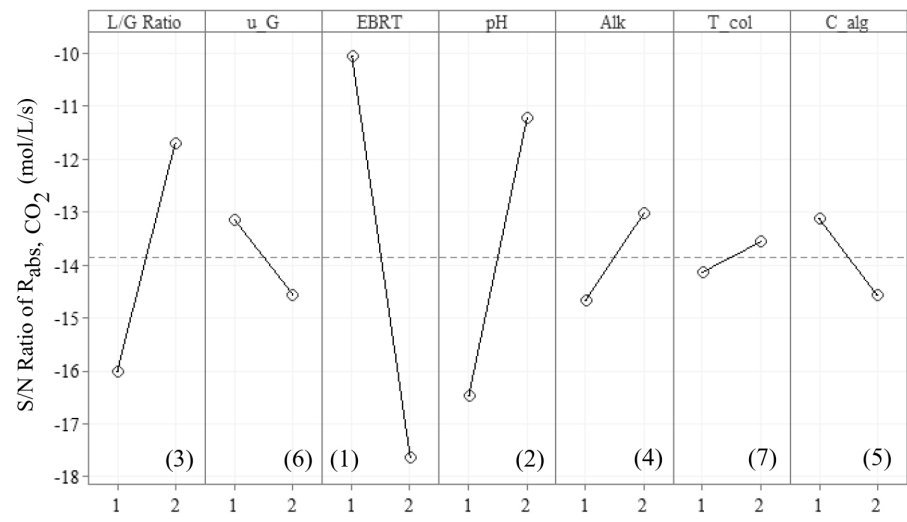

d

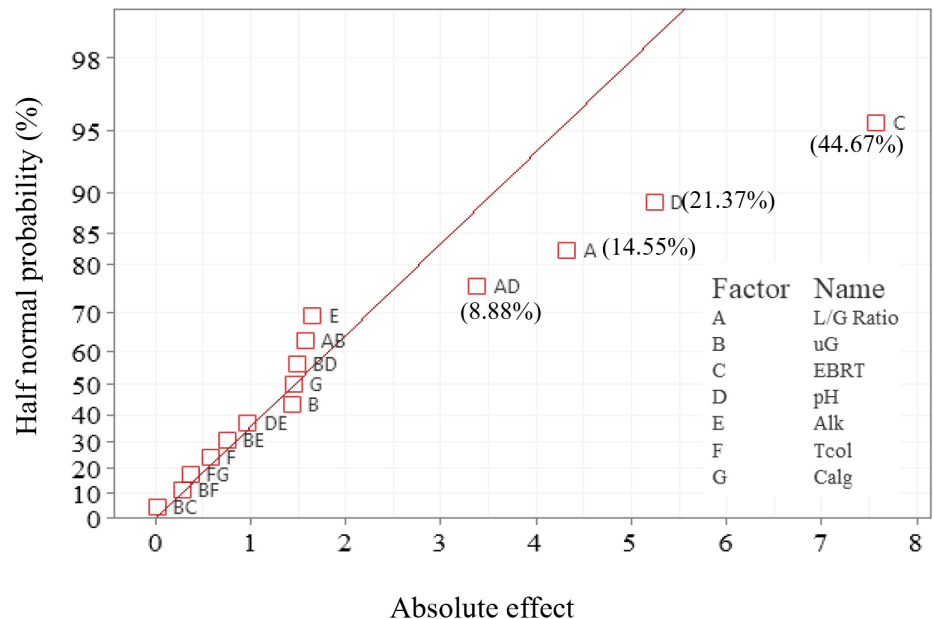

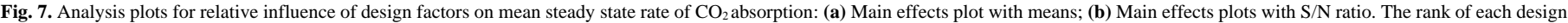

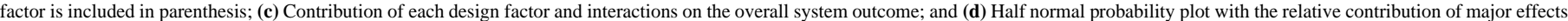
highlighted in brackets.

Accordingly, to reduce the operating $\mathrm{pH}$, the $\mathrm{L} / \mathrm{G}$ ratio must be increased to ensure effective $\mathrm{CO}_{2}$ removal performance, i.e., ensure a higher $\mathrm{S} / \mathrm{N}$ ratio. However, under high $\mathrm{pH}$ levels (pH 10.5, factor level of "2"), much more flexibility in operation with regards to $\mathrm{L} / \mathrm{G}$ ratio can be envisaged. Indeed, as can be seen from Figure 6a, even at a low L/G of 0.2 ratio (factor level "1"), a $\mathrm{pH}$ of 10.5 (factor level "2") would ensure a high $\mathrm{CO}_{2}$ removal efficiency indicated by higher system robustness or $\mathrm{S} / \mathrm{N}$ ratio. The subsequent increase in the system performance on increasing the L/G ratio to 1 (factor level "2") would hence be minimal.

Respectively, Figures $6 \mathrm{~b}$ and $\mathrm{c}$ reveal that both a high $\mathrm{pH}$ and a high $\mathrm{L} / \mathrm{G}$ ratio would allow the superficial gas velocity and hence the gas flow rate to be increased without a substantial drop in $\mathrm{CO}_{2}$ removal efficiency and hence the robustness of the bubble column operations. Of course, this is assuming the fact that all other effects not included in the interaction are set at the desirable set points that will maximise the $\mathrm{S} / \mathrm{N}$ ratio (for example, alkalinity at $2.5 \mathrm{~g}-\mathrm{IC} / \mathrm{L}$ and algal concentration at $0.05 \mathrm{~g}-\mathrm{DW} / \mathrm{L}$ ). In comparison, at lower $\mathrm{pH}$ and $\mathrm{L} / \mathrm{G}$ ratios, the superficial gas velocity would cause larger fluctuations in the $\mathrm{S} / \mathrm{N}$ ratio, lowering the $\mathrm{CO}_{2}$ removal efficiency to the extent that grid quality biomethane might no longer be obtained.

\subsubsection{Mean steady state $\mathrm{CO}_{2}$ absorption rate $\left(\mathrm{R}_{a b s, \mathrm{CO}_{2}}\right)$}

Similar to the discussion above, for the mean steady state $\mathrm{CO}_{2}$ absorption rate $\left(R_{a b s, \mathrm{CO}_{2}}\right)$, Figures 7a-d lead to the conclusion that EBRT is the most influential design factor. To understand this result, it must be understood that $R_{a b s, C O}$ signifies a lumped estimate of the kinetics of $\mathrm{CO}_{2}$ absorption in the algal buffer solution. A large drop in the mean $R_{a b s, \mathrm{CO}_{2}}$ at a higher EBRT, therefore, indicates a non-linear $\mathrm{CO}_{2}$ absorption reaction along the length of the bubble column, with a rapid drop in the absorption rates along the height of the column. Correspondingly, the system also becomes more susceptible to uncontrollable variabilities, indicated by a drop in the $\mathrm{S} / \mathrm{N}$ ratio (Fig. 7b). Nonetheless, for a specific bubble column with a fixed height of liquid column and hence a fixed EBRT, $\mathrm{pH}$ would have the largest positive influence followed by $\mathrm{L} / \mathrm{G}$ ratio on $R_{a b s, C O}$. Similar to $\mathrm{CO}_{2}$ removal efficiencies, a higher setting of these design factors would thus yield both better performance (Fig. 7a, mean of response increases as the factor level increases) and more replicable responses (Fig. 7b, S/N ratio increases as factor level increases). Figure $7 \mathrm{c}$ confirms the ranking of factors showing their percentage contributions towards the process response. Additionally, the half normal probability plot in Figure 7d high- 
lights the importance of the interaction between $\mathrm{pH}$ and $\mathrm{L} / \mathrm{G}$ ratio on influencing the current process response.

The confirmatory ANOVA test in Table 7 with factors affecting $95 \%$ of the variations in mean $\mathrm{CO}_{2}$ absorption rate, revealed that $\mathrm{EBRT}, \mathrm{pH}$, and $\mathrm{L} / \mathrm{G}$ ratio, and the interaction between $\mathrm{pH}$ and $\mathrm{L} / \mathrm{G}$ ratio, were the only statistically significant $(\mathrm{P}<0.05)$ factors. Thus, to optimise $R_{a b s, \mathrm{CO}_{2}}$ in a specific bubble column (fixed EBRT), $\mathrm{pH}$ and $\mathrm{L} / \mathrm{G}$ ratio would be sufficient to describe the system kinetics.

The only statistically significant $(\mathrm{P}<0.05)$ interactive effect between $\mathrm{pH}$ and $\mathrm{L} / \mathrm{G}$ ratio had a similar profile to that presented in Figure 6a for $\mathrm{CO}_{2}$ removal efficiency (and hence not shown). Therefore, for a lower operating $\mathrm{pH}$, to increase $R_{a b s, \mathrm{CO}_{2}}, \mathrm{~L} / \mathrm{G}$ ratio must be high. However, a higher $\mathrm{pH}$ would ensure a high $R_{a b s, \mathrm{CO}_{2}}$ irrespective of the influence of the $\mathrm{L} / \mathrm{G}$ ratio varying between 0.2 (factor level "1") and 1 (factor level "2").

\subsubsection{Mean overall $\mathrm{CO}_{2}$ mass transfer coefficient $\left(k_{\mathrm{GO}_{2}}\right.$ a)}

Following similar arguments as discussed above, it can be concluded from Figures 8a-d that $\mathrm{pH}$ had the highest influence on the mean overall $\mathrm{CO}_{2}$ mass transfer coefficient, a measure of the hydrodynamic performance of the $\mathrm{CO}_{2}$ absorption in the alkaline algal medium. This is followed (in order) by superficial gas velocity, L/G ratio, EBRT, and alkalinity, which all showed substantial influences on both the mean response and the $\mathrm{S} / \mathrm{N}$ ratio. However, unlike the rest, an increase in the superficial gas velocity was found to lower
Table 7.

Results of ANOVA assessment for mean steady state absorption rate of $\mathrm{CO}_{2}$ with mai effects and interaction contributing over $95 \%$ towards the output response.

\begin{tabular}{lcccccc}
\hline Source & DoF & Adj SS & Adj MS & F-Value & P-Value & $\begin{array}{c}\text { Contribution } \\
(\%)\end{array}$ \\
\hline EBRT $^{*}$ & 1 & 229.965 & 229.965 & 97.45 & $<0.001$ & 44.67 \\
$\mathrm{pH}^{*}$ & 1 & 110.024 & 110.024 & 46.62 & $<0.001$ & 21.37 \\
$\mathrm{~L}_{\mathrm{G}}{ }^{*}$ & 1 & 74.911 & 74.911 & 31.74 & 0.001 & 14.55 \\
$\mathrm{~L} / \mathrm{G} v$ s. $\mathrm{pH}^{*}$ & 1 & 45.692 & 45.692 & 19.36 & 0.003 & 8.88 \\
$\mathrm{Alk}$ & 1 & 10.893 & 10.893 & 4.62 & 0.069 & 2.12 \\
$\mathrm{~L} / \mathrm{G} v s . \mathrm{u}_{\mathrm{G}}$ & 1 & 9.842 & 9.842 & 4.17 & 0.08 & 1.91 \\
$\mathrm{u}_{\mathrm{G}}$ vs. pH & 1 & 8.773 & 8.773 & 3.72 & 0.095 & 1.70 \\
$\quad \mathrm{u}_{\mathrm{G}}$ & 1 & 8.159 & 8.159 & 3.46 & 0.105 & 1.58 \\
Pooled error & 7 & 16.519 & 2.36 & - & - & 3.21 \\
Cumulative total & 15 & 514.778 & - & - & - & 100.00 \\
\hline
\end{tabular}

"Denotes the statistically significant $(\mathrm{P}<0.05)$ source (factors). a
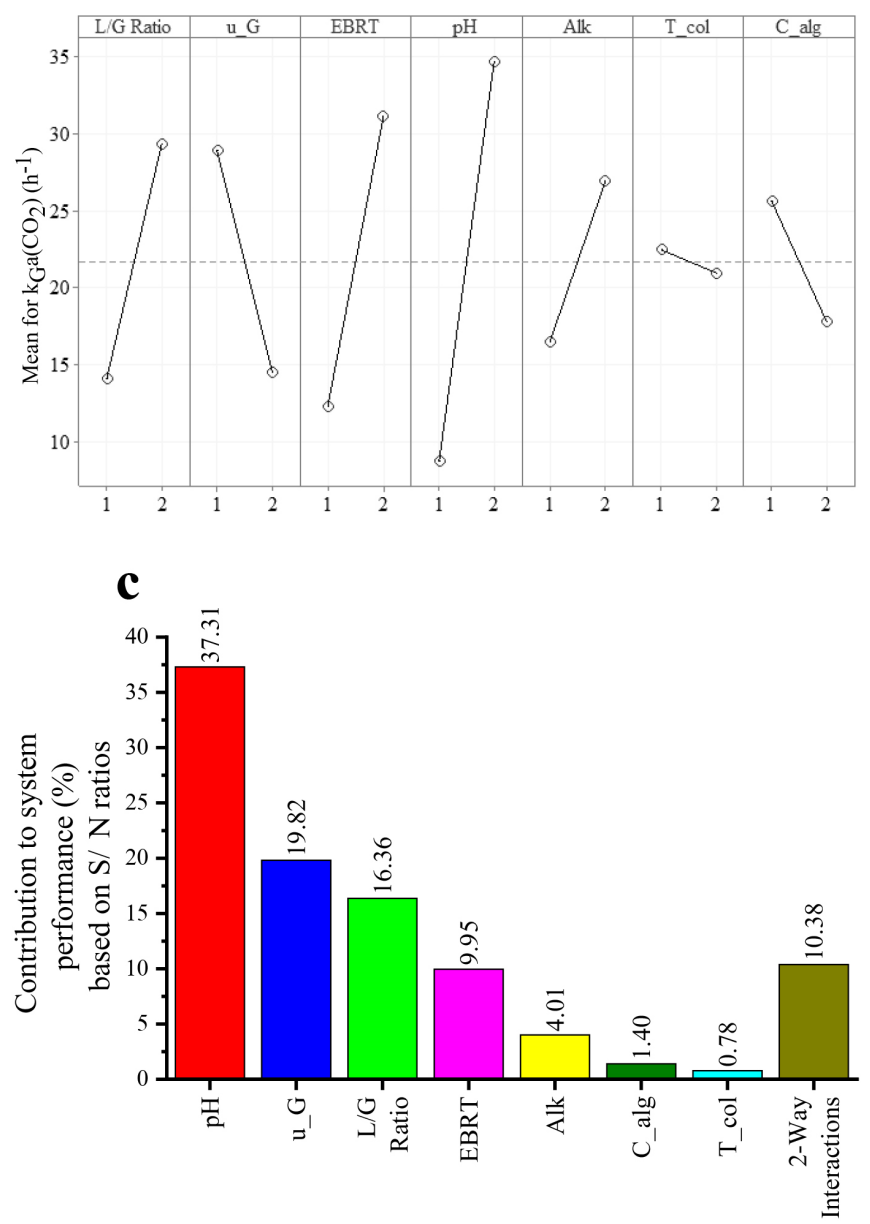

b

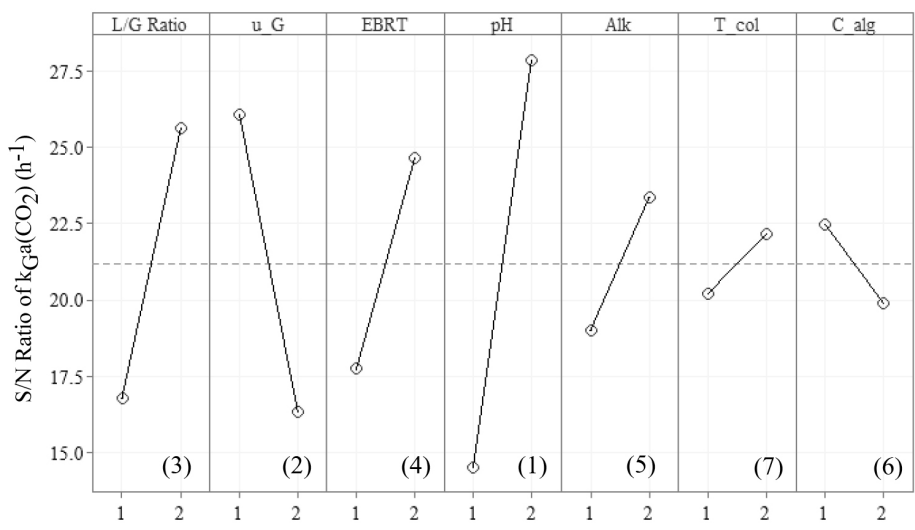

d

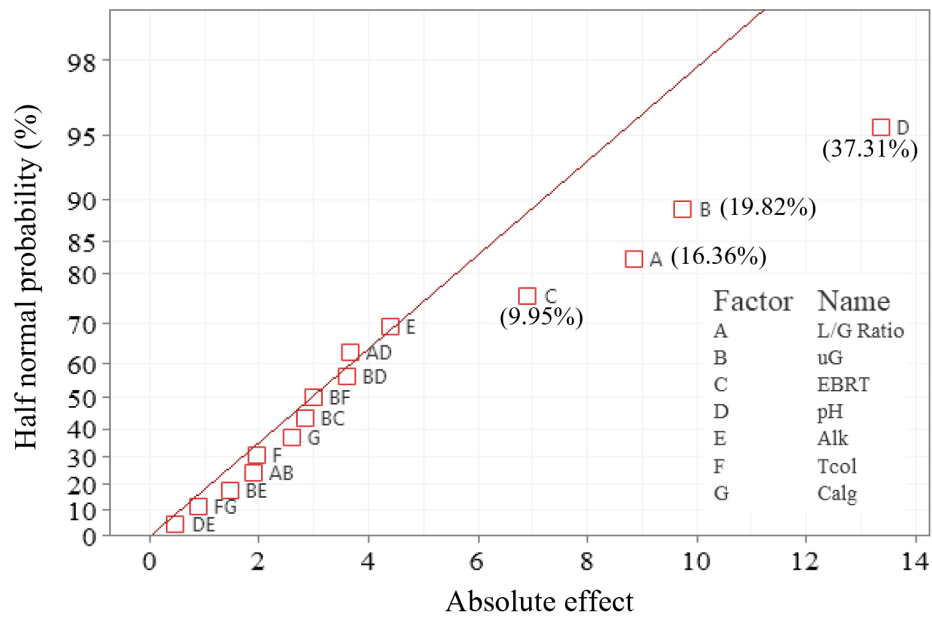

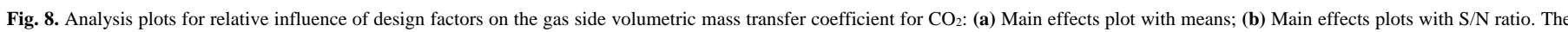

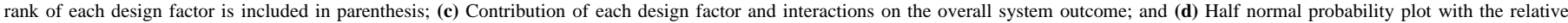
contribution of major effects highlighted in brackets. 
the hydrodynamic performance (a lower $\mathrm{k}_{\mathrm{G}_{\mathrm{CO}_{2}}}$ a, Fig. 8a) and its corresponding resilience (a lower $\mathrm{S} / \mathrm{N}$ ratio, Fig. $8 \mathrm{~b}$ ). Figure $8 \mathrm{c}$ shows the relatively large contributions of $\mathrm{pH}(37.31 \%)$, superficial gas velocity (19.82\%), L/G ratio $(16.36 \%)$, and EBRT $(9.55 \%)$ on the hydrodynamic parameter of $\mathrm{k}_{\mathrm{G}_{\mathrm{CO}_{2}}}$ a. However, although the contribution of alkalinity was substantial (over 4\%, Fig. $8 \mathrm{c}$ ), the half normal probability plot in Figure $8 \mathrm{~d}$ indicated its weak influence on the mean overall $\mathrm{CO}_{2}$ mass transfer coefficient (being located on the $45^{\circ}$ line).

The pooled ANOVA presented in Table 8 nonetheless confirmed the statistical significance $(\mathrm{P}<0.05)$ of the influence of alkalinity, alongside those of $\mathrm{pH}$, superficial gas velocity, L/G ratio and EBRT on the bubble column hydrodynamics with respect to $\mathrm{CO}_{2}$ absorption. None of the other main effects and interactions caused any statistically significant $(\mathrm{P}<0.05)$ variation on the current process response.

\subsection{4. $\mathrm{O}_{2}$ content in biomethane $\left(\mathrm{O}_{2, \%, B M}\right)$}

The $\mathrm{L} / \mathrm{G}$ ratio had by far the largest influence among all other design factors on the $\mathrm{O}_{2}$ content of the upgraded biomethane $\left(\mathrm{O}_{2, \% \text {,BM }}\right)$ (Figs. 9a-d) whereby, a higher setting of $\mathrm{L} / \mathrm{G}$ ratio led to the increase of $\mathrm{O}_{2, \%, \mathrm{BM}}$. Besides $\mathrm{L} / \mathrm{G}$ ratio, $\mathrm{pH}, \mathrm{EBRT}$, and algal concentration increased $\mathrm{O}_{2 \%} \%$ BM (a higher mean response, Fig. 9a) when operated at the higher setting ("2"). On the contrary, both temperature and alkalinity were found to lower $\mathrm{O}_{2 \%}$, BM when increased. The increase of $\mathrm{O}_{2, \%, \mathrm{BM}}$ from an increased superficial gas velocity was minimal. To achieve grid quality biomethane, the aim is to minimise oxygen stripping; however, an increase in the mean process response $\left(\mathrm{O}_{2, \%, \mathrm{BM}}\right)$, would lower

a

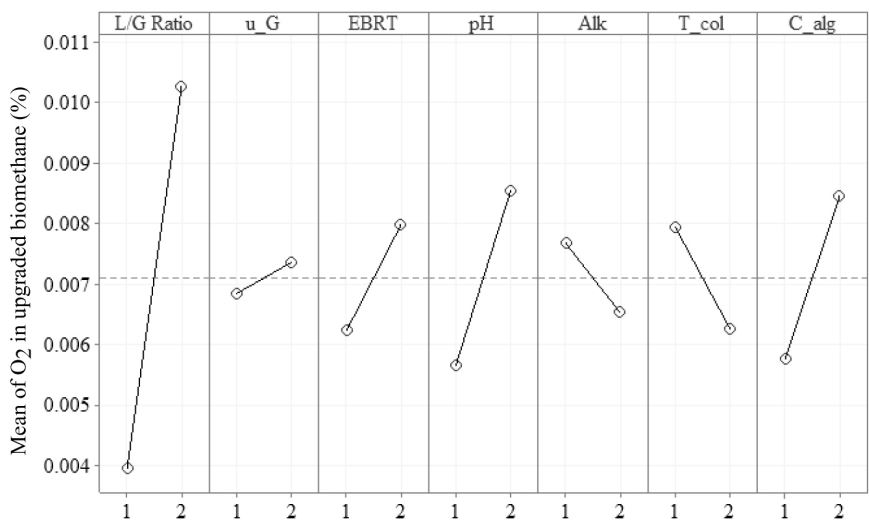

c

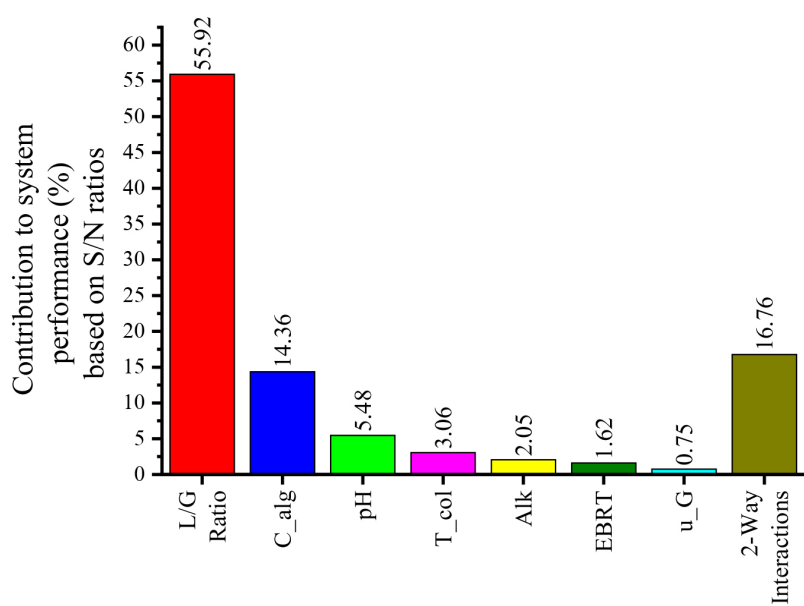

Table 8.

Results of ANOVA assessment for mean overall $\mathrm{CO}_{2}$ mass transfer coefficient with main effects and interaction contributing over $95 \%$ towards the output response.

\begin{tabular}{|c|c|c|c|c|c|c|}
\hline Source & DoF & Adj SS & Adj MS & F-Value & P-Value & $\begin{array}{c}\text { Contribution } \\
(\%)\end{array}$ \\
\hline $\mathrm{pH}^{*}$ & 1 & 715.65 & 715.65 & 67.08 & $<0.001$ & 37.31 \\
\hline $\mathrm{u}_{\mathrm{G}}{ }^{*}$ & 1 & 380.13 & 380.13 & 35.63 & 0.002 & 19.82 \\
\hline $\mathrm{L} / \mathrm{G}^{*}$ & 1 & 313.79 & 313.79 & 29.41 & 0.003 & 16.36 \\
\hline EBRT $^{*}$ & 1 & 190.91 & 190.91 & 17.89 & 0.008 & 9.95 \\
\hline Alk ${ }^{*}$ & 1 & 76.89 & 76.89 & 7.21 & 0.044 & 4.01 \\
\hline $\mathrm{L} / \mathrm{G} v s . \mathrm{pH}$ & 1 & 53.39 & 53.39 & 5 & 0.075 & 2.78 \\
\hline $\mathrm{u}_{\mathrm{G}}$ vs. $\mathrm{pH}$ & 1 & 51.36 & 51.36 & 4.81 & 0.08 & 2.68 \\
\hline $\mathrm{u}_{\mathrm{G}}$ vs. $\mathrm{T}_{\mathrm{col}}$ & 1 & 35.59 & 35.59 & 3.34 & 0.127 & 1.86 \\
\hline $\mathrm{u}_{\mathrm{G}} v s . \mathrm{EBRT}$ & 1 & 32.13 & 32.13 & 3.01 & 0.143 & 1.68 \\
\hline $\mathrm{T}_{\text {col }}$ & 1 & 15.01 & 15.01 & 1.41 & 0.289 & 0.78 \\
\hline Pooled error & 5 & 53.34 & 10.67 & - & - & 2.78 \\
\hline Cumulative total & 15 & 1918.19 & - & - & - & 100 \\
\hline
\end{tabular}

"Denotes the statistically significant $(\mathrm{P}<0.05)$ source (factors).

b

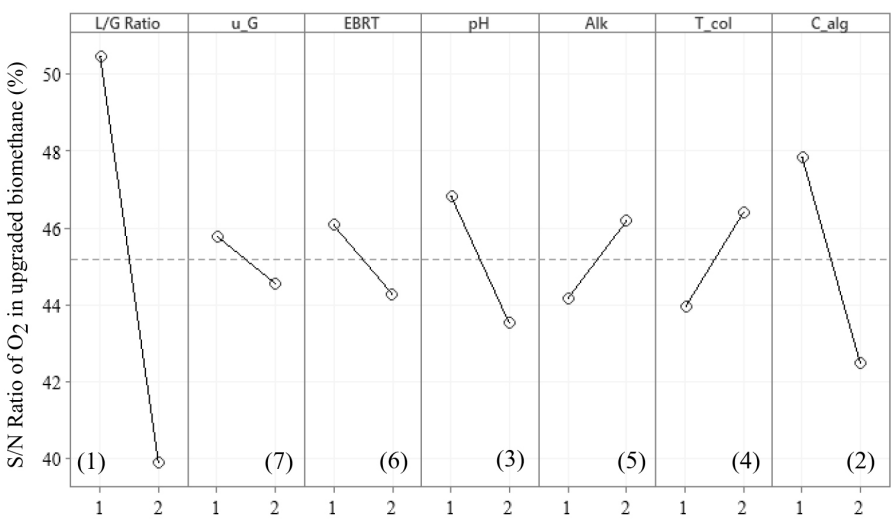

d

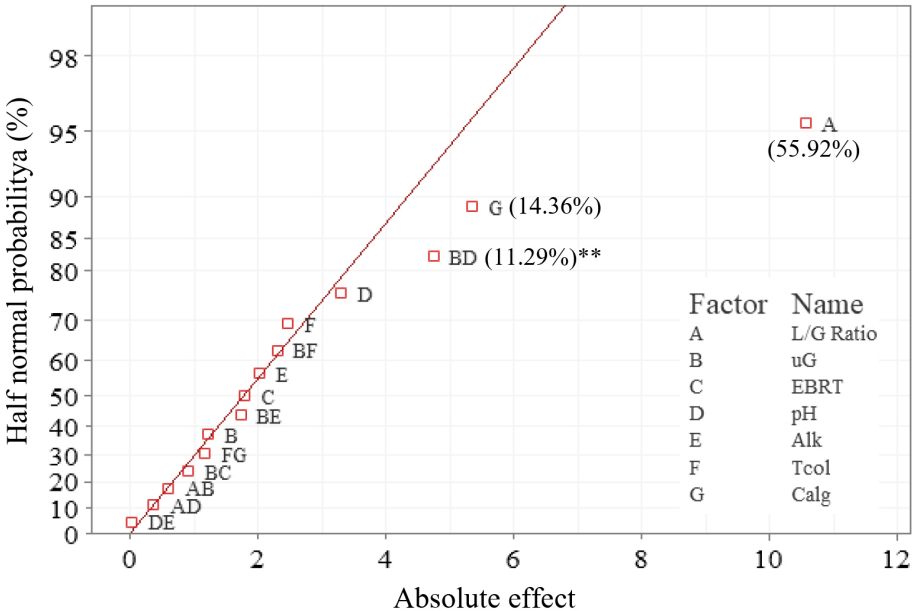

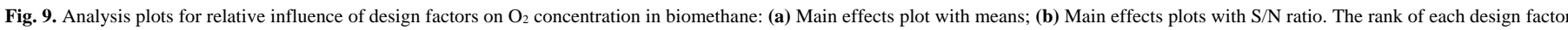

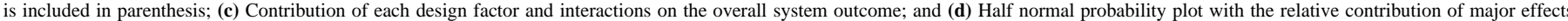
highlighted in brackets. 
the robustness of operation. As a result, unlike the plots for $\mathrm{CO}_{2}$, where the 'larger-the-better' response was desired, the main effects plot with $\mathrm{S} / \mathrm{N}$ ratio for oxygen stripping had an opposite slope to that of the main effects plot with means. Accordingly, the factors such as $\mathrm{L} / \mathrm{G}$ ratio that raised the mean response on their increase, resulted in the drop of $\mathrm{S} / \mathrm{N}$ ratio for the same and vice versa (Fig. 9b). Following L/G ratio, algal concentration was the second most influential design factor, followed by $\mathrm{pH}$. Numerically, they accounted for $55.92 \%, 14.36 \%$, and $5.48 \%$ of the total variations in $\mathrm{O}_{2, \%, \mathrm{BM}}$ (Fig. 9c). All interactions combined caused $16.76 \%$ of the variations in the oxygen concentrations in biomethane.

On further investigation into the half normal probability plot in Figure 9d, the interaction between superficial gas velocity and $\mathrm{pH}$ was obtained as the only major interaction (lying farthest from the $45^{\circ}$ line). However, this is while the contribution of superficial gas velocity was not only low $(0.75 \%$, Fig. $9 \mathrm{c})$ but it can also be seen to be lying over the $45^{\circ}$ line in Figure 9d, indicating its weak statistical significance. To confirm this phenomenon, the pooled ANOVA was performed, including superficial gas velocity to maintain hierarchy. As can be seen from Table 9, while the influence of $\mathrm{pH}$ on the oxygen concentration in biomethane was statistically significant $(\mathrm{P}=0.014)$, that of superficial gas velocity was not $(P=0.252)$. In contrast, their interaction showed a statistically significant effect $(\mathrm{P}=0.003)$, contributing to over $11 \%$ in the variability of the current response (Fig. 9d and Table 9). This can be explained from the alias structure of the designed $\mathrm{L}_{16} \mathrm{OA}$, whereby the interactions between $\mathrm{L} / \mathrm{G}$ and algal concentration were found to be confounded with the interactions between superficial gas velocity and $\mathrm{pH}$ and between EBRT and the bubble column temperature. To solve this issue, the hierarchical model was adopted, whereby the aliased effect can be assigned to the interaction that had both the main effects as statistically significant $(\mathrm{P}<0.05)$ (Myers et al., 2017). Accordingly, the observed statistically significant $(\mathrm{P}<0.05)$ interaction was concluded to be that between the two of the most impactful factors, L/G ratio and algal concentration $(\mathrm{P}<0.001)$. The influence of temperature towards oxygen concentration in upgraded biomethane was also confirmed to be statistically significant $(\mathrm{P}<0.05)$ via the pooled ANOVA (Table 9).

Figure 10a depicts the interactive effect between $\mathrm{L} / \mathrm{G}$ ratio and the algal concentration on the $\mathrm{O}_{2, \%, \mathrm{BM}}$. A higher $\mathrm{S} / \mathrm{N}$ ratio is always desired, as can be followed from Figure 10a, at a lower algal concentration (factor level "1"), $\mathrm{L} / \mathrm{G}$ ratio is the primary influencer of oxygen stripping, with a higher $\mathrm{L} / \mathrm{G}$ ratio signifying a higher $\mathrm{O}_{2, \%, \mathrm{BM}}$. At a higher algal concentration (factor level "2"), however, the relative variation in oxygen stripping between the extreme L/G

Table 9.

Results of ANOVA assessment for $\mathrm{O}_{2}$ content in the upgraded biomethane with main effects and interaction contributing over $95 \%$ towards the output response.

\begin{tabular}{|c|c|c|c|c|c|c|}
\hline Source & DoF & Adj SS & Adj MS & F-Value & p-Value & $\begin{array}{c}\text { Contribution } \\
(\%)\end{array}$ \\
\hline L/G ratio* & 1 & 447.04 & 447.04 & 118.82 & $<0.001$ & 55.92 \\
\hline $\mathrm{C}_{\mathrm{alg}}{ }^{*}$ & 1 & 114.808 & 114.808 & 30.51 & 0.001 & 14.36 \\
\hline $\mathrm{u}_{\mathrm{G}}$ vs. $\mathrm{pH}^{*}$ & 1 & 90.228 & 90.228 & 23.98 & 0.003 & 11.29 \\
\hline $\mathrm{pH}^{*}$ & 1 & 43.779 & 43.779 & 11.64 & 0.014 & 5.48 \\
\hline $\mathrm{T}_{\mathrm{col}}{ }^{*}$ & 1 & 24.457 & 24.457 & 6.5 & 0.044 & 3.06 \\
\hline $\mathrm{u}_{\mathrm{G}}$ vs. $\mathrm{T}_{\mathrm{col}}$ & 1 & 21.215 & 21.215 & 5.64 & 0.055 & 2.65 \\
\hline Alk & 1 & 16.392 & 16.392 & 4.36 & 0.082 & 2.05 \\
\hline EBRT & 1 & 12.963 & 12.963 & 3.45 & 0.113 & 1.62 \\
\hline $\mathrm{u}_{\mathrm{G}}$ & 1 & 6.031 & 6.031 & 1.6 & 0.252 & 0.75 \\
\hline Pooled error & 6 & 22.575 & 3.762 & - & - & 2.82 \\
\hline Cumulative total & 15 & 799.488 & - & - & - & 100 \\
\hline
\end{tabular}

"Denotes the statistically significant $(\mathrm{P}<0.05)$ source (factors).
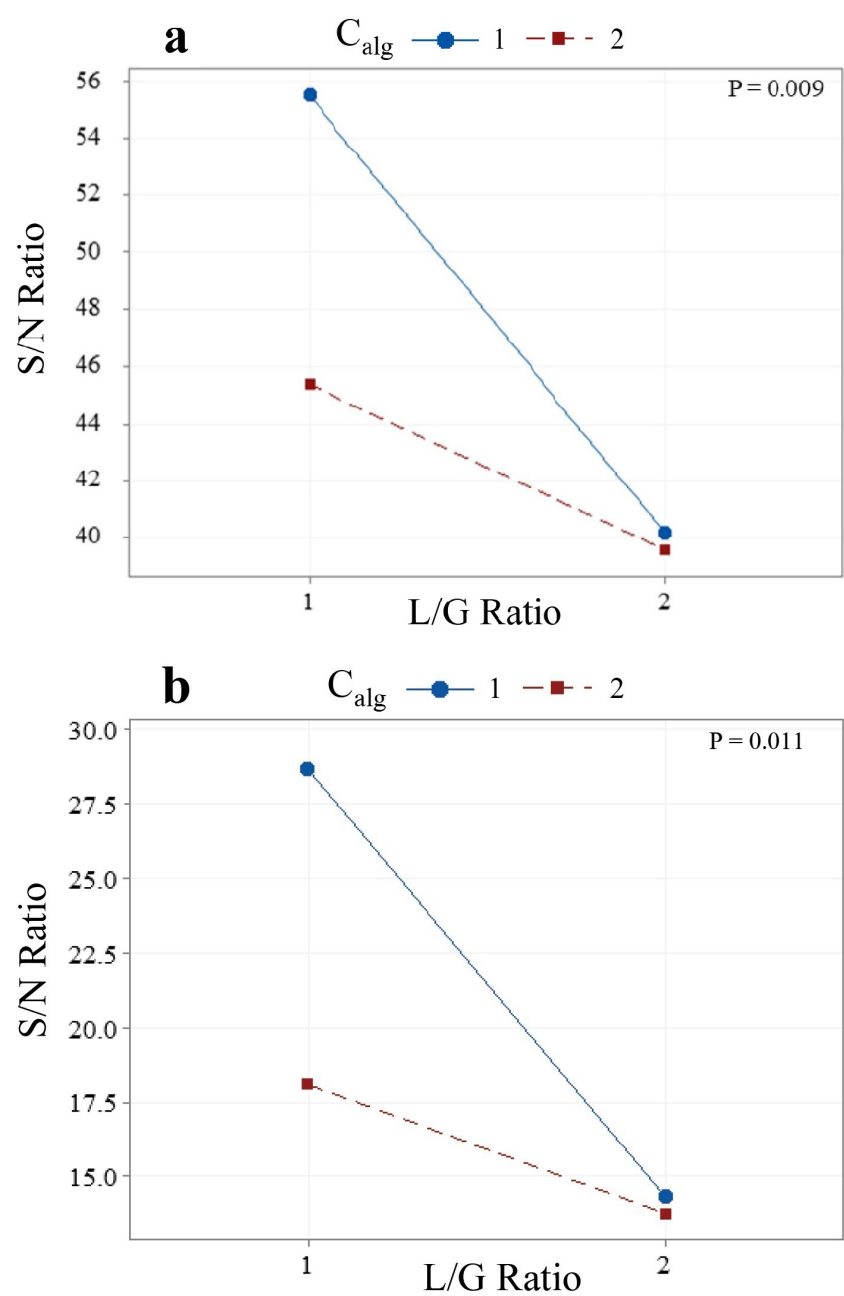

Fig. 10. Interaction between $L / G$ ratio and algal concentration $\left(C_{\text {alg }}\right)$ for $(a) \mathrm{O}_{2}$ concentration in outlet biomethane and (b) $\mathrm{O}_{2}$ outflow rate within upgraded biomethane.

ratios is considerably reduced. Especially at lower L/G ratios (factor level " 1 "), the increased presence of algae plays a major role in oxygen stripping (Fig. 10a), while at higher L/G ratios (factor level "2"), a comparable $\mathrm{O}_{2}$ stripping leading to similar $\mathrm{O}_{2}$ concentrations in biomethane can be noticed irrespective of the algal concentration. This indicates that although the hydrodynamics related to oxygen stripping are greatly affected by the increased presence of algae at lower $\mathrm{L} / \mathrm{G}$ ratios, the effect diminishes largely at higher $\mathrm{L} / \mathrm{G}$ ratios. A plausible explanation could be the relatively large influence of superficial liquid velocities on the system hydrodynamics, including bubble diameter and bubble rise velocity at higher liquid flow rates (Kulkarni and Joshi, 2005) (bubble column diameter being constant). Thus, at higher L/G ratios (factor level "2"), the ensuing biomethane would contain a high concentration of oxygen irrespective of the algal concentration in the circulating liquid.

\subsection{5. $\mathrm{O}_{2}$ outflow within biomethane $\left(\mathrm{O}_{2, B M}\right)$}

Opposite to that observed for $\mathrm{O}_{2, \% \text {,BM }}$, Figures 11a-d reveals that the superficial gas velocity has the strongest proportional influence on the volume of oxygen stripped into the biogas per unit time $\left(\mathrm{O}_{2, \mathrm{BM}}\right)$. The resulting increase of oxygen stripping would inherently cause a decreased performance of the bubble column, indicated by a corresponding drop in the $\mathrm{S} / \mathrm{N}$ ratio on increasing the superficial gas velocity (Fig. 11b). This is 
a

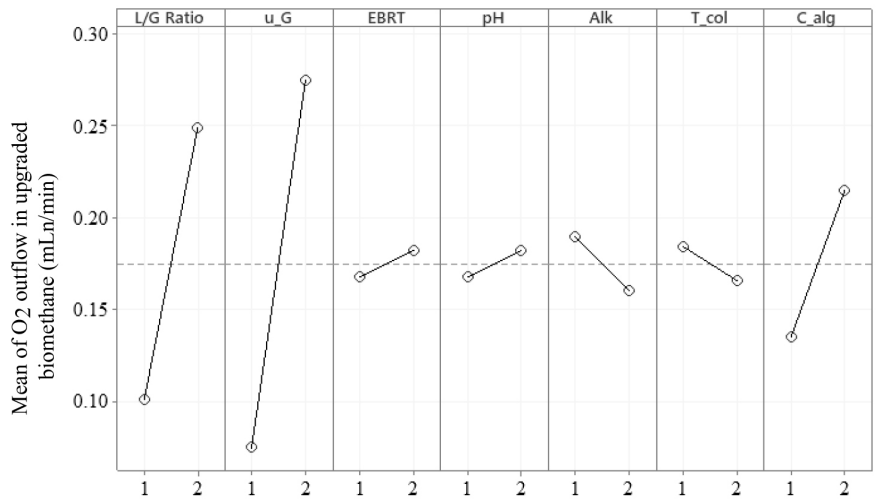

C

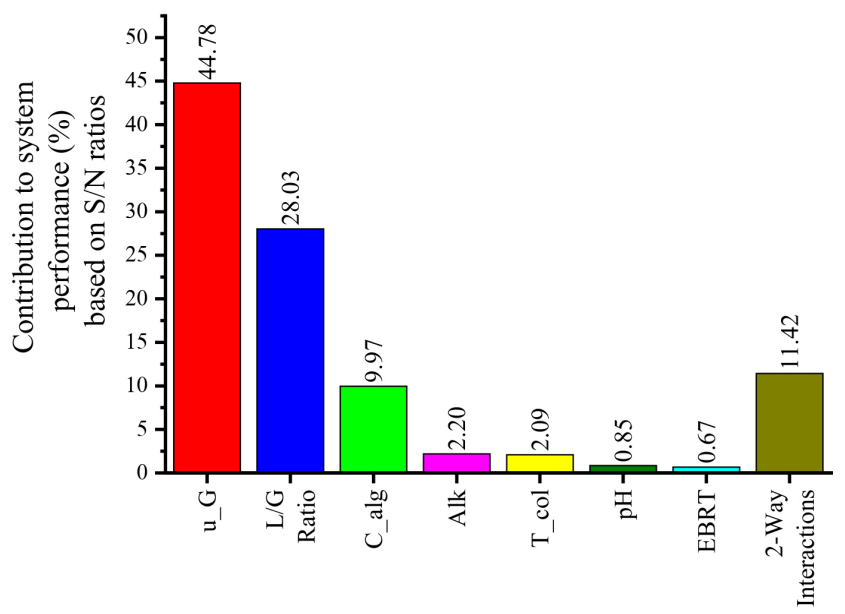

b

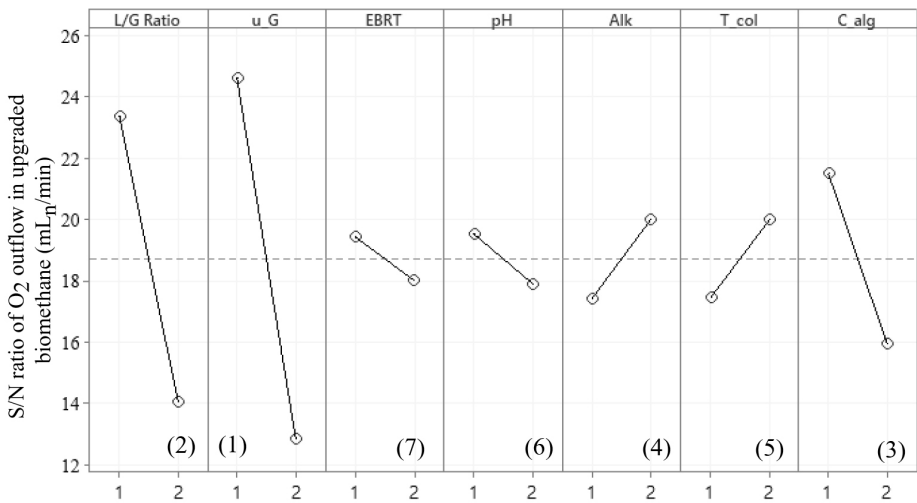

d

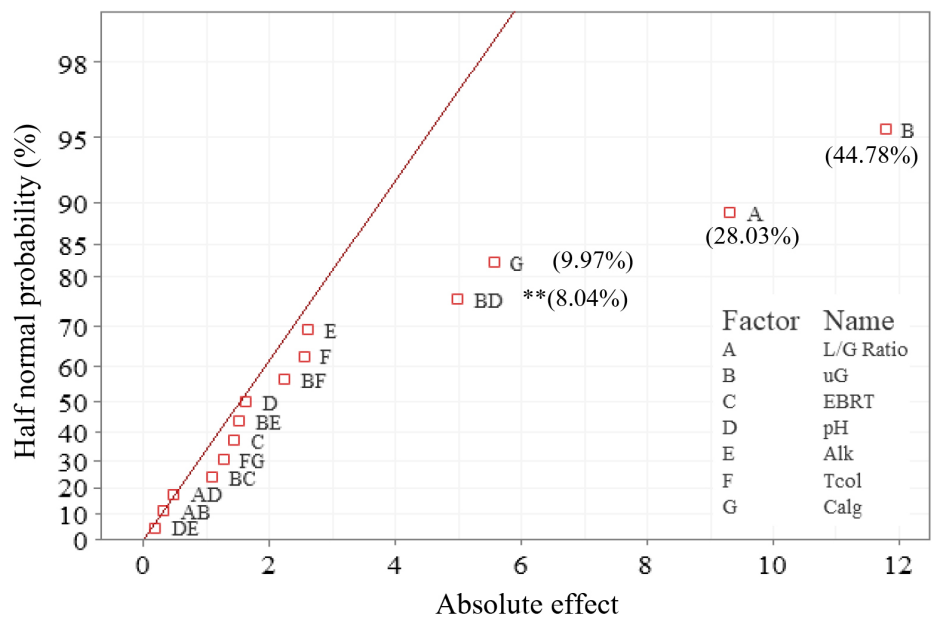

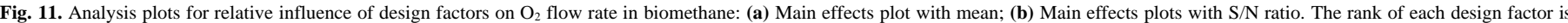

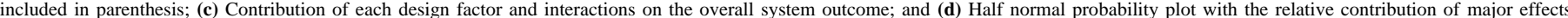
highlighted in brackets.

followed in order by the influence of L/G ratio and algal concentration. EBRT and $\mathrm{pH}$, on the other hand, were seen to only slightly increase the oxygen stripping, while alkalinity and temperature resulted in the lowering of the same (Fig. 11a). On the aspect of contribution, therefore, only superficial gas velocity $(44.78 \%)$, L/G ratio $(28.03 \%)$, and algal concentration $(9.97 \%)$ affected oxygen stripping by more than 5\% (Fig. 11c).

The confirmatory pooled ANOVA established the statistical significance $(\mathrm{P}$ $<0.05$ ) of the three major design factors (superficial gas velocity, L/G ratio,

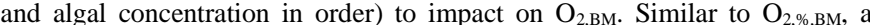
statistically significant $(\mathrm{P}=0.004)$ interaction between superficial gas velocity and $\mathrm{pH}$ was obtained (seen as interaction $\mathrm{BD}$, lying away from the $45^{\circ}$ line in the half normal probability plot in Figure 11d and also confirmed by pooled ANOVA in Table 10). $\mathrm{pH}$, however, had no statistically significant main effect $(\mathrm{P}=0.231)$. By the hierarchical principle adopted above, the interaction was thus concluded to be that of the aliased interaction between the two statistically significant main effects, $L / G$ ratio and algal concentration $(P<0.001)$. The interaction plot shown in Figure 10b shows a similar interactive effect to that of $\mathrm{O}_{2, \%, \mathrm{BM} \text {. }}$

\subsection{Comparison between design factors and significant interactions}

\subsubsection{Main effects}

Grid quality biomethane requires simultaneous maximisation of $\mathrm{CO}_{2}$ removal and minimisation of $\mathrm{O}_{2}$ stripping. As can be seen from Table 11, L/G
Table 10.

Results of ANOVA assessment for $\mathrm{O}_{2}$ outflow with biomethane with main effects and interaction contributing over $90 \%$ towards the output response.

\begin{tabular}{|c|c|c|c|c|c|c|}
\hline Source & DoF & Adj SS & Adj MS & F-Value & P-Value & $\begin{array}{c}\text { Contribution } \\
(\%)\end{array}$ \\
\hline $\mathrm{u}_{\mathrm{G}}{ }^{*}$ & 1 & 555.55 & 555.547 & 88.46 & $<0.001$ & 44.78 \\
\hline L/G ratio* & 1 & 347.78 & 347.778 & 55.38 & $<0.001$ & 28.03 \\
\hline $\mathrm{C}_{\mathrm{alg}}{ }^{*}$ & 1 & 123.65 & 123.646 & 19.69 & 0.002 & 9.97 \\
\hline $\mathrm{u}_{\mathrm{G}}$ vs. $\mathrm{pH}^{*}$ & 1 & 99.78 & 99.78 & 15.89 & 0.004 & 8.04 \\
\hline Alk & 1 & 27.29 & 27.29 & 4.35 & 0.071 & 2.20 \\
\hline $\mathrm{T}_{\text {col }}$ & 1 & 25.89 & 25.893 & 4.12 & 0.077 & 2.09 \\
\hline $\mathrm{pH}$ & 1 & 10.55 & 10.551 & 1.68 & 0.231 & 0.85 \\
\hline Pooled error & 8 & 50.24 & 6.28 & - & - & 4.05 \\
\hline Cumulative total & 15 & 1240.72 & - & - & - & 100 \\
\hline
\end{tabular}

"Denotes the statistically significant $(\mathrm{P}<0.05)$ source (factors). 
Table 11.

Comparison and primary conclusions about the design factors affecting the studied process responses to assess the performance of the bubble column in photosynthetic biogas upgrading for both $\mathrm{CO}_{2}$ removal and $\mathrm{O}_{2}$ stripping. The values in brackets indicate the rank of the design factors based on $\mathrm{S} / \mathrm{N}$ ratios for the respective response. The arrows indicate the direction of the responses on increasing the setting of the design factors.

\begin{tabular}{|c|c|c|c|c|c|c|}
\hline \multirow[b]{2}{*}{$\begin{array}{l}\text { Design } \\
\text { Factors }\end{array}$} & \multicolumn{3}{|c|}{ Performance of $\mathrm{CO}_{2}$ removal } & \multicolumn{2}{|c|}{$\mathrm{O}_{2}$ stripping } & \multirow[b]{2}{*}{ Inference } \\
\hline & $\begin{array}{c}\mathrm{R}_{\text {eff, } \mathrm{CO}_{2}} \\
(\%)\end{array}$ & $\begin{array}{c}\mathrm{R}_{\mathrm{abs}, \mathrm{CO}_{2}} \\
\left(\times 10^{-4}\right. \\
\mathrm{mol} / \mathrm{L} / \mathrm{s})\end{array}$ & $\begin{array}{l}\mathbf{k}_{\mathrm{G}_{\mathrm{CO}_{2}}} \mathbf{a} \\
\left(\mathbf{h}^{-1}\right)\end{array}$ & $\begin{array}{c}\mathrm{O}_{2} \text { in } \\
\text { biomethane } \\
(\%)\end{array}$ & $\begin{array}{c}\mathrm{O}_{2} \text { outflow } \\
\text { in } \\
\text { biomethane } \\
\left(\mathrm{mL}_{\mathrm{n}} / \mathrm{min}\right)\end{array}$ & \\
\hline $\mathrm{L} / \mathrm{G}$ ratio & $(2)^{*} \uparrow$ & $(3)^{*} \uparrow$ & $(3)^{*} \uparrow$ & $(1)^{*} \uparrow$ & $(2)^{*} \uparrow$ & $\begin{array}{l}\text { Critical } \\
\text { influence }\end{array}$ \\
\hline $\begin{array}{l}\text { Superficial } \\
\text { gas velocity }\end{array}$ & $(5)^{*} \downarrow$ & (6) $\downarrow$ & $(2)^{*}$ & (7) & $(1)^{*} \uparrow$ & $\begin{array}{c}\text { Minor } \\
\text { influence }\end{array}$ \\
\hline $\begin{array}{l}\text { Empty bed } \\
\text { residence } \\
\text { time }\end{array}$ & (7) $\uparrow$ & $(1)^{*} \downarrow$ & $(4)^{*}$ & (6) & (6) $\uparrow$ & $\begin{array}{l}\text { Negligible } \\
\text { influence }\end{array}$ \\
\hline $\begin{array}{l}\mathrm{pH} \text { of inlet } \\
\text { liquid }\end{array}$ & $(1)^{*} \uparrow$ & $(2)^{*} \uparrow$ & $(1)^{*} \uparrow$ & $(3)^{*} \uparrow$ & (7) $\uparrow$ & $\begin{array}{c}\text { Critical } \\
\text { influence }\end{array}$ \\
\hline $\begin{array}{l}\text { Alkalinity of } \\
\text { inlet liquid }\end{array}$ & $(3)^{*} \uparrow$ & (4) $\uparrow$ & (5) $\uparrow$ & (5) & (4) $\downarrow$ & $\begin{array}{l}\text { Major } \\
\text { influence } \\
\text { on } \mathrm{CO}_{2} \\
\text { removal } \\
\text { only }\end{array}$ \\
\hline Temperature & (6) $\uparrow$ & (6) $\uparrow$ & (7) $\uparrow$ & $(4)^{*} \downarrow$ & (5) $\downarrow$ & $\begin{array}{l}\text { Negligible } \\
\text { influence }\end{array}$ \\
\hline $\begin{array}{l}\text { Algal } \\
\text { concentration }\end{array}$ & $(4)^{*} \downarrow$ & (5) $\downarrow$ & (6) $\downarrow$ & $(2)^{*} \uparrow$ & $(3)^{*} \uparrow$ & $\begin{array}{c}\text { Major } \\
\text { influence } \\
\text { on } \mathrm{O}_{2} \\
\text { stripping } \\
\text { only }\end{array}$ \\
\hline
\end{tabular}

${ }^{*}$ Indicates the statistically significant main effects $(\mathrm{P}<0.05)$.

ratio is a critical design factor, having a major influence (within the top 3 factors) on each studied response. While a higher $\mathrm{L} / \mathrm{G}$ ratio is desirable for better $\mathrm{CO}_{2}$ removal, a lower $\mathrm{L} / \mathrm{G}$ ratio would minimise both oxygen stripping and corresponding concentration in upgraded biomethane. This trend is similar to those reported in multiple literature sources (Toledo-Cervantes et al., 2017; Bose et al., 2019). $\mathrm{pH}$ is another critical design factor; a high $\mathrm{pH}$ would improve both the $\mathrm{CO}_{2}$ absorption hydrodynamics and reaction rates, resulting in a consistent and robust $\mathrm{CO}_{2}$ removal but would also increase $\mathrm{O}_{2}$ stripping. Although this increase in $\mathrm{O}_{2}$ stripping was not statistically significant $(\mathrm{P}=$ $0.231)$, the resulting increase in $\mathrm{O}_{2}$ concentration in biomethane was $(\mathrm{P}=$ $0.014)$. This also validates the claim made by the authors in a previous study that a higher $\mathrm{pH}$ results in increased $\mathrm{O}_{2}$ stripping (Bose et al., 2019). Thus, optimisation of the bubble column (not included in this work) must be performed with $\mathrm{pH}$ and $\mathrm{L} / \mathrm{G}$ ratio as the most significant factors.

Higher algal concentration has a major influence on the $\mathrm{O}_{2, \%, \mathrm{BM}}$. It could be both due to the improved hydrodynamics and/or the transfer of a considerable amount of $\mathrm{O}_{2}$ produced by photosynthesising microalgae into the biomethane. On the contrary, the absorption of $\mathrm{CO}_{2}$ showed no statistically significant $(\mathrm{P}>$ $0.05)$ correlation with increasing algal concentration. However, the increased algal concentration resulted in a significant drop in the $\mathrm{CO}_{2}$ removal efficiency of the bubble column. This could be because of non-uniform mixing due to the presence of filamentous microalgae (S. platensis), as well as from increased foaming and clogging observed at operations with higher algal concentrations. A similar drop in $\mathrm{CO}_{2}$ removal efficiencies from increased algal concentration has also been reported by del Rosario Rodero et al. (2020b), although it was not statistically significant. Alkalinity was a major factor in $R_{\text {eff. }} \mathrm{CO}_{2}$ both increasing $\mathrm{CO}_{2}$ removal and providing operation robustness when alkalinity was increased. A similar improvement in the consistency of $R_{e f f, \mathrm{CO}_{2}}$ was reported by del Rosario Rodero et al. (2020b) by increasing the alkalinity from $1.3 \mathrm{gIC} / \mathrm{L}$ to $2.4 \mathrm{gIC} / \mathrm{L}$ and above. However, it had no major contribution to either the kinetics or the hydrodynamics of $\mathrm{CO}_{2}$ absorption, as well as on oxygen stripping.

Although superficial gas velocity plays a major role in defining the system hydrodynamics, it had a minor impact on the overall biomethane composition. In agreement with existing literature (Zedníková et al., 2018), superficial gas velocity had the highest influence on increasing the volume of $\mathrm{O}_{2}$ stripped into the biogas. However, as the bubble column diameter was fixed, an increase in the superficial gas velocity was accompanied by a proportional increase in the gas flow rate. This ensured that there was no significant change in $\mathrm{O}_{2, \%, \mathrm{BM}}$ with the variation in the superficial gas velocity. From the perspective of $\mathrm{CO}_{2}$ removal, a higher superficial gas velocity would not only increase bubble diameter but also increase the bubble rise velocity (Kulkarni and Joshi, 2005), decreasing the gas-liquid contact time irrespective of EBRT. Expectedly, all the metrics for $\mathrm{CO}_{2}$ removal barring the $\mathrm{CO}_{2}$ removal rate, showed a significant drop in performance on increasing the superficial gas velocity. However, it must be remembered that to increase the throughput of the bubble column with regards to biogas upgraded; the superficial gas velocity must be increased. Thus, to counter the drop in $\mathrm{CO}_{2}$ removal performance with regards to increasing the superficial gas velocity, the operating $\mathrm{pH}, \mathrm{L} / \mathrm{G}$ ratio, and alkalinity must be included in process control and optimisation.

Compared to other design factors, the influence of temperature was minimal. Although $\mathrm{O}_{2, \%, \mathrm{BM}}$ had a statistically significant $(\mathrm{P}=0.044)$ decrease upon the increase in the temperature, the net contribution of temperature towards the overall variation in the response was only around $2 \%$ (Table 10). Thus, the influence of temperature on the bubble column operations and controls can generally be neglected. Finally, beyond indicating a drop in reaction rates and hydrodynamic performance along the length of the reactor, which is expected from its co-current flow configuration, EBRT had no statistically significant contribution towards the upgraded biomethane composition and can hence be regarded as a minor factor when varied between 6 and $15 \mathrm{~min}$. The major conclusions from the comparative assessment of the design factors on the design, operation, and control strategy of the bubble column for photosynthetic biogas upgrading are compiled in Table 11.

\subsubsection{Interactions}

A few interactive effects between the design factors were also found to have a major and statistically significant $(\mathrm{P}<0.05)$ effect on the performance of $\mathrm{CO}_{2}$ removal from biogas and $\mathrm{O}_{2}$ stripping from the alkaline algal medium. For the former, the largest interaction was between $\mathrm{pH}$ and $\mathrm{L} / \mathrm{G}$ ratio, affecting the rate of $\mathrm{CO}_{2}$ absorption and hence the overal efficiency of $\mathrm{CO}_{2}$ removal. The implications of the interactive effects between the superficial gas velocity and $\mathrm{pH}$ and $\mathrm{L} / \mathrm{G}$ ratio imply the necessity to control both $\mathrm{pH}$ and $\mathrm{L} / \mathrm{G}$ ratio at higher levels to enable an increase of the throughput of the bubble column (a higher gas superficial velocity for constant diameter). This is especially important, as the higher setting (factor level "2") of superficial gas velocity was limited by the practicality of the experimental setup. However, as both the upper levels (factor level "2") of $\mathrm{pH}$ and L/G were set at their maximum intended values, the conclusions of the present study would remain valid when the effect of higher superficial gas velocities is studied in future works. For $\mathrm{O}_{2}$ stripping, the only statistically significant $(\mathrm{P}<0.05)$ interaction was between algal concentration and $\mathrm{L} / \mathrm{G}$ ratio. The results indicated the important influence of the algal concentration on increasing $\mathrm{O}_{2, \%, \mathrm{BM}}$ at a lower $\mathrm{L} / \mathrm{G}$ ratio; however, at a higher $\mathrm{L} / \mathrm{G}$ ratio, the $\mathrm{O}_{2, \%, \mathrm{BM}}$ was found to be independent of the algal concentration.

Of the interactive effects that were not statistically significant $(P>0.05)$, the interaction between temperature and algal concentration bears importance in that it provides conclusive evidence that the photosynthesising microalgae would not play a significant role in catalysing $\mathrm{CO}_{2}$ removal. By this, it can also be confirmed that the absorption of $\mathrm{CO}_{2}$ is chemically driven by the carbonate/ bicarbonate present in the solution.

\subsection{Prediction of bubble column operation and confirmatory experiment}

Using the statistically significant $(\mathrm{P}<0.05)$ main effects and interactions derived in Section 3.3, Equations 15 and 16 were used to predict the $\mathrm{CO}_{2}$ 
removal efficiency $\left((\mathrm{S} / \mathrm{N})_{\mathrm{R}_{\text {eff, } \mathrm{CO}_{2}}}\right)$ and the oxygen outflow within biomethane $\left((\mathrm{S} / \mathrm{N})_{\mathrm{O}_{2, \mathrm{BM}}}\right)$ in terms of the $\mathrm{S} / \mathrm{N}$ ratio. For physical interpretation, the obtained values could be converted back into practical units using Equations 10 and 11, respectively.

$(\mathrm{S} / \mathrm{N})_{\mathrm{R}_{\mathrm{eff}, \mathrm{CO} 2}}=$

$-53.25+56.69 L / G-164.5 u_{G}+5.04 p H+1.1 A l k-2.07 C_{a l g}+28.01 L / G^{*} u_{G}$

$$
-5.63 L / G^{*} p H+14.1 u_{G}^{*} p H
$$

$(\mathrm{S} / \mathrm{N})_{\mathrm{O}_{2 . \mathrm{BM}}}=44.13-18.79 L / G-84.2 * u_{G}-18.65 C_{a l g}+17.84 L / G^{*} C_{a l g}$

Eq. 16

To assess the performance of the derived regression models, their statistical characteristics were calculated and compared. As can be seen from the results summarised in Table 12, both the regression equations for $\mathrm{R}_{\text {eff, } \mathrm{CO}_{2}}$ and $\mathrm{O}_{2, \mathrm{BM}}$ have a much higher $F_{\text {model }}$ value (27.96 and 27.19 , respectively) than critical values ( 3.725 and 3.36, respectively) with a $P$ value of less than 0.001 in both cases. This confirms the statistical significance of the proposed regression models for a confidence interval of $95 \%$. Simultaneously, the $\mathrm{R}^{2}$ values of the models were also above 0.9 , indicating a good linear agreement between the observed and the predicted data (Smith et al., 2016).

Table 12.

Statistical characteristics of the models for predicting $\mathrm{CO}_{2}$ removal efficiency and $\mathrm{O}_{2}$ flow rate in upgraded biomethane in order to predict the biomethane composition.

\begin{tabular}{|c|c|c|c|c|c|c|}
\hline \multirow{2}{*}{ Model } & \multicolumn{6}{|c|}{ Model Characteristics } \\
\hline & DoF & $\mathbf{R}^{2}$ & $\mathbf{S}$ & $\mathbf{F}_{\text {model }}$ & $F_{\text {critical }}$ & P-value \\
\hline $\mathrm{CO}_{2}$ removal efficiency & 7 & 0.9697 & $1.11 \%$ & 27.96 & $\begin{array}{c}3.725 \\
\left(\mathrm{~F}_{0.05(8,7)}\right)\end{array}$ & $<0.001$ \\
\hline $\mathrm{O}_{2}$ flow in biomethane & 4 & 0.9081 & $3.22 \%$ & 27.19 & $\begin{array}{c}3.36 \\
\left(\mathrm{~F}_{0.05(5,10)}\right)\end{array}$ & $<0.001$ \\
\hline
\end{tabular}

A study of the $\mathrm{S}$ value, which represents the average deviation of the predicted model from the observed data, shows that the model for $\mathrm{R}_{\mathrm{eff}, \mathrm{CO}_{2}}$ would be able to predict the performance based on $\mathrm{S} / \mathrm{N}$ ratio with an average error of $\pm 1.11 \%$; the corresponding average error in prediction of $\mathrm{O}_{2, \mathrm{BM}}$ is \pm $3.22 \%$. Graphical representation of this argument is presented in Figure 12 that reveals a good agreement between the experimental and the predicted values for both $\mathrm{S} / \mathrm{N}$ ratios of $\mathrm{R}_{\text {eff, } \mathrm{CO}_{2}}$ and $\mathrm{O}_{2, \mathrm{BM}}$. All the experimental values were found to lie within the $95 \%$ prediction interval, confirming the adequacy of the simplified model with the chosen main effects and interactions.

A confirmatory experiment, separate from the sixteen Taguchi trials, was performed with $\mathrm{pH} 10.5$ (to maximise $\mathrm{CO}_{2}$ removal), $\mathrm{L} / \mathrm{G}$ ratio 0.2 (to minimise $\mathrm{O}_{2}$ stripping), and alkalinity $2.5 \mathrm{gIC} / \mathrm{L}$ (to maximise $\mathrm{CO}_{2}$ removal efficiency) while the superficial gas velocity was set at $0.2 \mathrm{~cm} / \mathrm{s}$ (to maximise throughput). The constant settings were selected as follows: temperature $20^{\circ} \mathrm{C}$, algal concentration $0.05 \mathrm{~g}-\mathrm{DW} / \mathrm{L}$, and EBRT $6 \mathrm{~min}$. Grid quality biomethane with a $\mathrm{CO}_{2}$ and $\mathrm{O}_{2}$ concentration of $0.19 \% \pm 0.17 \%$ and $0.2 \% \pm 0.01 \%$, respectively, was obtained. The corresponding $\mathrm{S} / \mathrm{N}$ ratio for $\mathrm{CO}_{2}$ removal efficiency of 0.0613 fell within the $95 \% \mathrm{CI}$ of -2.28 and 1.66 , while that for oxygen (20.77) matched closely with the predicted value of 22.78 while also being within the 95\% CI $(18.82,23.74)$.

Following the predictive regression equations, Figures 13a and b represent the variation in biomethane composition between a $\mathrm{pH} 9$ and $\mathrm{pH} 10.5$ and an L/G ratio 0.2 and 1 for the superficial gas velocity of $0.06 \mathrm{~cm} / \mathrm{s}$ (factor level " 1 ") and $0.2 \mathrm{~cm} / \mathrm{s}$ (factor level "2"), respectively. EBRT and temperature were set at the lowest ranges, while alkalinity was set at $2.5 \mathrm{gIC} / \mathrm{L}$. Algal concentration was considered fixed at $0.05 \mathrm{~g}-\mathrm{DW} / \mathrm{L}$. As can be seen, with the increase in superficial gas velocity, the allowable range of operation to produce grid quality biomethane narrows significantly, especially with respect to $\mathrm{CO}_{2}$ removal. This can be understood from the interactive effect between superficial $\mathbf{a}$
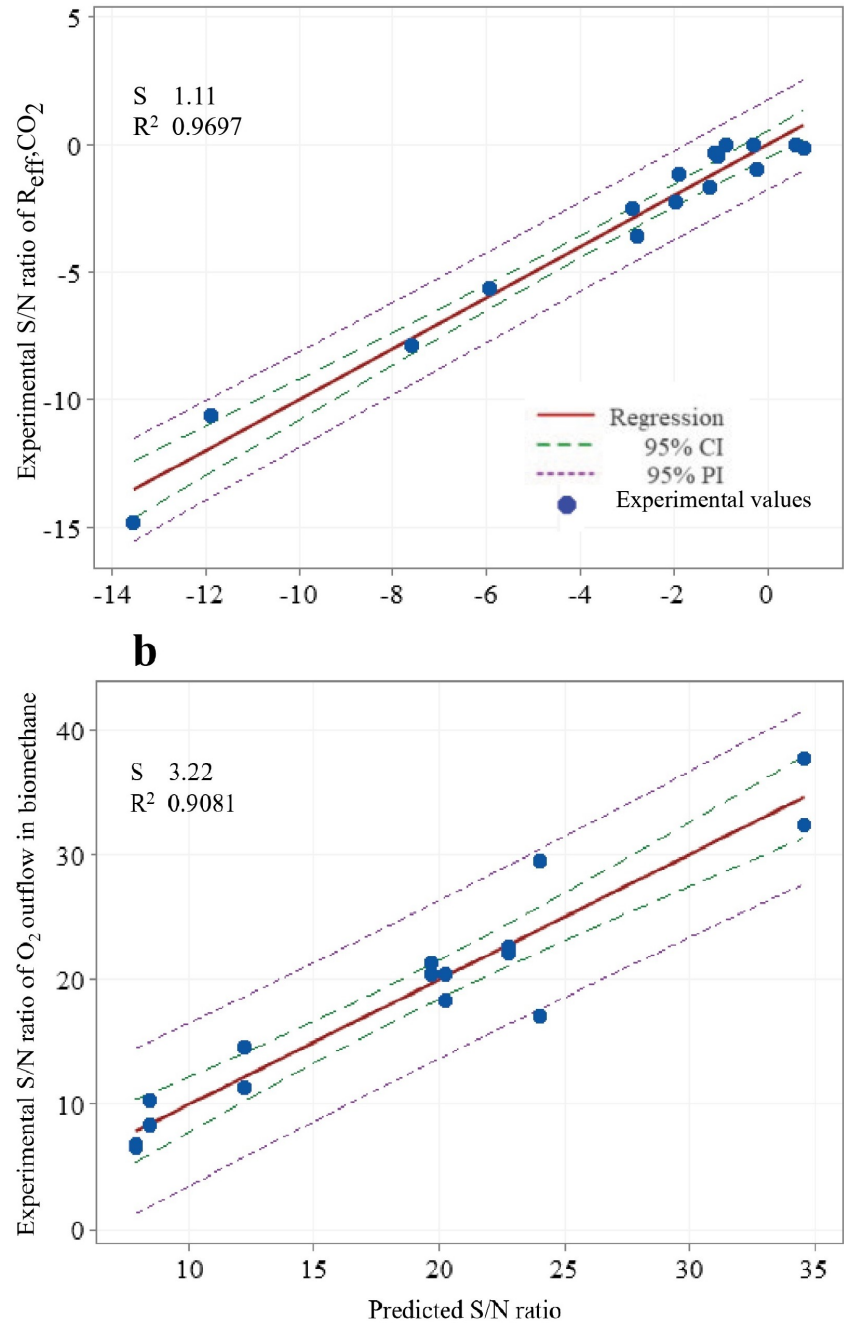

Fig. 12. Comparison of regression model and experimental data along with $95 \%$ Confidence Interval and 95\% Prediction Interval for the $\mathrm{S} / \mathrm{N}$ ratios of (a) $\mathrm{R}_{\text {eff, }} \mathrm{CO}_{2}$ and (b) $\mathrm{O}_{2, \mathrm{BM}}$.

gas velocity and both $\mathrm{pH}$ and $\mathrm{L} / \mathrm{G}$ ratio alike, whereby an increase in $\mathrm{pH}$ and $\mathrm{L} / \mathrm{G}$ ratio was necessary at higher superficial gas velocity (throughput rates) to achieve grid quality biomethane, all other conditions being fixed.

Figure 13 must, however, be studied with caution as it is not an optimised plot, nor can it be extrapolated above the studied range of superficial gas velocity $0.2 \mathrm{~cm} / \mathrm{s}$. Indeed, this graph provides an indication and estimation of the profiles of biomethane composition to be expected while working with photosynthetic biogas upgrading. More accurate predictive models and contour plots must be generated with detailed optimisation experiments, which is beyond the scope of the present work.

\subsection{Significance of results}

Similar global hydrodynamic parameters, such as the gas hold-up (i.e., the ratio of the gassed volume to the static liquid volume in the bubble column), are necessary and sufficient to achieve dynamic similarity upon scale up (Shaikh and Al-Dahhan, 2010). For low superficial gas velocities below $1 \mathrm{~cm} / \mathrm{s}$, a minimal gas hold-up together with a negligible impact of pressure on the same allows scale-up of results with minimal errors (Bose et al., 2021). Accordingly, the current results would remain valid for industrial-scale bubble columns operated under similar superficial gas velocities irrespective of the bubble column dimensions. The following sections, therefore, focus on the significance of the results on the industrial 

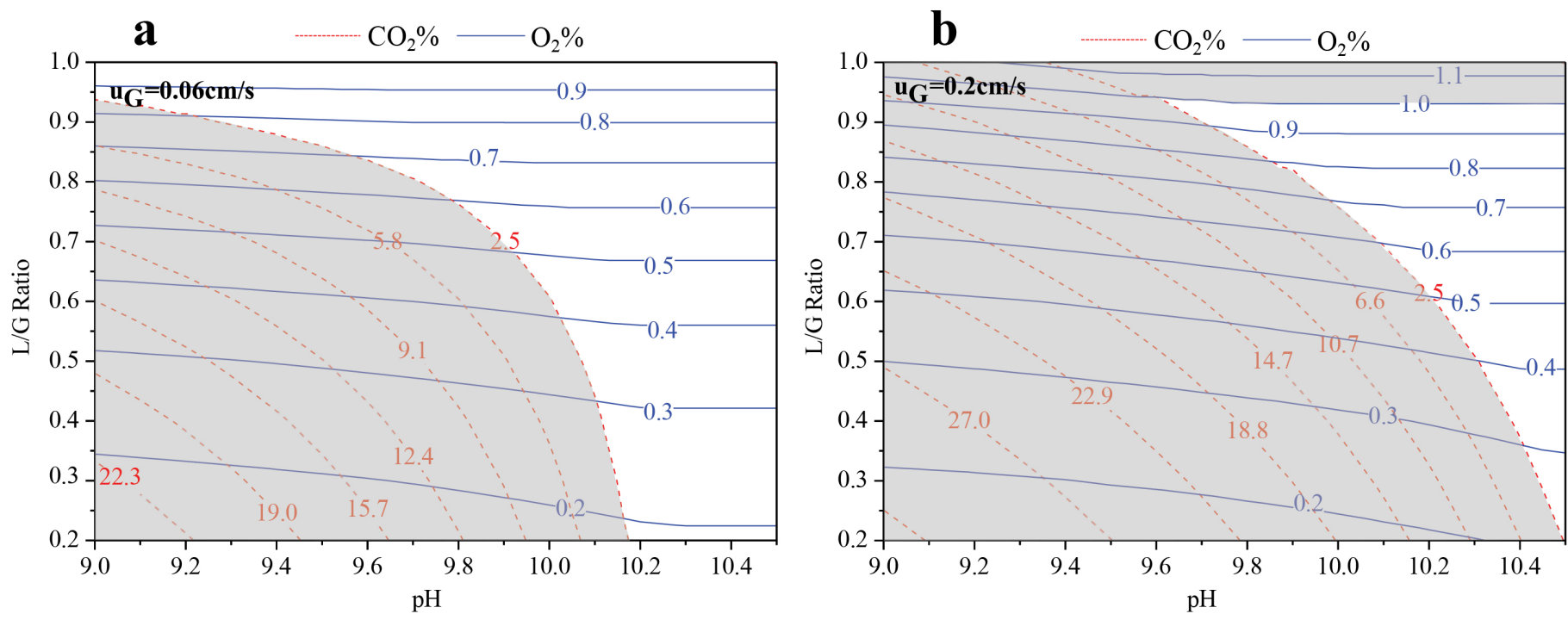

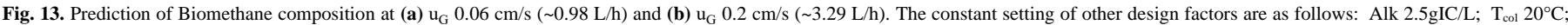
$\mathrm{C}_{\text {alg }} 0.05 \mathrm{~g}-\mathrm{DW} / \mathrm{L}$; and EBRT $6 \mathrm{~min}$. The acceptable region of operation is indicated in white.

scale design, operation, and costs of the bubble column, together with its integration with photobioreactors for the continuous operation of photosynthetic biogas upgrading system producing grid quality biomethane.

\subsubsection{On bubble column design, operation, and costs}

To ensure robust and repetitive operation of the bubble column, against uncontrollable factors or noise such as DO in the algal liquid or seasonal and diurnal cycles, process control strategies for bubble column operation must include $\mathrm{L} / \mathrm{G}$ ratio and $\mathrm{pH}$ as critical factors along with alkalinity. The compelling evidence of the benefits of operation with a low algal concentration and the minor influence of temperature between $20^{\circ} \mathrm{C}$ and $35^{\circ} \mathrm{C}$ would further ease the design and operation of the bubble column. Not only does a lower algal concentration signify that light would not play a signify role in bubble column operations, but also that control of temperature and pressure are not crucial elements to its operation and control. From the bubble column design aspect, the relatively minor influence of EBRT as it varied between 6 and $15 \mathrm{~min}$, indicates the possibility to reduce the height of the bubble column from that currently employed in literature for photosynthetic biogas upgrading. On the other hand, for a fixed bubble column diameter, to ensure a constant EBRT, the bubble column height would increase proportionally with the superficial gas velocity. Indeed, within the present experiments, this resulted in the aspect ratio (the ratio of the height of the bubble column to the diameter) to vary from 9 to 22.5 at superficial gas velocities of $0.06 \mathrm{~cm} / \mathrm{s}$ and $0.2 \mathrm{~cm} / \mathrm{s}$, respectively, and an EBRT of 6 min. Thus, it can be concluded with confidence $(\mathrm{P}<0.05)$ that biomethane production in photosynthetic biogas upgrading would be possible in industrial bubble columns with their aspect ratios typically varying between 3 and 10 (Jakobsen, 2009). Traditional materials such as stainless steel could be used for bubble column construction without the need for specialised design and materials. However, to further increase the superficial gas velocity without having to build a considerably tall bubble column, an investigation into lowering the EBRT further can be made in future studies. $\mathrm{pH}$ and alkalinity must be set to the maximum setting ( 10.5 and $2.5 \mathrm{~g}-\mathrm{IC} / \mathrm{L}$, corresponding to factor level " 2 " in the present study), with the L/G being adjusted accordingly to ensure generation of grid quality biomethane.

\subsubsection{On the operation of algae cultivation and harvesting system}

From mass balance, the $\mathrm{CO}_{2}$ removed from the biogas in the bubble column would be added into the alkaline algal liquid, increasing its alkalinity and producing bicarbonates from carbonates (Eq. 1). Based on the $\mathrm{CO}_{2}$ removal efficiency, Table 13 indicates the predicted effective amount of inorganic carbon added into the algal liquid from biogas in terms of alkalinity ( $\mathrm{g}$ $\mathrm{IC} / \mathrm{L}$ ). Operation at two extremes of $\mathrm{pH}$ and $\mathrm{L} / \mathrm{G}$ ratios when the superficial gas velocity is $0.2 \mathrm{~cm} / \mathrm{s}$ is considered as a representative case. A high $\mathrm{pH}$ and low $\mathrm{L} / \mathrm{G}$ ratio, ensuring $96.5 \% \mathrm{CO}_{2}$ removal (predicted), would maximise the inorganic carbon addition per litre of alkaline solution. However, when the $\mathrm{L} / \mathrm{G}$ ratio is increased to 1 , IC added would drop to $0.2 \mathrm{gIC} / \mathrm{L}$ at a $\mathrm{CO}_{2}$ removal efficiency of $100 \%$.

\section{Table 13.}

Statistical Impact of $\mathrm{pH}$ and $\mathrm{L} / \mathrm{G}$ ratio on the inorganic carbon added to the algal liquid from biogas with the corresponding $\mathrm{CO}_{2}$ removal efficiency in brackets. $\mathrm{CO}_{2}$ removal efficiencies are based on the predicted values obtained using Equations 15 and 10 in order.

\begin{tabular}{lcc}
\hline \multirow{2}{*}{$\mathbf{p H}$} & \multicolumn{2}{c}{ LG ratio } \\
\cline { 2 - 3 } & $\mathbf{0 . 2}$ & $\mathbf{1}$ \\
\hline 9 & $0.30(30.1 \%)$ & $0.17(87.7 \%)$ \\
10.5 & $0.96(96.5 \%)$ & $0.20(100 \%)$ \\
\hline
\end{tabular}

To ensure a continuous cycle, the added carbon must account for that consumed by the algae and also meet system losses. Carbon losses in closed and open pond photobioreactors have been reported to be similar (Bose et al., 2019), often increasing at higher alkalinity (del Rosario Rodero et al., 2020b). Assuming the average productivity of S. platensis in inorganic media to be around $0.175 \mathrm{~g} / \mathrm{L} / \mathrm{d}$ at $30{ }^{\circ} \mathrm{C}$ (De Oliveira et al., 1999), and that S. platensis comprises 50\% carbon per dry weight (Binaghi et al., 2003), the daily carbon assimilation rate would be $0.088 \mathrm{~g} / \mathrm{L}$. Also, considering a carbon loss of $24 \%$ at an alkalinity of $2.5 \mathrm{gIC} / \mathrm{L}$ (del Rosario Rodero et al., 2020b), the cultivation of $S$. platensis at $30{ }^{\circ} \mathrm{C}$, connected to a bubble column operating at $\mathrm{pH} 10.5$ and $\mathrm{L} / \mathrm{G} 0.2$ would require an estimated 8 days of hydraulic retention time (HRT) to assimilate the added carbon. However, when the $\mathrm{L} / \mathrm{G}$ ratio is increased to 1 , the HRT could be reduced to 2 days only. The corresponding algal concentrations generated would vary between $2.8 \mathrm{gDW} / \mathrm{L}$ and $0.35 \mathrm{gDW} / \mathrm{L}$, respectively. Sufficient year-round 
$\mathrm{CO}_{2}$ uptake could be ensured by temperature-controlled microalgae cultivation, either in closed photobioreactors (Bose et al., 2019) or open ponds within greenhouses (Marín et al., 2021). A higher algal concentration is always desired, as it greatly simplifies the harvesting system design and cost.

\section{Conclusions and future directions}

In this work, a quantitative comparison among seven design factors affecting bubble column performance in photosynthetic biogas upgrading has been developed. The $\mathrm{L}_{16}$ Taguchi OA as a screening design of experiment was selected as the statistical tool. Experiments were conducted in a lab-scale bubble column reactor. Assessments regarding the performance of $\mathrm{CO}_{2}$ removal and $\mathrm{O}_{2}$ stripping into biomethane were performed using the $\mathrm{S} / \mathrm{N}$ ratio statistic derived from the experimental data. The output of the four objectives as described in the introduction along with future research needs are synthesised as below:

i. $\mathrm{pH}$ and $\mathrm{L} / \mathrm{G}$ ratio are the most critical design factors affecting $\mathrm{CO}_{2}$ removal and $\mathrm{O}_{2}$ stripping alike. For $\mathrm{CO}_{2}$ removal in a specific bubble column, besides $\mathrm{pH}$ and $\mathrm{L} / \mathrm{G}$ ratio, alkalinity, followed by algal concentration and superficial gas velocity are statistically significant $(\mathrm{P}<0.05)$ design factors. On the other hand, over $90 \%$ of the variations in $\mathrm{O}_{2}$ concentration in biomethane were explained by the main effects of $L / G$ ratio, algal concentration, and $\mathrm{pH}$ (in descending order of importance).

ii. The interactive effect between $\mathrm{pH}$ and $\mathrm{L} / \mathrm{G}$ ratio was the most impactful on the efficiency of $\mathrm{CO}_{2}$ removal. Although superficial gas velocity had limited contribution to $\mathrm{CO}_{2}$ removal, its interactions with both $\mathrm{L} / \mathrm{G}$ ratio and $\mathrm{pH}$ caused statistically significant $(\mathrm{P}<0.05)$ variation in the $\mathrm{CO}_{2}$ composition in biomethane. For $\mathrm{O}_{2}$ stripping, algal concentration had a diminishing role in increasing the $\mathrm{O}_{2}$ concentration in biomethane as the $\mathrm{L} / \mathrm{G}$ ratio increased. At higher $\mathrm{L} / \mathrm{G}$ ratios, similar $\mathrm{O}_{2}$ concentration in biomethane was observed irrespective of the algal concentration in the circulating algal medium.

iii. A higher alkalinity $(2.5 \mathrm{gIC} / \mathrm{L})$ is required to ensure consistent $\mathrm{CO}_{2}$ removal while a lower algal concentration $(0.05 \mathrm{gDW} / \mathrm{L})$ would minimise $\mathrm{O}_{2}$ stripping into biomethane, and also maximise and staibilise $\mathrm{CO}_{2}$ removal. Although a high $\mathrm{pH}$ and $\mathrm{L} / \mathrm{G}$ ratio improves $\mathrm{CO}_{2}$ removal, it increases $\mathrm{O}_{2}$ content in the biomethane. A higher superficial gas velocity, on the other hand, reduces the $\mathrm{CO}_{2}$ removal efficiency without affecting the $\mathrm{O}_{2}$ concentration in biomethane. Thus, future studies aiming to increase the throughput of the system and optimise the bubble column would require $\mathrm{pH}, \mathrm{L} / \mathrm{G}$ ratio, and superficial gas velocity as mandatory design factors.

iv. Using only the statistically significant main effects and interactions, the biomethane composition $\left(\mathrm{CO}_{2} \%\right.$ and $\left.\mathrm{O}_{2} \%\right)$ was predicted with fair confidence for superficial gas velocities up to $0.2 \mathrm{~cm} / \mathrm{s}$ using regression equations derived from the ANOVA analysis. To achieve grid quality biomethane, operations at $\mathrm{pH}$ between 10.3 and 10.5 and $\mathrm{L} / \mathrm{G}$ ratio between 0.5 and 0.8 , with an alkalinity of $2.5 \mathrm{gIC} / \mathrm{L}$ and algal concentration of 0.05 $\mathrm{gDW} / \mathrm{L}$ would ensure robust operations. However, to generate more accurate predictive models, detailed optimisation experiments with the selected critical design factors must be conducted; these were beyond the scope of the present work. The minimal impact of temperature and gas residence times on the system performance further indicates the possibility to use state-of-the-art bubble column designs and operational strategies for photosynthetic biogas upgrading.

Based on the results of the current work, the need to perform further research to examine increasing the superficial gas velocities and lowering the EBRT can be established. This would be essential to increase the throughput of the bubble columns without requiring them to be considerably tall. In all cases, however, $\mathrm{pH}, \mathrm{L} / \mathrm{G}$ ratio, and alkalinity must be varied taking into account the feasibility of integration with the photobioreactor for microalgae cultivation to achieve the optimal design and operating conditions of the bubble column.

\section{Acknowledgments}

This work acknowledges the support from Science Foundation Ireland (SFI) through the MaREI Centre for Energy, Climate, and Marine under Grant No. 12/RC/2302_P2 and 16/SP/3829, with industrial funding from Gas Networks Ireland through The Green Gas Innovation Group and by ERVIA and IDL
Pernod Ricard. This work was also supported by the Environmental Protection Agency - Ireland (2018-RE-MS-13).

\section{References}

[1] American Public Health Association (APHA), 1992. APHA Method 2320, in: standard methods for the examination of water and wastewater. American Public Health Association (APHA), Washington, DC.

[2] Angelidaki, I., Treu, L., Tsapekos, P., Luo, G., Campanaro, S., Wenzel, H., Kougias, P.G., 2018. Biogas upgrading and utilization current status and perspectives. Biotechnol. Adv. 36(2), 452-466.

[3] Antony, J., 2014. 4 - A systematic methodology for design of experiments, $2^{\text {nd }}$ ed. Des. Exp. Eng. Sci. 33-50.

[4] Awty-carroll, D., Ravella, S., Clifton-brown, J., Robson, P., 2020. Using a Taguchi DOE to investigate factors and interactions affecting germination in Miscanthus sinensis. Sci. Rep. 10(1), 1-11.

[5] Bahr, M., Díaz, I., Dominguez, A., González Sánchez, A., Muñoz, R., 2014. Microalgal-biotechnology as a platform for an integral biogas upgrading and nutrient removal from anaerobic effluents Environ. Sci. Technol. 48(1), 573-581.

[6] Barros, A.I., Gonçalves, A.L., Simões, M., Pires, J.C., 2015. Harvesting techniques applied to microalgae: a review. Renew. Sustain. Energy Rev. 41, 1489-1500.

[7] Binaghi, L., Del Borghi, A., Lodi, A., Converti, A., Del Borghi, M. 2003. Batch and fed-batch uptake of carbon dioxide by Spirulina platensis. Process Biochem. 38(9), 1341-1346.

[8] Borhani, T.N.G., Azarpour, A., Akbari, V., Alwi, S.R.W., Manan, Z.A., 2015. $\mathrm{CO}_{2}$ capture with potassium carbonate solutions: a stateof-the-art review. Int. J. Greenhouse Gas Control. 41, 142-162.

[9] Bose, A., Lin, R., Rajendran, K., Xia, A., O'Shea, R., Murphy, J.D., 2019. How to optimize photosynthetic biogas upgrading: a perspective on system design and microalgae selection. Biotechnol Adv. 37(8), 107444

[10] Bose, A., O'Shea, R., Lin, R., Murphy, J.D., 2020. A perspective on novel cascading algal biomethane biorefinery systems. Bioresour. Technol. 304, 123027.

[11] Bose, A., O’Shea, R., Lin, R., Murphy, J.D., 2021. Design, commissioning and performance assessment of a lab-scale bubble column reactor for photosynthetic biogas upgrading with Spirulina platensis. Ind. Eng. Chem. Res. 60(15), 5688-5704.

[12] Chen, P.C., Huang, C.H., Su, T., Chen, H.W., Yang, M.W, Tsao, J.M., 2015. Optimum conditions for the capture of carbon dioxide with a bubble-column scrubber. Int. J. Greenhouse Gas Control. 35 , 47-55.

[13] Chen, P.C., Lin, S., 2018. Optimization in the absorption and desorption of $\mathrm{CO}_{2}$ using sodium glycinate solution. Appl. Sci. 8(11), 2041.

[14] Chiranjeevi, P., Mohan, S.V., 2016. Critical parametric influence on microalgae cultivation towards maximizing biomass growth with simultaneous lipid productivity. Renewable Energy. 98, 64-71.

[15] Clark, K.N., 1990. The effect of high pressure and temperature on phase distributions in a bubble column. Chem. Eng. Sci. 45(8), 2301 2307

[16] Costa, J.A.V., Colla, L.M., Duarte Filho, P., 2003. Spirulina platensis growth in open raceway ponds using fresh water supplemented with carbon, nitrogen and metal ions. Z. Naturforsch. C. 58(1-2), 76-80

[17] Davis, R., John, P., 2018. Application of Taguchi-Based Design of Experiments for Industrial Chemical Processes, in: Silva, V. (Ed.), Statistical Approaches With Emphasis on Design of Experiments Applied to Chemical Processes Montgomery. IntechOpen.

[18] Deckwer, W.D., Louisi, Y., Zaidi, A., Ralek, M., 1980 Hydrodynamic properties of the fischer-tropsch slurry process. Ind. Eng. Chem. Process Des. Dev. 19(4), 699-708.

[19] del Rosario Rodero, M., Carvajal, A., Castro, V., Navia, D., de Prada, C., Lebrero, R., Muñoz, R., 2019a. Development of a control strategy to cope with biogas flowrate variations during photosynthetic biogas upgrading. Biomass Bioenergy. 131, 105414.

[20] del Rosario Rodero, M., Lebrero, R., Serrano, E., Lara, E., Arbib, Z., García-Encina, P.A., Muñoz, R., 2019b. Technology validation of 
photosynthetic biogas upgrading in a semi- industrial scale algalbacterial photobioreactor. Bioresour. Technol. 279, 43-49.

[21] del Rosario Rodero, M., Carvajal, A., Arbib, Z., Lara, E., de Prada, C., Lebrero, R., Muñoz, R., 2020a. Performance evaluation of a control strategy for photosynthetic biogas upgrading in a semi-industrial scale photobioreactor. Bioresour. Technol. 307, 123207.

[22] del Rosario Rodero, M., Severi, C.A., Rocher-Rivas, R., Quijano, G., Muñoz, R., 2020b. Long-term influence of high alkalinity on the performance of photosynthetic biogas upgrading. Fuel. 281, 118804.

[23] del Rosario Rodero, M., Posadas, E., Toledo-Cervantes, A., Lebrero, R., Muñoz, R., 2018. Influence of alkalinity and temperature on photosynthetic biogas upgrading efficiency in high rate algal ponds. Algal Res. 33, 284-290.

[24] De Oliveira, M.A.C.L. Monteiro, M.P.C., Robbs, P.G., Leite, S.G.F., 1999. Growth and chemical composition of Spirulina maxima and Spirulina platensis biomass at different temperatures. Aquacult. Int. 7(4), 261-275.

[25] Fernández, I., Guzmán, J.L., Berenguel, M., Acién, F.G., 2017. Dynamic modeling of microalgal production in photobioreactors, in: tripathi, Bhumi Nath, Kumar, D. (Eds.), Prospects and Challenges in Algal Biotechnology. Springer, pp. 49-86.

[26] Franco-Morgado, M., Alcántara, C., Noyola, A., Muñoz, R., GonzálezSánchez, A., 2017. A study of photosynthetic biogas upgrading based on a high rate algal pond under alkaline conditions: influence of the illumination regime. Sci. Total Environ. 592, 419-425.

[27] Ganapathy, T., Murugesan, K.A., Gakkhar, R.P., 2009. Performance optimization of Jatropha biodiesel engine model using Taguchi approach. Appl. Energy. 86(11), 2476-2486.

[28] Gas Networks Ireland, 2018. Code of Operations, Part G.

[29] Hikita, H., Asai, S., Takatsuka, T., 1976. Absorption of carbon dioxide into aqueous sodium hydroxide and sodium carbonate-bicarbonate solutions. Chem. Eng. J. 11(2), 131-141.

[30] Hu, G., Nicholas, N.J., Smith, K.H., Mumford, K.A., Kentish, S.E., Stevens, G.W., 2016. Carbon dioxide absorption into promoted potassium carbonate solutions: a review. Int. J. Greenhouse Gas Control. $53,28-40$.

[31] Hu, Q., Guterman, H., Richmond, A., 1996. A flat inclined modular photobioreactor for outdoor mass cultivation of photoautotrophs. Biotechnol. Bioeng. 51(1), 51-60.

[32] Huang, Q., Jiang, F., Wang, L., Yang, C., 2017. Design of photobioreactors for mass cultivation of photosynthetic organisms. Engineering. 3(3), 318-329.

[33] Jakobsen, H.A., 2009. Bubble Column Reactors, in: Chemical Reactor Modeling, Multiphase Reactive Flows. Springer Berlin Heidelberg, Trondheim, pp. 335-501.

[34] Jones, B., 2016. 21st century screening experiments: what, why, and how. Qual. Eng. 28(1), 98-106.

[35] Kaye, G. W.C., Laby, T.H., 1986. Tables of physical and chemical constants and some mathematical functions, $15^{\text {th }}$ Ed. London, New York, Longman.

[36] Kim, H.Y., 2017. Statistical notes for clinical researchers: chi-squared test and Fisher's exact test. Restor. Dent. Endod. 42(2), 152.

[37] Kishore, R.A., Kumar, P., Priya, S., 2018. A comprehensive optimization study on $\mathrm{Bi}_{2} \mathrm{Te}_{3}$-based thermoelectric generators using the Taguchi method. Sust. Energy Fuels. 2(1), 175-190.

[38] Kitchin, J., 1994. 6 - Basic statistical inference, in: dunning, F.B. (Ed.), Methods in Experimental Physics. Elsevier Masson SAS, Houston, Texas, pp. 28, 155-186.

[39] Knuutila, H., Juliussen, O., Svendsen, H.F., 2010. Kinetics of the reaction of carbon dioxide with aqueous sodium and potassium carbonate solutions. Chem. Eng. Sci. 65(23), 6077-6088.

[40] Krishnaiah, K., Shahabudeen, P., 2012. Applied Design of Experiments and Taguchi Methods. PHI Learning Private Limited, New Delhi.

[41] Kulkarni, A.A., Joshi, J.B., 2005. Bubble formation and bubble rise velocity in gas - liquid systems : a review. Ind. Eng. Chem. Res. 44(16), 5873-5931

[42] Madkour, F.F., Kamil, A.E.W., Nasr, H.S., 2012. Production and nutritive value of Spirulina platensis in reduced cost media. Egypt. J. Aquat. Res. 38(1), 51-57.

[43] Marín, D., Carmona-Martínez, A.A., Blanco, S., Lebrero, R., Muñoz, R.,
2021. Innovative operational strategies in photosynthetic biogas upgrading in an outdoors pilot scale algal-bacterial photobioreactor Chemosphere. 264(1), 128470.

[44] Marín, D., Posadas, E., Cano, P., Pérez, V., Blanco, S., Lebrero, R., Muñoz, R., 2018. Seasonal variation of biogas upgrading coupled with digestate treatment in an outdoors pilot scale algal-bacterial photobioreactor. Bioresour. Technol. 263, 58-66.

[45] Mehta, P.D., 2001. Control variable in research. Int. Encycl. Social Behav. Sci. 2727-2730.

[46] Meier, L., Barros, P., Torres, A., Vilchez, C., Jeison, D., 2017 Photosynthetic biogas upgrading using microalgae: effect of light/dark photoperiod. Renewable Energy. 106, 17-23.

[47] Meier, L., Martínez, C., Vílchez, C., Bernard, O., Jeison, D., 2019. Evaluation of the feasibility of photosynthetic biogas upgrading: Simulation of a large-scale system. Energy. 198, 116313.

[48] Meier, L., Pérez, R., Azócar, L., Rivas, M., Jeison, D., 2015. Photosynthetic $\mathrm{CO}_{2}$ uptake by microalgae: an attractive tool for biogas upgrading. Biomass Bioenergy. 73, 102-109.

[49] Mohsin, I., He, K., Li, Z., Zhang, F., Du, R., 2020. Optimization of the polishing efficiency and torque by using Taguchi method and ANOVA in robotic polishing. Appl. Sci. 10(3), 824.

[50] Molina, E., Ferna, J., Acie, F.G., Chisti, Y., 2001. Tubular photobioreactor design for algal cultures. J. Biotechnol. 92(2), 113131

[51] Montgomery, D.C., 2012. Design and Analysis of Experiments, $9^{\text {th }}$ ed. John Wiley and Sons, Inc.

[52] Myers, R.H., Montgomery, D.C., Anderson-Cook, C.M., 2017. Response surface methodology: process and product optimization using designed experiments, $4^{\text {th }}$ ed. John Wiley \& Sons Inc, New Jersey.

[53] Posadas, E., del Mar Morales, M., Gomez, C., Acién, F.G., Muñoz, R., 2015a. Influence of $\mathrm{pH}$ and $\mathrm{CO}_{2}$ source on the performance of microalgae-based secondary domestic wastewater treatment in outdoors pilot raceways. Chem. Eng. J. 265, 239-248.

[54] Posadas, E., Serejo, M.L., Blanco, S., Pérez, R., García-Encina, P.A., Muñoz, R., 2015b. Minimization of biomethane oxygen concentration during biogas upgrading in algal-bacterial photobioreactors. Algal Res. 12, 221-229.

[55] Priyadarshi, D., Paul, K.K., 2019. Optimisation of biodiesel production using Taguchi model. Waste Biomass Valorization. 10(6), $1547-1559$.

[56] Rajendran, K., O’Gallachoir, B., Murphy, J.D., 2019. The combined role of policy and incentives in promoting cost ef fi cient decarbonisation of energy : a case study for biomethane. J. Clean. Prod. 219, 278-290.

[57] Rao, R.S., Kumar, C.G., Prakasham, R.S., Hobbs, P.J., 2008. The Taguchi methodology as a statistical tool for biotechnological applications : a critical appraisal. Biotechnol. J. 3(4), 510-523.

[58] Roy, R.K., 2010. A primer on the Taguchi method, second edition. Society of Manufacturing Engineers.

[59] Shah, S.R., Parikh, R.H., Chavda, J.R., Sheth, N.R., 2013. Application of Plackett-Burman screening design for preparing glibenclamide nanoparticles for dissolution enhancement. Powder Technol. 235, 405-411.

[60] Singh, G., Patidar, S.K., 2018. Microalgae harvesting techniques: a review. J. Environ. Manage. 217, 499-508.

[61] Shaikh, A., Al-Dahhan, M., 2010. A new methodology for hydraulic similarity in bubble columns. Can. J. Chem. Eng. 88(4), 503-517.

[62] Smith, Z.D., Keller, J.R., Bello, M., Cordes, N.L., Welch, C.F., Torres, J.A., Goodwin, L.A., Pacheco, R.M., Sandoval, C.W., 2016. Plackett-Burman experimental design to facilitate syntactic foam development. J. Appl. Polym. Sci. 133(1).

[63] Sun, Z., Liu, J., Zhou, Z.G., 2016. Algae for biofuels: an emerging feedstock, in: Luque, R., Lin, C.S.K., Wilson, K., Clark, J. (Eds.), Handbook of Biofuels Production, $2^{\text {nd }}$ ed. Elsevier, pp. 673-698.

[64] Toledo-Cervantes, A., Madrid-Chirinos, C., Cantera, S., Lebrero, R. Muñoz, R., 2017. Influence of the gas-liquid flow configuration in the absorption column on photosynthetic biogas upgrading in algalbacterial photobioreactors. Bioresour. Technol. 225, 336-342. 
[65] Vasumathi, K.K., Premalatha, M., Subramanian, P., 2012. Parameters influencing the design of photobioreactor for the growth of microalgae. Renew. Sust. Energy Rev. 16(7), 5443-5450.

[66] Wall, D.M., McDonagh, S., Murphy, J.D., 2017. Cascading biomethane energy systems for sustainable green gas production in a circular economy. Bioresour. Technol. 243, 1207-1215.

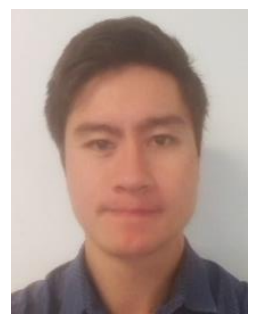

Dr. Richard O'Shea is a lecturer in the Science Foundation Ireland MaREI centre based in the Environmental Research Institute in University College Cork, Ireland. Dr. O'Shea received a Ph.D. in Energy Engineering from University College Cork in 2018. He has published 34 research articles in the academic press with an h-index of 15 and over 600 citations. His current research interests are anaerobic digestion, sustainability, multicriteria decision analysis, technoeconomic analysis, and decarbonization of the food and beverage industry. His Google Scholar profile can be found at the following link:

https://scholar.google.com/citations?user=dGm5ysAAAAAJ\&hl=en.

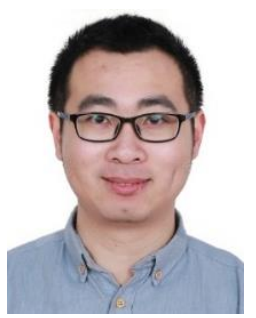

Dr. Richen Lin is a lecturer in the Science Foundation Ireland MaREI centre headquartered in the Environmental Research Institute in University College Cork, Ireland. He has a Ph.D. degree in Energy and Environmental Engineering from Zhejiang University, China, in 2016. He was a previous Marie SkłodowskaCurie Fellow (2018-2020) with a research focus on microbial electron transfer in anaerobic digestion. He has published over 50 peer-reviewed journal papers with an h-index of 23 and over 1700 citations. His research interests include (1) bio/electrochemical $\mathrm{CO}_{2}$ valorisation; (2) cascading circular bio-based systems; and (3) negative carbon emission technologies, such as pyrochar. His research profile on Google Scholar can be found at the following link:

https://scholar.google.com/citations?user=otyeO6QAAAAJ\&hl=en.
[67] Yang, J., Cui, X., Feng, Y., Jing, G., Kang, L., Luo, M., 2017. Experimental study on microalgae cultivation in novel photobioreactor of concentric double tubes with aeration pores along tube length direction. Int. J. Green Energy. 14(15), 1269-1276.

[68] Zedníková, M., Orvalho, S., Fialová, M., Ruzicka, M.C., 2018. Measurement of volumetric mass transfer coefficient in bubble columns. ChemEngineering 2(2), 19.

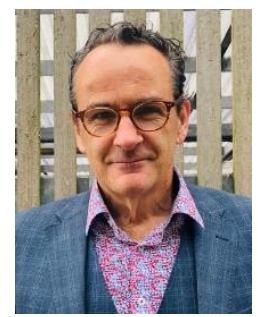

Prof. Jerry Murphy serves as the Director of the SFI funded MaREI centre for energy, climate, and marine, as Professor Chair of Civil Engineering at UCC, and as Leader of the Biogas Task at International Energy Agency (IEA) Bioenergy. He has authored and edited numerous IEA Bioenergy reports. He serves on the advisory board of a number of international organisations, including DBFZ (German Bioenergy Research Centre). He has authored over 160 peer-review journal papers and is listed in the top $2 \%$ of cited academics worldwide. His research profile is available at http://orcid.org/0000-0003-2120-1357.

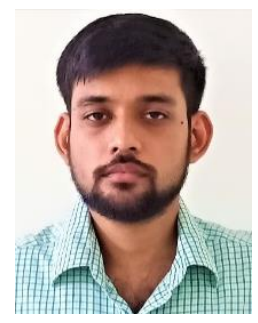

Archishman Bose is a Ph.D. researcher at the Bioenergy and Biofuels Research Group within the Science Foundation Ireland MaREI centre headquartered in the Environmental Research Institute in University College Cork, Ireland. He has a dual Master's degree in Energy Engineering from KTH Royal Institute of Technology, Sweden and Politecnico di Torino, Italy and a Bachelor`s Degree in Mechanical Engineering from Jadavpur University, India. He has previously published over 10 peer-reviewed journal papers with an h-index of 6 covering a wide range of subjects within sustainable energy. His research interests include (1) novel biogas upgrading technologies; (2) microalgal systems; (3) circular and bioeconomy systems; and (4) techno-economic and sustainability analysis of energy systems. His research profile on Google Scholar can be found at the following link:

https://scholar.google.com/citations?user=DT5wyDIAAAAJ\&hl=en. 